\title{
Psychology for the Classroom: E-Learning
}

Document administration

Words $\mathbf{4 4 7 8 4}$ of 40,000

Pages: 85

File name: Elearningka.doc

Psychology for the Classroom Series

Author: John Woollard

Series Editors: Alan Pritchard and John Woollard

http://www.routledge.com/books/details/9780415590938

Psychology for the Classroom: E-Learning describes and reflects upon the developing nature of technologysupported teaching and learning and the educational psychology associated with those developments.

Through examples drawn from research, presentation of theory, description of pedagogy and illustration by vignette, the book informs teachers and allows them to modify and develop their teaching in order to exploit the affordances of the new technologies and our understanding of their applications as well as to better meet the challenges both to teachers and teaching but also to the intellectual and cognitive demands placed upon learners. There is a particular emphasis placed upon the developing theories and practice of cybergogy as well as an interpretation of conventional theories of behaviourism, cognitivism and constructivism in the light of the online teaching and training practices.

The author has taken an overview of what has been written and promoted to educators in the area of elearning theory and practice, and the result is an informative and potentially very useful guide which should be read by all of us who are interested in, or responsible for, planning and encouraging effective teaching and learning with technology.

Back piece

The purpose of the proposed book is to provide background, detail of research in the topic of e-learning through internet-based technologies and the implications for teaching and learning to date, an outline of the main points of theory generated from the research, a view of the pedagogical implications which can be drawn out of the research, a consideration of how the pedagogical suggestions are being turned into teaching practice. The book will provide a foundation of research leading to practical strategies, all presented in an unbiased way, in order to inform teachers and to allow them to make choices about possible changes to their ways of teaching in the e-learning environment.

Much of the research and development related to e-learning includes the actions of the teachers and trainers, the technology in the form of hardware, the technology in the form of software and the strategies and procedures of technology-enabled teaching. 
Acknowledgements

Contributors

Introduction

Towards a definition of e-learning

Changing thinking; changing the ways of learning.

A brief history of technology-enabled learning

Pedagogy, andragogy and cybergogy.

Mapping the psychology

\section{Research}

Online Learning - a meta-analysis of research

Collaborative and social learning

Using ICT to support teaching

Technology mediated learning

E-safety in e-learning; safe-working in the virtual world

\section{Theory}

Stages of cognitive development

ID, Id, avatar and persona; the changing face of self.

Pedagogy

Using learning technologies

belief

motivation

emotional engagement

immediacy

action engagement

cognitive engagement

creative and critical thinking

Using virtual learning environments

social interaction

Cybergogy - learning in virtual worlds

\section{Strategy}

Strategies of the technology-enabled teacher

Computer mediated collaboration

Sustained online learning

Teaching in the virtual world 
The focus of this series of books is the psychological elements of educational practice. The series aims to draw together and elucidate, at more than a superficial level, the major current topics of concern that are related to learning and to other important areas of psychological interest.

In the past teachers in training were introduced, at an entry level at least, to some of the psychology of learning and education. Although this element of the United Kingdom teacher training curriculum (TDA, 2008) has not quite disappeared completely, there is a considerably reduced emphasis placed on it in teacher training than previously. Teachers currently in post report that they were not introduced satisfactorily to what they consider important aspects of learning, theory in particular, during their training (Pritchard, 2005). The relative success of 'Ways of Learning' (Pritchard, 2005, 2009), and other books dealing with the same subject matter, can be seen as indicative of a need for more psychology for teachers and teachers in training.

In support of the wider rationale for the series, the work of Burton and Bartlett (2006:44-45) has some important points to make. They suggest that there is a danger that new ideas for pedagogical approaches in the classroom are often promoted, sometimes by government agencies, without the detailed research and theoretical underpinning relating to it being considered due diligence: 'The speed with which the internet and television can transmit ideas and information and appear to afford them (often spurious) validation should concern us as educators.' (:44). They are concerned that, 'high-profile education consultants deliver courses on new pedagogies...' (:45). The presentations are '... drawn eclectically from a range of research findings thought to have practical benefits for learning' $(: 45)$ and that teachers 'generally enjoy these stimulating sessions and the recipe approach to pedagogic techniques but they are not encouraged to look deeper into the research that underpins them' (:45). The books in this series aim to provide the opportunity, in an accessible and relevant way, to enable teachers, teachers in training, and others with a professional interest in children, classrooms and learning, to look more deeply at topics, their background research and potential efficacy, and to be able to make choices about their own pedagogical approaches and preferences from a position of knowledge and understanding. The authors will consider the needs of those in training following courses that expect the detailed presentation of ideas at Masters level giving leads to follow, ideas to develop and exemplary writing of a professional and academic quality. This is important, as it is increasingly the case that courses leading to Qualified Teacher Status (QTS) in the UK are linking assessed work to Masters level expectations, and awarding credits towards Masters degrees. This is particularly the case with postgraduate level teacher training courses.

The series, in turn, presents and examines the detail and potential of a range of psychology related topics in the light of their value and usefulness for practising teachers. Each of the authors presents an outline of the topic, a review of the research which underpins its principles, the implications of the underpinning theory for pedagogy, and lastly a consideration of strategies which teachers might employ if they were to wish to implement the precepts of theory in their teaching. The books aim to outline a trail from research and theory, to pedagogy and thence to teaching strategies in practice. There is a clear pedagogical element to the books presenting the ideas in the perspectives of research, theory, pedagogy and strategies for teaching. There are suggestions for further reading and activities, both written to develop understanding and classroom-based to develop skills and knowledge. The more general strategies will provide teachers with sound starting points for developing their own particular plans for lessons and series of lessons including activities which will be informed by the principles of the topic in question.

Research is presented and explored, the theory generated by the research is outlined and the pedagogical implications of the theory, leading to teaching strategies follow. Within a set, but flexible, framework individual authors have written in a way suited both to them and to the topic in question. 


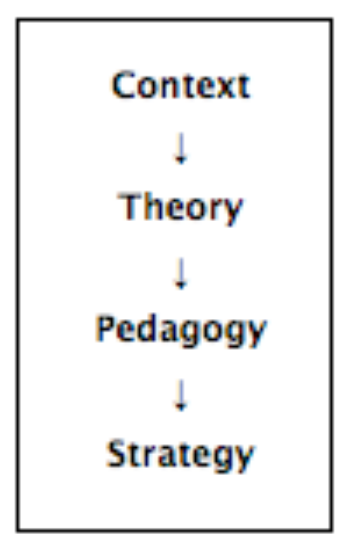

Figure 1 The conceptual path taken by each author when writing.

A part of the intention of the series is to look beyond the charisma of the presenters of day courses, and similar, for teachers (Burton and Bartlett, 2006) and beyond the showy and commercialised publications aimed at selling expensive materials. Each book aims to give an evidence-based consideration of the possibilities afforded by new findings and ideas, and give a review of research upon which claims for teaching efficacy have been built and a solid foundation for teachers and those in training to build their own ideas and strategies. The new ideas and findings are presented in the context of existing knowledge, understanding and practice of the topic in question. 
I would like to say thanks to the colleagues and students who have enhanced my experiences and influenced my views during the previous 32 years of using computers in my teaching. Working at the leading edge of educational innovation can be challenging, for the learners as well as the teachers, and so, to my pupils and students I am particularly grateful. Special thanks go to: Andy Neil, Catherine Richards, Ce Amey, Claire Johnson, Fengyin Lin, Gill Piper, Lesley Scopes, Mariam Mohamad, and Tamer Abd El-Gawad who have influenced my thinking in these matters.

This book is dedicated to my wife, Heather.

John Woollard

September 2010

\section{CONTRIBUTORS}

Lesley Scopes completed her Masters degree in computer based learning and training at the University of Southampton with a dissertation 'Learning Archetypes as Tools of Cybergogy for 3D Educational Landscape: A Structure for Eteaching in Second Life'. She now teaches and trains in virtual world environment in the US and the UK and presents her work in conventional and virtual world conferences. Catch up with her, as Light Sequent, on YouTube, blip.tv and Second Life.

Tim Williams is Programme Leader (Work Centred Learning Programme) in the Faculty of Education at Anglia Ruskin University and has been part of the development of the Ultraversity online degree programme since its inception at UltraLab, Anglia Ruskin University in 2003. He is now also involved in supporting faculties across the university develop online learning pathways based on the experience gained from Ultraversity. He is particularly interested in the new possibilities and implications for the assessment of students using technology. 
By the end of the chapter you will be able to:

- recall the historical perspective of technology-enabled teaching and learning;

- understand the scope of technology-enabled learning and explain the terminology;

- define, in terms of your practice, the scope of technology-enabled teaching;

- understand the concept of e-learning, that is, the special form of learning only associated with the use of technology; and

- relate the key features of technology with the key areas of educational theory and psychology.

The developments in teaching and learning in the 21st century are growing more and more dependent upon web-based and computer-based technologies. Technology is having a positive impact upon learning: the ImpaCT2 study (DfES, 2002a) showing increased grades for school pupils; the ICT Test Bed programme (Somekh et al, 2007) reported that learner satisfaction rose dramatically with them showing greater independence in their learning; and students in UK further education showed better understanding and speedier progress through their courses (Finlayson et al, 2006). These developments are presenting new opportunities, contexts and environments for learning; 'e-learning', within the title of this book, subsumes the diverse range of theories and applied aspects of teaching and learning including: virtual learning environments, cybergogy, social networking, social justice, cyber-bullying, new patterns of learning, visualisations, algorithm, programmed learning, and so on. Indeed, the very letter ' $e$ ' is developing other meanings such as e3-learning (effective, efficient, and engaging learning) (Spector and Merrill, 2008).

This book, like others in the series, will follow the same format of exploring the research, presenting the theories, describing the pedagogy (and cybergogy) and illustrating with vignettes. First, there is an exploration of the scope and diversity within the field of e-learning and a definition of the terms that will be encountered.

\section{Towards a definition of e-learning}

E-learning is a complex construct of teaching and learning strategies, a way of organising the curriculum and a method of teaching. E-learning is also a learning theory identifying those aspects of knowing and understanding that relate to computers or occur as a direct result of the use of computers. Perceptions of elearning amongst teachers, theorists and the public are varied and the socially constructed definition is continuing to form. The following table illustrates the diversity, complexity and pervasive nature of e-learning.

\begin{tabular}{|c|c|c|}
\hline what & $\begin{array}{l}\text { is a form of teaching, training or tutoring; } \\
\text { it is a technology for teaching; } \\
\text { is a facilitator of learning; } \\
\text { sometimes through social interaction. }\end{array}$ & $\begin{array}{l}\text { CAL, CBL, CAI, CML, CBA, CAA; } \\
\text { IT, ICT, microcomputers, computers, PCs, laptops, web } \\
\text { books, SMS, MMS; } \\
\text { MLE, VLE, PLE, LP, LMS, CMS, VIE, CMC, CSCL; } \\
\text { social site, profile, 3Di, VW, avatar. }\end{array}$ \\
\hline who & $\begin{array}{l}\text { is for learners of all ages; } \\
\text { is for all abilities; }\end{array}$ & $\begin{array}{l}2 \text { years and older including the silver surfers; } \\
\text { special educational needs to post-doctorate. }\end{array}$ \\
\hline when & $\begin{array}{l}\text { is always available; or } \\
\text { is scheduled and time structured. }\end{array}$ & $\begin{array}{l}\text { 24-7, web pages, Web 2.0, wiki, blog, forum, } \text { Twitter }^{\mathrm{TM}} \text {, } \\
\text { email, RSS, podcasting; } \\
\text { webinar, videoconferencing, web conferences, chat, } \\
\text { chat rooms, internet messenger, e-conferences, virtual } \\
\text { worlds. }\end{array}$ \\
\hline where & $\begin{array}{l}\text { is everywhere, accessible by the internet; } \\
\text { is also provided through resources; } \\
\text { and/or } \\
\text { can be integrated with face-to-face teaching. }\end{array}$ & $\begin{array}{l}\text { WWW, email, IM, FTP, Available HTTPS, cloud } \\
\text { technology, cyber-spaces; } \\
\text { presentation files, pdf, CD, DVD, audio files (e.g. MP3), } \\
\text { video files (e.g. MP4), SMS (text) and MMS (media } \\
\text { message service); } \\
\text { blended learning. }\end{array}$ \\
\hline how & through a computer; & $\begin{array}{l}\text { technology-enabled teaching, learning technologies, } \\
\text { educational technology, technology-enhanced } \\
\text { teaching; }\end{array}$ \\
\hline
\end{tabular}




\begin{tabular}{|l|l|l|}
\hline why & through other technologies such as... & $\begin{array}{l}\text { mobile-learning (m-learning), audio player, telephone, } \\
\text { mobile telephone (GPRS/3G), internet-enabled mobile } \\
\text { telephone, podcasting, vodcasting. }\end{array}$ \\
\hline $\begin{array}{l}\text { to enable personal advancement through informal } \\
\text { engagement; } \\
\text { to support and complement formal tuition; } \\
\text { to provide just enough, just in time support; } \\
\text { to provide tuition that takes place away from the } \\
\text { classroom; } \\
\text { to meet learner expectations. }\end{array}$ & $\begin{array}{l}\text { inclusion: accessibility, convenience, user-friendly; } \\
\text { personalisation: student-centeredness, individualised, } \\
\text { learner-centred; } \\
\text { open learning; life-long learning; }\end{array}$ \\
\hline
\end{tabular}

\section{Figure 2 What is e-learning?}

It is evident that the world of e-learning is dominated by technical words, abbreviations and acronyms. This book endeavours to both explain and rationalise the range and diversity of e-learning facilities, whether of the past but having significance for current practice, or the practice of the present with significance for how elearning customs will change. Because of the diverse and varied nature of e-learning activity, it is also likely that any single definition will omit or reduce in emphasis one or more aspects that other practitioners might deem important. However, an attempt at definition must be made.

For the purposes of the book, the working definition for e-learning is...

E-learning is any form of teaching, training or tutoring designed to meet the needs of identified learners of any age and ability by scheduled or continual provision via the internet or mobile telephones, using electronic multimedia resources, computers and computer-based devices.

The three essential components can be represented diagrammatically as:

\section{the action of}

for example, teaching, training or tutoring

\section{by means of}

a technology or technology-based resources

\section{with the intention to}

enable learners to learn

(skills, knowledge or understanding)

Figure 3 The three components of e-learning

This definition is broad so that it encompasses practices of the foreseeable future as well as many of the practices of using computers in education that have taken place over the previous fifty years. Many of those bygone activities have characteristics that remain valid today and, importantly, the underpinning principles of psychology remain valid. However, there is another meaning of e-learning; the next section explores the changing act of learning.

\section{Changing thinking; changing the ways of learning.}

However, there is one meaning of e-learning that is very different to the definition above - it is where elearning is the act of the learner to learn something in a specific way or of a specific type that is not the same as conventional learning.

\section{E-learning is different from ordinary learning.}

This is a challenging concept and this definition of e-learning is one worthy of study and discussion. E-learning is learning that is different from any form of learning prior to the use of technology. The context for this discussion is emphatically expressed by lan Jukes in his keynote presentation (Jukes, 2010) where he describes Marc Prensky's idea of digital natives and digital immigrants and how they show signs of thinking differently (Prensky, 2001b). Today's young learners are of a generation where the mouse and the keypad are as natural tools for interaction, communication and expression as the pen and voice. The pervasive nature of ICT, the 
continual digital bombardment, has impacted upon every facet of life and skills development in one area leads naturally into another. Being able to handle the on-screen games console helps the learner drive and explore the virtual learning environment; navigating an entertainment DVD helps learners use an education-based video presentations. Learners today see images on screens as objects to be manipulated; they see scenes on the screen as environments to be explored and they recognise themselves as avatars, profiles and IDs. Ian Jukes' analysis speculates on the developments in our understanding of neuroscience, describes the concept of neuro-plasticity and asserts that intelligence is not fixed but develops as the capacity of neurons develop to make ever more complex structures, patterns and relations. Susan Greenfield, in her book The Quest for Identity in the 21st Century, drawing on evidence from neurological science, argues that the levels of visual stimulation when working, learning and being entertained today is impacting upon the brain and are reflected in terms of behaviour and personality (Greenfield, 2009).

Steven Johnson, in his book Everything Bad Is Good for You (Johnson, 2005), suggests that the challenges met by the digital generation when engaging with the television, computers and games has positive impacts upon the way they think. They are better able to make risk-taking judgements, they are well motivated, they can deal with failure and they have developed thinking skills. The earlier TV generation experienced the singularity of plots and storylines that required no engagement by the viewer. The experiences of the current generation of television consumers are of complex scenarios, parallel plot lines, analogies and metaphors. Marc Prensky describes the younger generation as the digital natives - those learners brought up with the technologies and integrating their technology experiences fully with their traditional learning real world and kinaesthetic experiences.

Sustained and successful electronic game playing requires high levels of concentration, rapid eye-finger coordination, spatial awareness and memory of places, objects and sprites. It could be conjectured that there are transferable aspects to those skills that may support learning in more traditional areas as well as learning in computer-based environments. Usha Goswami believes that video gaming could be used to enhance skills of flexibility and behavioural inhibition. 'This would have a significant impact on their ability to regulate their own thoughts and behaviour, which is one of the developmental challenges of childhood and could be of great benefit to children' (Byron, 2008:155). 'Cognitive neuroscience research shows that an area of the brain called the frontal cortex plays a key role in self-regulation, in particular via inhibition. This brain region appears to govern the ability to inhibit particular actions in the light of new knowledge, and to shift attention flexibly as updating is required' (Goswami, 2008:33). Tanya Byron makes the assertion more strongly, 'there are certain speculations we can make about the potential impact on children's development, including the possibility for them to lead to deeper learning, having a more significant impact on a child's sense of self and the potential for higher degrees of excessive use due to the 24/7 nature of the games (Byron, 2008:158).

A useful analysis of e-learning has arisen from Andrew Churches' interpretation of Bloom's cognitive taxonomy. The original hierarchy consists of, from lower order to higher order cognitive skills: knowledge, comprehension, application, analysis, synthesis and evaluation. More recently it has been revised (Anderson and Krathwohl, 2001) and operationalised using the verbs: remembering, understanding, applying, analysing, evaluating and creating. Churches makes the observation that this analysis is not about the tools of online learning but it is about the learning. The analysis enables trainers and tutors to determine the nature of the learning and then look to the best tools to meet the needs of the learners (Churches, 2010). Steve Kennewell used the term 'affordances' of technology in a similar way, to identify what the technologies could do to support learning, what learning activities they supported, rather than considering the functionality of the software or online tools (Kennewell, 2001). Pat Maier and Adam Warren identified the values of learning technologies in terms of the learning that they supported (Maier and Warren, 2002).

For clarity from this point onward, e-learning is only used to represent the psychology of learning when that learning is specifically dependent upon or arising from the impact of technology. E-learning is concerned with the learning patterns never witnessed before the introduction of technology. That is, e-learning is, the actions of learners (pupils, students, trainees, tutees, etc.) to acquire skills, knowledge, understanding and attitudes of the curriculum through their use of technology-enabled teaching or technology-based resources. All other references to what is more generally called e-learning will be by use of specific terms described below. 
- computer assisted learning (CAL) or computer based learning (CBL) or computer assisted instruction (CAI) and are usually used to describe practice that pre-dates the worldwide web;

- computer assisted assessment (CAA), computer based assessment (CBA), e-assessment, portfolio, e-portfolio (EP) all relate to the judgements of attainment and occasionally progress and mostly include feedback to the learner and teacher;

- virtual learning environment (VLE), managed learning environment (MLE), learning platform (LP), personalised learning environment (PLE), learner management system (LMS), content management system (CMS) all refer to various ways in which the teaching materials are managed or presented in a coherent, pedagogically structured way - characteristically protected by a username/password login and the learner is called/identified by their username with no control over their accessibility rights and representation;

- computer mediated communication (CMC): e-mail, webmail, text (SMS) and media message service (MMS), picture messaging - the learner is identified by a telephone number or email address;

- social networking through internet messaging (IM), MSN Messenger, Twitter ${ }^{\mathrm{TM}}$, Facebook ${ }^{\mathrm{TM}}$, chat, chat rooms, where the learner is identified by a profile and can modify their profile;

- role-playing games (RPG), massively multiplayer online gaming (MMOG), massively multiplayer online role-playing games (MMORPG) utilised the virtual immersive environment (VIE) and 3D immersive applications (3Di), virtual worlds $(\mathrm{VW})$ where the learner is represented by an avatar and can see themselves immersed in the learning environment;

- virtual reality (VR), augmented reality (AR);

- Web 2.0-related learning: web pages (HTML, HTPPS), wiki, web log (blog);

- computer mediated conferencing (CMC): e-conferences, webcast, webinar, video conferencing (VC);

- media, presentations and publishing: pdf, CD, DVD, audio files, video files, mp3, jpeg, mov, Flash ${ }^{\mathrm{TM}}$, QuickTime ${ }^{\mathrm{TM}}$;

- technology-enabled learning: mobile-learning (m-learning), web book, telephone, mobile phone, personal digital assistant (PDA), internet enabled mobile phones (XDA), MP3 players, iPod ${ }^{\mathrm{TM}}$, podcasting, vodcasting.

Figure 4 The range and diversity of technology-enabled learning

In this section where the meaning of technology-enabled teaching and learning is being defined, it is important to realise that teaching and learning is not just about the technologies. The enablement also includes elements of:

- accessibility, user friendliness and social justice;

- personalisation, individualisation and learner-centeredness;

- open-learning and lifelong learning;

- bridging the digital divide within society, within families and between generations; and

- learner expectations.

\section{A brief history of technology-enabled learning}

In 1968, Herbert Hallworth in his review of the use of 'electronic computers' described a 'lop-sided development' within educational computing with the emphasis on programs to teach numeracy and little else. He describes the problem arising from a 'lack of personnel: it is difficult to find people with time and ability to use the equipment that already exists' and concludes that in order to make an efficient use of computers 'a prerequisite is the systematic training of both graduate and undergraduate students of education in computer techniques' (Hallworth, 1968:240). The mid-1970s saw the arrival of the first microcomputers including Apple ${ }^{\mathrm{TM}}$, IBM ${ }^{\mathrm{TM}}$, Commodore Business Machines ${ }^{\mathrm{TM}}$ and Atari $^{\mathrm{TM}}$ (Atari, 2010) each making a contribution to the use of computers in the classroom. In 1975 the Commodore PET and in 1977 the Apple II appeared in schools. They featured an integrated keyboard and tape device, sound and an input/output port. The software focussed on drill and practice computer assisted instruction (CAI). In the UK educational computing received a boost through the 'BBC Computer Literacy Project', Harold Wilson's 'white heat of technology' speech and the UK government's investment in computers for schools programmes based on two UK manufacturers, Acorn (Cambridge) and Research Machines (Oxford). Acorn, with its product the BBC micro, eventually sold over a million computers into schools and homes. An early-celebrated use of computers is Seymour Papert's development of LOGO, a programming environment based upon spatial 
awareness and list processing, in the 1960s (Papert, 1980; Abelson, 1982). Subsequently, programmable devices such as Bigtrak (Meredith and Briggs, 1982) and turtles appeared. In the UK, the Education Reform Act (1988) proposed a National Curriculum that included within the attainment targets for 10 year-olds (level 5),

'Understand programs like

10 FOR NUMBER $=1$ TO 10

20 PRINT NUMBER NUMBER

30 NEXT NUMBER' (Straker, 1989:274)

Other computing activities for younger pupils included: give and understand instructions... help design a data collection sheet... use Logo commands... know that computers can be used for storing information ( 7 year olds)... enter and access information in a simple database... create shapes using DRAW and MOVE commands... create a decision tree... and create, read and interpret a flow diagram. The most able primary aged pupils were expected to "know about two-state electronic devices and the application of such devices to logical decision making, binary counting and information storage' (Straker, 1989:275). Sherry Turkle observed that people (children, parents and programmers) considered that the computer had a 'psychological' being with a sense of will and purpose (Turkle, 1984). It is something to which humans can 'relate'.

With the advent of English language based programming languages like BASIC, computer literate teachers could develop lesson support materials. Small programs were written by teachers to meet specific learning objectives and particularly for students with special educational needs (Hope, 1986). Computer assisted learning $(\mathrm{CAL})$ promoted through a wide range of skills-orientated programs dominated the scene in the early 1980s (Chandler, 1984; Govier, 1985). Then there was a rise of the importance of generic programs within the curriculum including: handling information (databases), modelling (spreadsheets) and text manipulation (word processors) (Loveless, 1995; Scrimshaw, 1993, Squires and McDougall, 1994). The Grass database and Grasshopper spreadsheet, developed by Newman College, Birmingham under direct funding from the UK government, introduced pupils to handling information and communicating the results of search, sorts and calculations. In the 1990s, the IT curriculum changed in response to the development of multimedia computers, videodiscs, media authoring tools and simulations; the windows-based computer interface also appeared. As a result of the change, more use of video and multimedia enhanced teaching materials occurred. Multimedia was used to create more interesting presentations of information (then known as interactive learning applications) and also a tool for the learners to create their own presentations (Acorn Computers, 1993; Heppell, 1993). This has not been without its critics because it has been seen to be a move away from creative, engaging and challenging activities to passive and undemanding information sources (Robertson, 1998).

The mid-1990s saw the arrival of the internet - e-mail and hypermail for communication, web browsing and web searching for handling information, satellite imagery and web cams for datacapture, real time communications for modelling and exploring microworlds. Digital video, virtual reality, augmented reality and 3D systems further enriched the appearance of the teaching resources. By then the classroom computer in US and UK classrooms is ubiquitous. The late 1990s saw the skills-based developments such as the European Computer Driving Licence (ECDL, 2010) in the workplace, objective based assessments in the key stages 1 and 2 classrooms such as those of the National Design and Technology Education Foundation (NDTEF) and elements of the UK New Opportunities (lottery) Funded (NOF) training for teachers. Both the NOF training and the initial teacher training programme emphasises understanding and application of ICT across the curriculum. There was a resurgence of computer managed learning under the guises of integrated learning systems (Wood, 1998; Williams, 2003) and open integrated learning systems replacing a lot of CAL driven activities.

At the turn of the millennium, the internet and, particularly, the worldwide web began to dominate the developments in educational technology and the popularity of CD ROM-based materials diminished. The single version Encarta CD ROM could not compete with the ever-updating online encyclopaedias and new forms of information. In the UK, the National Grid for Learning and later the Secondary Strategy for ICT capability (DfES, 2002) saw a renewed focus on computer suites in primary education and specialist teaching in secondary education (DfES, 2002a; Kennewell et al, 2003) and investment in hardware (Cuban, 2001; 
Twining, 2002). Issues of teacher attitudes are still factors in the effective use of ICT across the curriculum (Williams et al, 1998; Amey, 2007) and in communication with students (Cunningham and Harris, 2003). More recently, we see the re-emergence of teaching ICT across the curriculum (ICTAC, pronounced ick-tack) in secondary schools (DfES, 2004a) and blended approaches (Condie and Livingston, 2007).

In 2003, the UK government released its policy outline for schools, colleges and universities 'Progress towards a Unified E-Learning Strategy' consultation with the expectation that all UK schools can provide an online, transferable e-portfolio and access-from-home facility for all pupils and their parents (DfES, 2004b). This has driven the rush to virtual learning environments (VLEs) and other online facilities such as pupil-authored websites, shared documents and email addresses for all pupils. There was a clearer understanding of the scope of technology-enabled learning emerging with a renewed interest in the principles of pedagogy (Conole et al, 2004) and assessment (Bull and McKenna, 2004) in the form of computer assisted assessment (CAA). The concept of cyber-spaces (virtual locations) colloquially known as 'the cloud' where learning can take place, is established.

The crossover between entertainment and education (edutainment) is increasing. The online gaming fraternity can lay claim to the educational value of many so-called gaming activities. The players exercise logic, exhibit good space perception and memory, strong control over their navigation (peregrination) and possess good eye-finger coordination. As a learning environment, the massively multiplayer online game (MMOG) environment can be considered a form of situated cognition, 'that allow learning to arise from active forms of engagement rather than the mere storage and retrieval of information from memory (Young et al, 2006:5). 2005 saw the release of the first 3D immersive environment especially designed specifically for young people - Teen Second Life ${ }^{\circledR}$ based on a similar grid and structure to the parent Second Life ${ }^{\circledR}$, both developed by Linden Lab. Both use a free client program to access the in-world environment through an internet connection. The world is based upon islands, owned by individuals and groups with most offering free access by the public. Second Life's popularity continues to grow with 'more than 3000 servers and has close to two million registered users' (Rymaszewski et al, 2008:iii). At the turn of the decade, teaching and learning through 3D immersive environment is now established as a suitable resource for all ages of learners (Dell, 2010).

In parallel with the developments of virtual worlds requiring high internet bandwidth and large-screen desktop computers there has been a move to make the opportunities for learning smaller and more mobile. Learning is taking place through text (SMS), media messaging (MMS), GPRS and lately 3 G connected devices, web-books and XDAs (internet enabled personal digital assistants). This is broadening access to learning because of flexibility, reduced costs and immediacy of the technology (Mohamad and Woollard, 2008, 2009; Shen et al, 2009).

\section{Pedagogy, andragogy and cybergogy.}

The term pedagogy is used to describe all forms of teaching strategies and principles of instruction in any learning environment and includes the activities of teachers, tutors and trainers. 'Pedagogy is the heart of teaching. It is the rules and principles that guide effective and efficient activities that lead to learning. It is

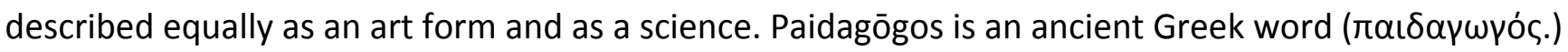
meaning 'a slave who takes children to school to learn'. That idea is almost at odds with the current idea of pedagogy 'enabling learners to learn' but it does remind us that it is 'working with children and providing the opportunity to learn' and so the less rigorous meaning 'child-leading' is more appropriate to our current understanding of the process. Pedagogy is about teaching methods and principles of instruction. It is assisting students through interaction and activity in the ongoing academic and social events of the classroom' (Pritchard and Woollard, 2010:45).

The term andragogy is used when those teaching strategies and principles of instruction are focusing on adults and engaging adult learners with the structure of the learning experience. The term 'andragogy' (manleading) was first used in 1833 German educator Alexander Kapp to describe the differences between working with adults and working with children. Malcolm Knowles developed the ideas into a theory of adult education. He felt that any experience that adults perceive as putting them in the position of being treated as children is bound to impact upon their learning (Knowles, 1970). He described andragogy as 'the art and science of

$$
--<11>--
$$


helping adults to learn' (Knowles, 1980:43). A full description of andragogy is made in Psychology for the Classroom: Constructivism and Social Learning (Pritchard and Woollard, 2010:45-50).

The term cybergogy is used when those teaching strategies and principles of instruction are within a computer-based environment. Recent and important developments in our understanding of cybergogy have highlighted three aspects: the implications of moving about in a virtual world (or navigating in a 2D world); the difference in engagement of learners when immersed (Wang, 2007) in the activity; and the effects of experiencing learning through the medium of an avatar.

There exists two views of cybergogy; the first relates the principles of teaching to any form of technologyenabled learning whereas the second restricts cybergogy to the study of learning and application of teaching in a 3D immersive environment.

1. Cybergogy is used to describe the principles of teaching practice when those teaching strategies and methods of instruction are within any computer-based environment.

2. Cybergogy is used to describe the principles of teaching practice when those teaching strategies and methods of instruction are within a virtual world and engaging the learner through the medium of an avatar.

In the first definition, cybergogy, like e-learning, has existed since the 1960s, although it has not been named as such until more recent times. 'The application of educational technology has created a new teaching and learning concept - cybergogy. One of the central elements of cybergogy is the intent to combine fundamentals of both pedagogy and andragogy to arrive at a new approach to learning... Cybergogy focuses on helping adults and young people to learn by facilitating and technologically enabling learner-centred autonomous and collaborative learning in a virtual environment' (Carrier and Moulds, 2003). Central to the idea is that teaching through technology is not the same as face-to-face teaching. James Cronin (Cronin et al, 2009) argue that applications of 'cybergogy' share characteristics in common with educational constructivism, namely, placing the learner at the centre of the teaching and learning experience. Their review of blended approaches in higher education is discussed in the next chapter.

The second definition is used by those who advocate that cybergogy applies only to the analysis of the principles of teaching practice in 3D immersive environments. During the most recent years there has been a development, emerging from computer-based game-playing, that places the learner at the heart of and total focus of the computer display, in a way that no other learning technology has been able to achieve and the learning experience has become immersive. It is this new environment that is attracting the attention of researchers (Kapp and O'Driscoll, 2010; Scopes, 2009) to understand a new way of teaching. They have defined the term cybergogy as the 3D immersive teaching in virtual world environments.

Throughout the book, the principles of technology-enhanced learning will be called pedagogy; if they are specifically directed to adults then the term andragogy is used. Cybergogy is reserved for the teaching and learning approaches that places the learner in the focal point of the activity whether it is through 3D immersive environments with avatars. As with pedagogy, there are many principles of practice of cybergogy but unlike the thousands of years of history celebrated by pedagogy, cybergogy history is measured in single years. Consequently many aspects of technology-enabled teaching will be described in terms of traditional pedagogy as well as the emerging models and terminology of cybergogy.

\section{Mapping the psychology}

The developments in technology-enabled teaching and learning have occurred quickly in its short life from the early microprocessors through to today's sophisticated application of web-based and mobile technologies. The previous sections outline the pervasive and impactful influence technology is having upon classroom, lecture theatre, training centre and learner practice. The classroom is changing and so are the learners. Prensky (2001a) coined the phrase 'digital natives' for those learners spending their formative years in the online world; they are 'used to receiving information really fast', 'prefer random access' and 'thrive on instant gratification and frequent rewards'. The others, the digital immigrants, may struggle to work as efficiently in such an environment or struggle to understand this new way of thinking and being and so not utilise the 
technologies to the best effect. John Cuthell when discussing the autonomous learner draws similar conclusions in his book Virtual Learning (Cuthell, 2002).

- A significant number of students expect to do more work at home than in school.

- Many students regard knowledge of 'how to' as more important than 'what'.

- The students' personal computers are the vehicles for learning.

- The students' patterns of learning are not found in the classroom.

- The computer accommodates the range of intelligences (Gardner, 1983) and preferred means of learning impacting on students' attainment.

Figure 5 The changing face of learning, based on Cuthell (2002:149-150)

This next section considers the interaction between the learners, teaching and the psychology of the classroom and maps each in relation to the developing practices.

There are three major underpinning approaches to learning theory simply described as behaviourist, cognitivist and constructivist. There is an increased complexity when we consider the different aspects of each area of learning theory, the proliferation of approaches that connect an aspect of theory with a specific teaching approach and the overlap and combination of theories as they become formalised in pedagogic practice. The figure below describes some of the relationships between the major areas of learning theory and the different and diverse areas of technology-enabled teaching and learning. To guide the design of the evaluation process with regard to pedagogy, a model relating learning theory to design is proposed.

- Behaviourism gives us: a focus on skills and observable evidence of learning; task analysis and structured learning opportunities; changing attitudes and responses; and objective assessment of progress.

- Social constructivism gives us: engaged learning through activity and communication; collaboration and cooperative activities to support learning; communities of practice; and socially constructed ideas and understanding.

- Cognitivism gives us a consideration of: different ways of learning; different types of learning; developing stages of learning; intelligence, learning styles and various strategies for learning.

Other theories reflecting psychological constructs and technology enabled learning are: motivation (Bolliger, 2010; Garris et al, 2002; Keller, 1999; Maslow, 1943; Prensky, 2001a); maturity (Erikson, 1968, Salmon, 2000); beliefs (Askew et al, 1997; Dwyer et al, 1990; Medwell et al, 2001; Turner-Bisset, 2001; Yero, 2002)), culture (Michael, 2000) and the regulation of learning (Perrenoud, 1998; Zimmerman and Schunk, 2011). 


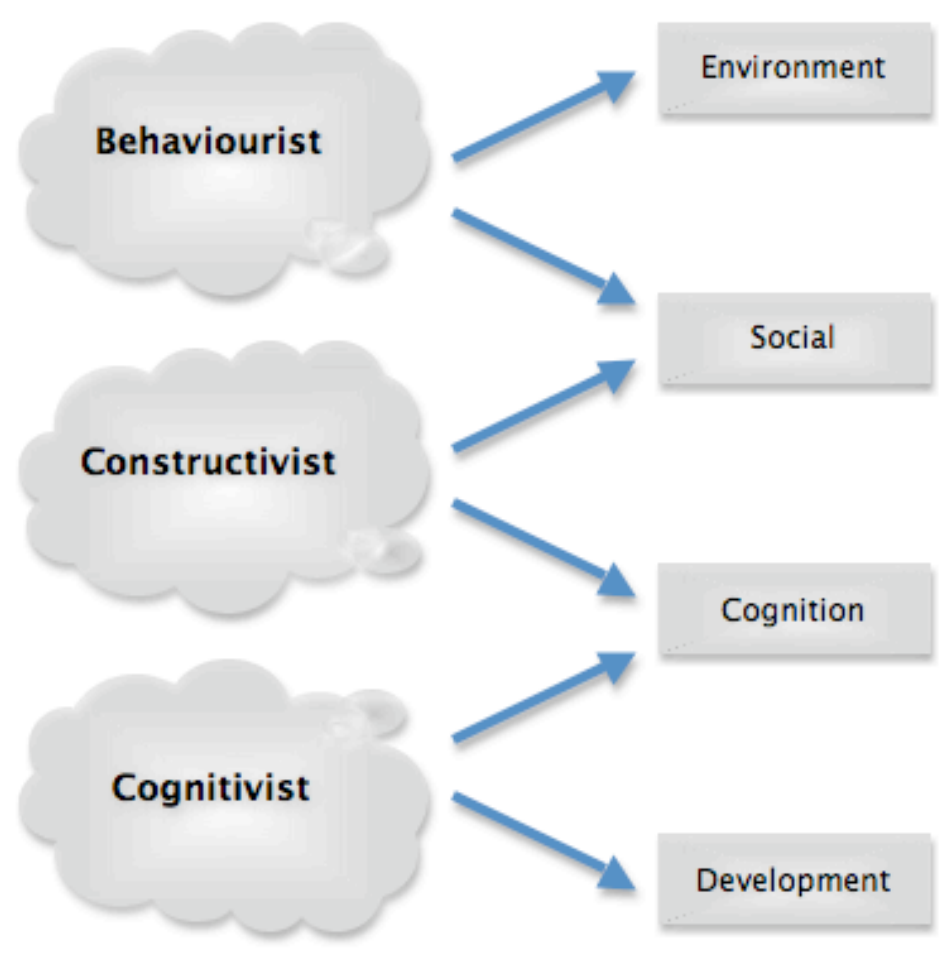

computer software interface design;

interactivity, feedback, reward and punishment; task analysis, sequencing learning experience; e-training;

social networking, personalised learning;

collaborative learning: WIKI, blog, forum, IM, email; fostoring communities of practice;

e-teaching, e-mentoring and e-tutoring styles; motivation and engagement;

de Bono learning hats, learning styles:

intelligence, g-factor, multiple intelligences;

Piagetian developmental stages;

emotional development;

e-safety and safe guarding, ethical aspects;

identity and personality;

moral development;

Figure 6 Mapping the psychology of e-learning

To help identify the psychological aspects of new technologies the next model identifies the affordances in terms of change that the online learning strategies enable. The model identifies the six major aspects of learning derived from theories and serves as a useful conceptual framework when considering the impact of new technologies on learning. Each aspect has associated with it a number of key questions to ask of the resource (application, artefact or system) when considering the design, development, implementation and evaluation.

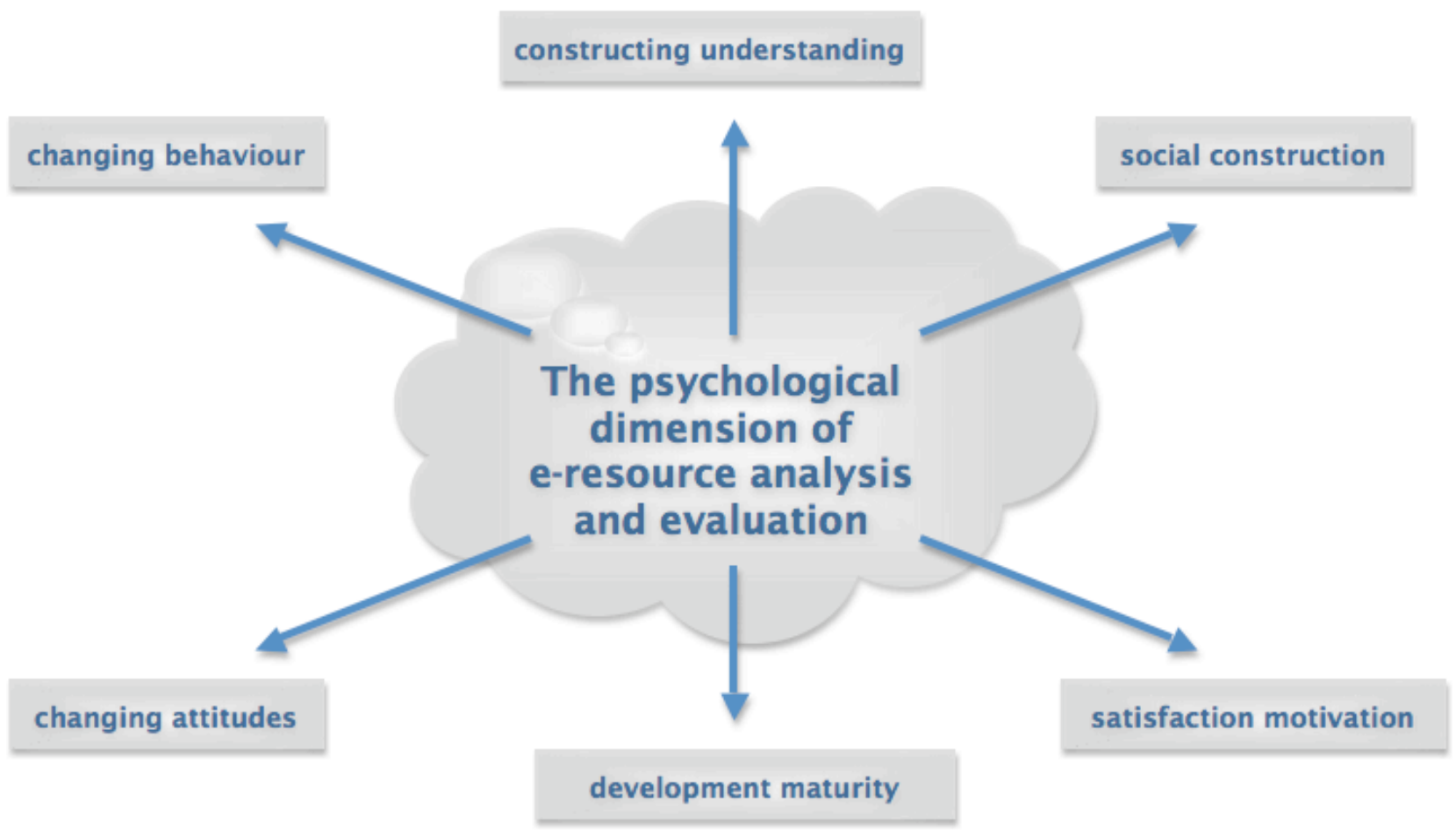

Figure 7 Analysing the psychological dimension of e-resources

The following questions help elucidate the meaning of each area of analysis. 


\section{Changing behaviour}

How does the resources identify learning outcomes? How does the resource reward/reinforce appropriate/good responses? How does the resource celebrate success? Does it provide clear information, advice and guidance? Is it structured?

\section{Constructing understanding}

How does the resource prescribe learning activities? How does the resource enable structured experiences? How does the resource enable the presentation of ideas; how does the resource build upon current knowledge and understanding?

\section{Socially engaged learning}

How does the resource foster cooperation? How does the resource foster collaboration? How does the resource support communication? How does the resource sustain the learners' engagement in the process? How does the resource foster communities of practice?

\section{Satisfaction and motivation}

How does the resource appeal to the learners' aesthetic and personal desires? How does the resource meet the learners' expectations? How does the resource meet the personalisation agenda (student-centeredness, individualisation)? How does the resource meet the needs relating to age, gender (GLBT\&H), ethnicity, culture, faith and belief? How does the resource meet the needs of different learning styles? How does the resource meet basic human needs?

\section{Development and maturity}

How does the resource respond differently to the different stages of development of the learners? How does it meet the needs arising from the stage of cognitive development? Does it reflect age and social appropriateness in the materials?

\section{Changing attitudes}

How does the resource impact upon attitudes? How does the resource promote particular value sets? How does the resource enable exploration of values, faiths and beliefs? Does it provide clear ethical instruction? Does it provide clear moral guidance and example?

\section{Summary}

E-learning is a special kind of learning that only occurs by means of the technology and is associated with the newly acquired abilities of the digital natives. Technology-enabled teaching is that pervasive use of technology to support teaching and learning in all fields of teaching, training and tutoring with all ages and abilities of learners from infants through to silver surfers, those with special educational needs and those with high level academic and learning skills.

The history of computers in education informs current practice and the understanding of why and how technology can support learning. The different aspects of technology-enabled learning reflect the different and contrasting theories of learning with some aspects being underpinned by behaviourist theory, others by social constructivism and some by cognitivist approaches.

\section{Activities}

Consider, in the light of the content of this chapter, the major differences between the earlier activities of computers in schools with the more recent descriptions of technology-enabled learning.

Consider the personalisation, socialisation, emotional and motivational aspects of technology-enabled learning and how they relate to your current practice.

Consider the evidence for a change in capability of digital natives and their capacity to utilise and benefit from the pervasive use of technology in their education. 
By the end of the chapter you will be able to:

- identify different approaches to research and their contribution to evaluating the use of technology in teaching and learning;

- identify the values of meta-analysis and critique and how the conclusions of individual research projects might be better judged;

- appreciate the contribution of technology-enabled teaching to social learning (Bandura, 1977); and

- identify the key issues of e-safety that relate to the learners for whom you are responsible.

Technology-enabled teaching and learning has been under considerable scrutiny from the academic educational fraternity and much is written in celebration of initiatives, exemplification of the affordances and the examination of learning. Identifying, through rigorous research methods, the efficacy or efficiency of elearning methods is not easy. As David Mitchell observes, the paradigm for most empirical educational research is based on 'an input-process-output model which assumes causality from independent to dependent variable' (Mitchell, 1997:53). The approach requires a high level of mathematical rigour in both establishing the quality of the raw data and application of statistics such as t-test, correlations, analysis of variance, etc. He also identifies the problems associated with 'passing subjective judgements off as measurements... by attaching numbers to constructs for which none of the properties of measurable magnitude are met' (Mitchell, 1997:53). With that caution in mind, this chapter begins with the description of a meta-analysis of the research carried out between 1996 and 2008. The other sections deal with particular foci of research: the collaborative and social aspects of technology-enabled learning, the classroom settings for e-learning and the technology focus of research. Finally, there is a description of a critique of one important aspect of learning through technology - e-safety.

\section{Online Learning - a meta-analysis of research}

Meta-analysis and systematic review of experimental results and literature is an important research methodological approach. The result is more powerful than the sum of the parts because the method exposes trends and patterns that are not identifiable by scrutinising the individual sources of evidence in isolation. Bias is avoided by obtaining as much material/data as possible; but the collection of that material must meet the strict selection criteria. Meta-analysis provides strong evidence because it avoids misrepresentation of the evidence. The quality of all the individual items in a review are judged against strict criteria that is set down before the review begins. The explicit nature of the criteria associated with the approach means that the process is open to scrutiny and could be replicated; checks can be made by independent parties after the review has been published. Importantly, because the protocol is set down before the review starts, the results cannot influence the procedures; that is, a particularly strong piece of evidence cannot change the focus of the study. 'As is the case for any good research, the methods for a systematic review are made explicit in a 'protocol' before it starts. This helps to reduce bias in the review process, for example by ensuring that reviewers' procedures are not overly influenced by the results of studies they find. If changes are needed to the protocol as the review progresses these needed to be noted in the review's final report and the rationale for making changes made clear' (EPPI, 2010). A meta-analysis of the results of many investigations enables an overall picture to be established. The degree of importance (the effect size) of an individual study can be estimated as the difference between the mean for that study and the mean for the control group of that study divided by the standard deviation of the combined results.

In 2009, the United States Department of Education commissioned a systematic study of the literature regarding practices in online learning (US DoE, 2009). This study considers the research literature from 1996 through July 2008 and identifies more than a thousand empirical studies of online learning. The systematic nature requires the researchers to specify the type of resources that will be searched, the selecting criteria, the criteria for analysis and quality assessment and the procedure for weighting and presenting individual works. The study provides four important areas of information. First it identifies a conceptual framework for online learning that relates directly to the psychology of learning; it establishes what is online learning and 
what is not online learning. Secondly, it establishes a quantitative means of calculating the relative effect of introducing online learning called the 'effect size'; only papers that present sufficient information for that to be calculated are included in the analysis. Thirdly, it provides a rich source of reliable studies that illustrate ways in which innovative practice can be developed. Finally, and most importantly, it provides a bottom-line statement as to the value of technology-supported teaching.

This conceptual framework for online learning helps guide the literature search and review. Their definition of online learning has 3 considerations:

- does it replace face-to-face teaching or enhance face-to-face teaching (known as blended learning)?

- what type of underlying pedagogy determines the learning experience?

- is the activity synchronous or asynchronous?

The classroom psychology questions relate to the means of learning and the motivation. The study identifies three forms of learning experience:

- expository, didactic instruction where the technology delivers the knowledge;

- active learning which engages the learner in exercises, quizzes, mindtools, etc.; and

- interactive learning involving collaboration and peer-to-peer or peer-to-teacher communication.

The belief of teachers is that 'the way in which teaching takes place impacts upon the quality of learning' and that some teachers believe that 'the quality of learning is proportional to the level of interactivity'.

The concept of synchronicity is important - are activities asynchronous or synchronous? The following Carroll diagram represents the main on-line learning devices and identifies whether they are predominantly used by learners at the same time or used at different times, as and when they wish.

\begin{tabular}{|l|l|l|}
\hline & Synchronous & Asynchronous \\
\hline $\begin{array}{l}\text { Communication } \\
\text { (two-way) }\end{array}$ & $\begin{array}{l}\text { chat } \\
\text { chat rooms } \\
\text { internet messenger } \\
\text { virtual worlds }\end{array}$ & $\begin{array}{l}\text { email } \\
\text { Web 2.0 } \\
\text { forum }\end{array}$ \\
\hline Information & $\begin{array}{l}\text { e-conferences } \\
\text { webinar (web conferences) } \\
\text { video conferencing }\end{array}$ & $\begin{array}{l}\text { web pages } \\
\text { wiki } \\
\text { podcasting } \\
\text { RSS }\end{array}$ \\
\hline Recording & $\begin{array}{l}\text { chat history } \\
\text { electronic footprint } \\
\text { VLE statistics }\end{array}$ & $\begin{array}{l}\text { Tlog } \\
\text { Twitter }\end{array}$ \\
& Facebook \\
\end{tabular}

Figure 8 Synchronous and asynchronous online learning opportunities

The e-learning facilities are represented as a dichotomy but in reality there are degrees of difference. For example, people can sustain a synchronous exchange of ideas through email by being continually logged on and replying immediately. Conversely, instant messenger becomes an asynchronous device when a correspondent leaves a message when the other is logged off. The value of synchronous exchange over asynchronous devices is not clear-cut; studies generally yield no significant differences (Gunawardena and Mclsaac, 2004). In fact, such debate misses the point that, as with all forms of technology, it is the nature of the learning aims or the learner's preferred mode of learning that should determine the technology and method of employment. However, in this debate, Stefan Hrastinski raises an interesting relationship between the asynchronous/synchronous nature of technology and the psychology of learning, whether it is cognitive or personal (social) in nature. He asserts 'personal participation describes a more arousing type of participation appropriate for less complex information exchanges, including the planning of tasks and social support. Cognitive participation describes a more reflective type of participation appropriate for discussions of complex issues... [he suggests] other things being equal, synchronous e-learning better supports personal 
participation and asynchronous e-learning better supports cognitive participation' (Hrastinski, 2008). As described in Figure xxx there are many routes and forms of communication in the classroom and in technology-enabled learning. An important factor that influences the effectiveness of the learning process is the interaction that exists between the teacher and the learner. The work of Baruch Offir and colleagues suggests that different interactions have different effects and they have investigated the differences between asynchronous and synchronous. They conclude, 'observations and interviews which we held with the students helped clarify the information that was obtained using the quantitative research tools, and showed that the presence of a teacher-student interaction which accompanies the learning process is very important for all learners. However, students with high-level thinking can overcome the low-level of interactions in asynchronous learning... the interaction level between the students and the teacher and among the students was found to be a significant factor in determining the effectiveness of the teaching method' (Offir et al, 2008, 1172). The following diagram shows the relationship between asynchronous and synchronous approaches and the nature of learning.

cognitive and social natures of learning

$$
\begin{gathered}
\text { cognitive } \\
\text { engagement } \\
\text { email (1:1) } \\
\text { email (1:many) }
\end{gathered}
$$

forum WIKI

(many:many)

long - degree of separation

between comment and response

understanding

expressing

concluding

cognitivist

constructivist

constructionist

asynchronous

engagement

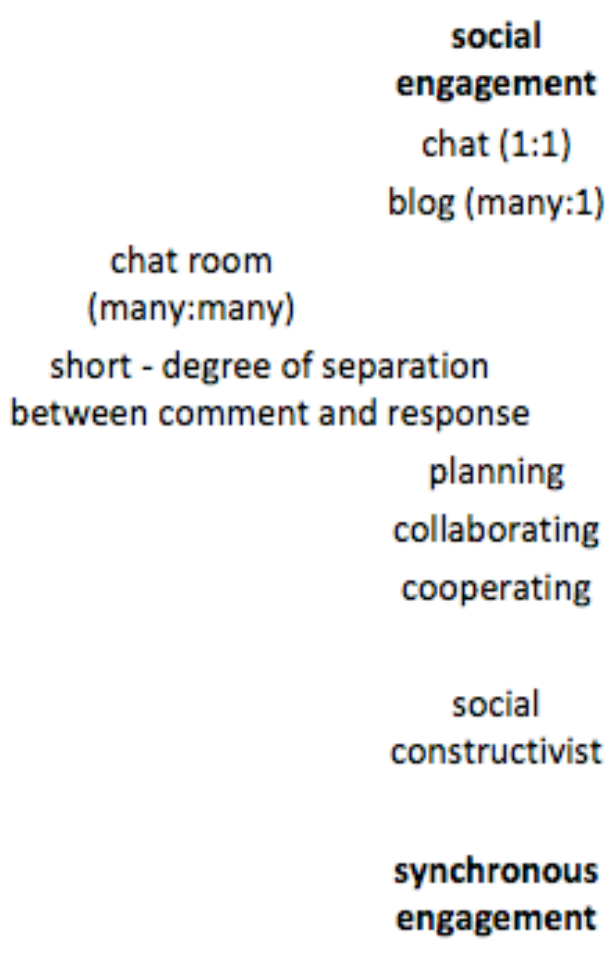

social

chat (1:1)

blog (many:1)

\section{asynchronous and synchronous nature of technology}

Figure 9 The cognitive/social asynchronous/synchronous dimensions of learning

The table illustrates the parallelism between synchronicity and the nature of learning. It also illustrates that the communication, regardless of synchronicity, can be one-to-one or many-to-many in nature. The intensity of the communication has an implication for social constructivism. There is also an implication for the preferred learning style of the individual. There are implications for physical/social needs of the individual.

This US meta-analysis of e-learning draws the following conclusions:

- The 'effect sizes were larger for studies that compared blended learning conditions with face-to-face instruction than for studies that compared purely online learning with face-to-face instruction' (US DoE, 2009:38).

- 'The majority of... studies that directly compared purely online and blended learning conditions found no significant differences in student learning' (US DoE, 2009:38).

- 'Seven of the eight studies found no significant differences' when using media such as embedded video and graphics (US DoE, 2009:40). The analysis suggests that the inclusion of media is not necessarily an efficient mechanism for enhancing learning. The video is acting as a medium for knowledge and nothing else. The 
study cites the work of Zhang et al (2006) that suggests that it is the interactive nature of the use of video is key to its value in supporting learning.

- With regard to the important consideration of learning experience (described above as expository, active and interactive) the study found the results mixed 'with respect to the relative effectiveness of the three learning experience types' (US DoE, 2009:41). It suggests that there is an advantage when learners are given a degree of control over their learning experience.

The main findings arising from this study reveals that there is little rigorous, quantitative research that enable the effect of online working to be measured. The study does conclude that, 'students who took all or part of their class online performed better, on average, than those taking the same course through traditional face-to-face instruction' (US DoE, 2009:xiv) but the study warns that other factors may influence the increased effect such as time spent on the tasks.

\section{Collaborative and social learning}

Computer supported collaborative learning (CSCL) has been established as an affordance of ICT in teaching and learning since the early 1990s with international conferences celebrating the work of researchers, practitioners and learners in 1995, 1997 and 2001 (ITCOLE, 2003). Recent research (Lockhorst et al, 2010) further explores the affordances of computer supported collaborative learning focusing on the training of teachers where the teachers in training were given compulsory collaborative tasks. Those tasks included a range of 'products' and different assessment methods including group, shared, blended, portfolio and reflective strategies.

Shared debate proposition on future history teaching assessed by face-to-face discussion of group propositions and reflections on group work in student portfolio.

A group list of criteria for effective teaching methods assessed by face-to-face discussion of group propositions and reflections on group work in student portfolio.

A series of lessons plans assessed by face-to-face group presentation and reflections on group work in student portfolio.

Description and comparison of educational curricula assessed by face-to-face group presentation and reflections on group work in student portfolio.

Design, revision and performance of a lesson assessed by peer feedback and student portfolio.

Small-group research assessed by face-to-face presentation and collective report.

Collection of information on 'teaching outside the classroom' assessed through a collective face-to-face presentation.

Reflection on teaching performance assessed through a written group story including reflections on teaching practice.

Figure 10 Examples of activities enhanced by computer supported collaboration

'The results indicate that reflection-oriented tasks stimulated participation, and in combination with task structure also interaction. Structured tasks which required critical reflection on personal experiences and perspectives triggered task-related communication and a deep level of information exchange' (Lockhorst et al, 2010:63). The interesting findings arising from this work come through the analysis of both the qualitative and quantitative data based on three perspectives: participation (the frequency of joining in and contributing), interaction (sustained response to other contributions and the nature of the threads) and the nature of communication. The final perspective was further measured by considering the level of information exchange (task related responses) and the nature of their regulatory communication including responses related to planning, organisation of task, technical issues and evaluative where the contributors are determining the skills and knowledge of group members or expressing feelings and thoughts.

This work brings a better understanding of two important concepts of online communication: threads and depth of contribution.

A thread is a continuous, but perhaps diverging, collection of contributions (sometimes called posts) on a particular topic under a specified name (subject) usually started by an opening statement or question, displayed in chronological order. It is a continuous train of thought contributed to by different people and 
The thread can be developed synchronously, as in chat, chat room, conferencing and webinar discussions or asynchronously, as in blogs, wiki, email exchanges and shared documents. Synchronicity becomes blurred in some instances when, say, people are exchanging emails simultaneously (perhaps that should be using a better online tool such as chat) or they are simultaneously editing the same online document. Chronology sometimes becomes blurred, particularly in the case of wikis and shared documents, where the display is of the latest version and the chronological order of contributions is recorded elsewhere. The developing nature of the thread and the degree to which contributors make reference to previous texts is a measure of their depth. The diagram below describes the generic aspects of a forum-type thread.

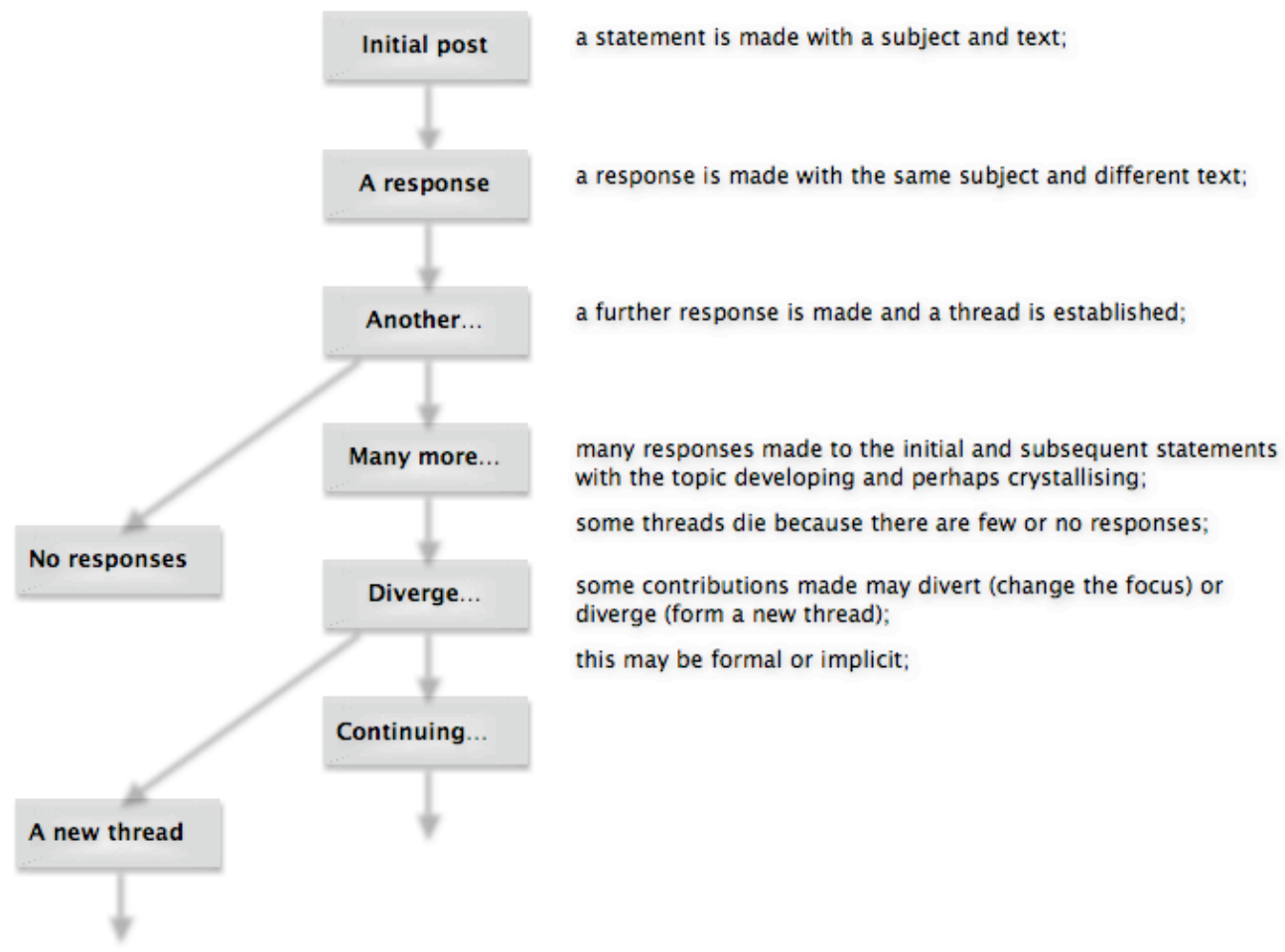

Figure 11 The life of a thread - key points in the chronology

The depth of a thread can be measured in a variety of ways according to purpose. The following analysis indicates those areas of concern when the contributors are learners and the act of learning is paramount. The table below identifies the key parameters.

\begin{tabular}{|c|c|}
\hline $\begin{array}{l}\text { Response } \\
\text { rate }\end{array}$ & $\begin{array}{l}\text { The number of responses or posts is a crude measure of popularity, surface engagement or participation with the thread; it does } \\
\text { not take into account the level of lurking or non-participatory views and may therefore not fully estimate the potential learning } \\
\text { taking place. }\end{array}$ \\
\hline View rate & $\begin{array}{l}\text { The number of views or visits is another crude measure but reveals attention to the topic under consideration and might indicate } \\
\text { that steps need to be taken to ensure full engagement in the discourse. }\end{array}$ \\
\hline Interaction & $\begin{array}{l}\text { This measure requires discourse analysis to determine if responses are reflecting the previous contributions and building upon the } \\
\text { body of knowledge or mutual understanding. Less good interaction is when responses do not make connections with }\end{array}$ \\
\hline $\begin{array}{l}\text { Evaluative } \\
\text { (deep) }\end{array}$ & $\begin{array}{l}\text { Evaluative communication contains elements of reflection; that reflection may refer to the self (feelings and thoughts) connected to } \\
\text { the focus of the thread or the reflection may refer to other people or other things, for example, 'assessment of the tasks or } \\
\text { appraisal of knowledge and skills of group members' (Lockhorst et al, 2010:68). Being a reflective practitioner is seen to be an } \\
\text { important feature of a successful teacher (Brindley, 2002; Turner-Bisset, 2001). }\end{array}$ \\
\hline Phatic & nication is associated with the social exchanges or phatic expressions (Malinowski, 1923). \\
\hline
\end{tabular}


(surface)

Figure 12 Measuring engagement in threaded discussions - the degree of social construction

The strong conclusions drawn from Ditte Lockhorst's work (Lockhorst et al, 2010:75) indicate that collaborative activities by teachers play an important role in their initial training and their continuing professional development and that technology enhances that process. Their research shows that the design of the tasks has an important influence upon the outcomes. Their conclusions identify a number of features that influence the degree of participation and communication within a group of and participating in online tasks. Firstly, tasks that require a single group product are more effectively developed if the product is to be used afterwards by the individuals of that group. The activities that have strong structures with a degree of didacticism can compensate for low learner participation but participation can be encouraged through the requirement to be reflective and to give peer feedback. Participation is also encouraged by reflection and peer feedback; these also promote learner communication. Complex tasks with defined roles for participants, choices of outcomes and controversial or unusual propositions promote communication. Discussion-focussed tasks and tasks relating to personal perspectives promote communication.

The term 'engagement' covers both participation in the task (thinking and doing) and communication between peers. It is at the heart of Vygotsky's dynamic involvement between the learner and the social context. That is, knowledge is a social product, and learning is a social process. The social constructivist view is meaning and understanding is forged out of an agreement between social partners. The following key prompts identify the way in which online tasks should be designed to promote that social and cognitive engagement - participation and communication.

products of tasks should be usable and/or be required to be used;

instructions should be clear and expectations explicit;

collaboration should be required;

cooperation should be expected;

peer review and peer-assessment should be integrated;

choice should be enabled but delimited; and

prompts should be interesting (unusual, perhaps controversial).

Figure 13 Promoting participation and interaction, based on Lockhorst et al (2010)

James Cronin (Cronin et al, 2009) reports a case study based on an online discussion forum used to help teach an evening diploma in European Art History. Their conclusions are interpreted in a constructivist paradigm emphasising the role of collaboration, blended approaches and structured learning experiences (learning enactments). The role of e-moderation is identified as being key to the social constructivist processes of stepby-step concept 'formation, refinement, application, and revision... [that is] fully visible to student peers as well as their mentors' (Cronin et al, 2009:209) supporting the idea that interactive and socially engaging activities such as forums, blogs, journals and chat room are appropriate strategies for enabling learners to develop their understanding. That is social constructivism in action. Important aspects of the actions include: clarifying concepts, making propositions and establishing meaningful links and relationships. Good methods for structuring knowledge should result in simplifying concepts, generating new propositions and increasing the manipulation of information. Jerome Bruner (1966) identified that these are the skills of teachers that enable learning to take place and they are now seen as the affordances of online-systems that enable learning to take place.

James Cronin's work was developed through a commercial VLE (Blackboard ${ }^{\mathrm{TM}}$ ) and used Gilly Salmon's fivestage model (Salmon, 2000:115-119) to ensure the online experience catered for all levels of expertise in online communication and also it also informed the forum design. (See the next chapter for an outline of the theory.) The aim of the forum on the VLE was to increase the contact time that the learners had with the materials and each other. 'It was anticipated that the discussion board would support and enhance discussion 
beyond face-to-face tutorial contact' (Cronin et al, 2009:210). Through the context of the art history course the researchers are able to interpret what Meyer and Land $(2003,2006)$ call a 'threshold concept represents a transformed way of understanding, or interpreting, or viewing something, which must be understood before a learner can progress' (Cronin et al, 2009:211) and considers that the transformation may be sudden or protracted over a considerable period of time. By identifying the difficult concepts in art history, such as student's understanding of the social and political context of the work, there is a better understanding of how the forum can aid the understanding of difficult concepts. An interesting statistic arising from their research is that although the forum received in the region of 900 views for each module (by about $70 \%$ of the students), there were much fewer posts ranging from 21 to 40 in different modules (by about one third of the students). The online public (http://www.urbandictionary.com/define.php?term=lurker, Wikipedia) and researchers (Nonnecke and Preece, 2000; Richards, 2003, 2009) identify the non-participants as lurkers and in this research, lack of confidence accounts for this online silence. The students who show more frequent participation are the higher achievers in the group.

The researchers obtained the views of the participants through face-to-face discussion (focus group) centring on deep learning, support, barriers and improvements associated with the virtual learning environment (VLE) and its resources. The conclusions include:

- the VLE would be more valuable if introduced at the start of the programme;

- the VLE was valuable in promoting better understanding and knowledge;

- the VLE supported learning by providing the resources;

- the developing resources of the lecturer's notes were particularly valued;

- 'initial feelings of inadequacy, lack of self-confidence, constraints of time, and issues of user-friendliness in site navigation were factors contributing to online silence';

- 'feelings of intimidation or embarrassment' and 'a sense of reticence' impeded participation;

- factors of 'user-friendliness' were cited as impedances with the structure of forum and sub-forum not helping ease of access;

- 'being named' and associated directly with the contribution was seen as a significant impediment to participation.

Reflecting upon this research, we can identify themes that reappear in the theory chapter when the concept of the digital immigrant and digital native are explored and the construct of digital divide and disenfranchisement. James Cronin relates some of these issues to the concept of Pierre Bourdieu's knowledge capital and explanation of inequalities in educational achievement (Cronin et al, 2009).

\section{Using ICT to support teaching}

The classroom use of ICT is an important aspect of technology-enhanced teaching. It is a rich mix of technologies, both hardware and software, being local, across the school network and across the internet and being synchronous with the classroom teaching and asynchronous supporting out-of-classroom learning. Consequently, methods of teaching and the ways of learning are equally complex and diverse.

The research, ImpaCT2, conducted between 2000 and 2002 is an intense analysis of classroom practice with ICT and exposes the models of working, the technology in use and the means of learning to scrutiny and evaluation (DfES, 2002a). The contributors, drawn from four leading universities in the UK, each have made subsequent contributions to our understanding of the role of ICT in learning. The results clearly define the potential of ICT to enhance learning. An important feature is that the measures are drawn from information provided by the pupils and how they experience using ICT.

The research identifies the areas where the use of ICT is having an impact upon outcomes, that is, the grades pupils achieve in assessments. In every case of 'lower use of ICT', there is no significant change in outcomes. An immediate conclusion must be drawn that, either ICT is used fully and in an integrated way, or there is little point in using it for a teaching strategy. Many argue that the use of ICT is of value in itself for preparing 
pupils for life, work and leisure. In a world where ICT has a pervasive presence then some use of ICT which does not have an impact on standards in other subjects can be justified. The report shows that where there is a high use of ICT, then statistically significant gains in learners' examination results and scores in standardised tests occur.

The research results for key stage 4 (14 to 16 year olds) dramatically illustrate the difference in gains in some subjects between those pupils exposed to low use of ICT and those exposed to high use. 'The differences are slight and not statistically significant for English, mathematics and history. The differences in performance are much more considerable for science... The greatest difference... is found in modern foreign languages' (DfES, 2002a:31) The increased performances in design technology were significant in all cases.

The nature of the ICT usage that provided such gains in science were:

- localised hardware resources - computers based subject teaching areas;

- the use of the Internet for revision and research where topics require up-to-date information;

- the use of simulations (enabling metaphor, analogy, modelling of the cognitivist school); and

- using ICT to provide instant feedback on strengths and weaknesses.

These observations can be interpreted using the language of the major learning theories as:

- context-based learning;

- exploring material to construct own understanding (internet and simulations); and

- positive reinforcement of appropriate/correct responses (feedback).

The localised resources enable better contextualised learning opportunities. The use of the internet and simulations enable constructivist approaches to knowledge acquisition and development of understanding. The instant feedback supports behaviourist positive reinforcement and encouragement.

In other subject areas of key stage 4, the positive of effects of using presentation technologies such as digital projectors and interactive whiteboards were noted. These provide immediate feedback, interactivity and the potential for the teacher to celebrate achievement and reinforce positive contributions to class work. In geography the use of data handling and graphing packages was noted; again, these applications enable learners to explore the materials, ask 'what if' questions, make hypotheses and test them, thus giving a high level of engagement with the subject.

Comparable results arose from the ImpaCT2 research for key stages 1, 2 and 3 but with different subjects responding differently. 'There is no consistent relationship between the average amount of ICT use reported for any subject at a given key stage and its apparent effectiveness in raising standards. It therefore seems likely that the type of use is all important' (DfES, 2002a:3). 'Early impact studies demonstrated that young people's use of technology to support learning across the curriculum could have significant positive impacts in a range of subjects. The embedding of technology across whole schools emerged as a key factor in improving outcomes' (Becta, 2010).

At a similar time to the ImpaCT2 studies, another research programme originally based around Manchester but extending across the whole of the UK investigated ICT practice, proposed a structuring of ICT teaching and evaluated the results. Bridget Somekh and Matthew Pearson led the Pedagogies with E-learning Resources (PELRS) action research project (Somekh and Pearson, 2002) with the research question 'Could we organise teaching and learning in radically different ways now we have the internet, internet-look-alike CD/DVD materials, digital imaging, video and other new technologies?'

The project was characterised by the fact that teachers were fully involved in the development, data gathering and reporting processes. It was the teachers' professional skills and knowledge that contributed to the design and implementation of the pedagogy. PELRS was also committed to working with pupilresearchers. The empirical data was gathered through observation, teacher reflections, pupils' work, digital videoing and photographs, The pupil researchers were involved in the interpretation of the videos who provided valuable insights into the processes of the project including motivation, excitement and enthusiasm. 
The first priority of PELRS work was to create transformative learning experiences for pupils in the participating schools, including both the pupil-researchers and their peers.

The proposed generic pedagogic framework places the learning focus (devised by teachers and pupils) at the centre of:

- the pupils in their context of family and peers;

- the teachers and other adults who influence learning;

- the location of the ICT whether it is school or home (hardware) or virtual.

The first point is well made by publications from Futurelab and GoodPlay. The report 'Developing the homeschool relationship using digital technologies' (Futurelab, 2010) which concludes that the learning process is not one that is isolated within the school but children need to make the connections between what they learn and their life experiences and the children need to be the mediators between the family context for learning and the school. Schools should not be imposing or transplanting school practices of teaching and learning into the home environment. That is 'unlikely to fit easily with parent's skills and the cultures of home... valuing and developing home practices may be more successful' (Futurelab, 2010:59). The value of impartial advice and support for parents as they adjust to accepting practices, similar to those that in the recent past have been criticised, for example, online-games, 3D graphics, social networking, widespread use of the open internet, is important. The GoodPlay Project based at Stanford University recognises the issues of the different perceptions of children and parents and provides a very useful guide (GoodPlay Project, 2009).

The PELRS conclusions are described as 'transformative learning outcomes'

1: Creative learning

\section{2: Active Citizenship}

\section{3: Cognitive Engagement}

4: Meta-cognition (Somekh and Pearson, 2006:4).

This work has implications for the psychological aspects of technology-enabled learning through:

creative learning is social construction;

changing behaviour is reflected in active citizenship;

cognitive engagement is about constructing understanding; and

meta-cognition relates to the developing mind and understanding the nature of learning.

More recent research identifies other technology-related factors that are impacting upon educational attainments. From a longitudinal study of people in England carried out by Institute for Fiscal Studies, one factor identified is the level of material resources such as computer and internet access in the home. They 'are important in explaining the gap in educational attainment between young people from rich and poor backgrounds' (Chowdry et al, 2009:8). However, the PERLS report, in contrast to the school-focussed curriculum-focussed Impact reports (DfES, 2002a), links educational gain most strongly with the motivation and attitudes of the pupil.

\section{Technology mediated learning}

Podcasts are audio files, usually in the of MP3 files, that can be played through a computer, a website/web page, a mobile telephone or an MP3 player. The medium for storage is conveniently a memory stick, memory card or the hard drives of computers. Podcasting is the distribution of those files, usually by subscription on a website and sent automatically to the computer (Kelly 2005; Patterson, 2006; Rogan et al, 2005). The term is a portmanteau of 'iPod,' and 'broadcast' (Patterson 2006). Podcasting enables the user to have fresh content downloaded to their computer or iPod on demand or by schedule (Harden, 2006). It can be described as the first application based on real simple synchronisation (RSS) to capture the imagination of users and developers of online audio media (Curran et al. 2006). With Apple's introduction of its video iPod, podcasting has moved into the video arena as well as audio. Instead of creating MP3 files, video podcasting uses the next 
generation of MPEG file format called MP4 (Patterson, 2006). Podcasting with video content is called vodcasting.

An important feature of podcasts is the ease of access; they are easy to download onto computers, laptops, internet-enabled mobile phones and subsequently transferred to MP3 players for more flexibility of use (Fose and Mehl, 2007). For the learner they have an advantage over traditional online training because of the possibility of multitasking; possible to listen to a podcast whilst doing other non-audio tasks, such as driving a car, relaxing with eyes closed or mowing the lawns. Podcasts can carry the human voice, which can convey conviction, compassion, empathy, experience, ethnicity and gender (Donnelly and Burge, 2006; Harden, 2006). Recent research (Bolliger et al, 2010) into the efficacy of using podcasts in teaching and learning has established a rationale for their use.

The 'Impact of podcasting on student motivation in the online learning environment' (Bolliger et al, 2010) reports on the investigation of podcasts being used with nearly 200 students across 14 online courses focussing on students' attention, confidence, satisfaction and appreciation of the relevance of the resource. This relates to the psychology model (Chapter 1) that recognises the importance of motivation (satisfaction and perceived relevance) and attitudes (confidence). The focus of the research on motivation gives rise to key questions about the use of any technology with teaching and learning. The Instructional Materials Motivation Survey (IMMS) (Keller, 1979, 1999) is a device for measuring the motivational impact of a teaching strategy the four key aspects of John Keller's analysis are attention, relevance, confidence and satisfaction (ARCS). Attention is the degree to which the learner engages with the material, either because of the sensory arousal (vivid colours, audio, movement, etc.) or the cognitive engagement (inquiry arousal) of the learner. The relevance of the learning activity has an impact upon the motivation - John Keller suggest several strategies: suggesting to the learner how the experience will build upon their current knowledge, skills and understanding parallel with the Zone of Proximal Development (Vygotsky, 1962,1978); making the activity of immediate value and valuable in the future (providing positive reinforcement for any learning); matching the activity with the learner's perceived needs; modelling the desired outcomes and giving choice or options. The degree to which the learning experience increases motivation is dependent upon the confidence that is instilled in the learner; key aspects that support that situation include: clear learning outcomes expressed in learner-speak; performance criteria that are SMART (specific, measurable, achievable, reinforceable and timely); experiencing success; success being notified, acknowledged and celebrated and learner control through choice. The learning process must be rewarding to establish a sense of satisfaction. The rewards can be intrinsic (pride, joy, well-being, sense of achievement, etc.) or extrinsic (awards, certificates, praise, acknowledgement, etc.).

The Doris Bolliger research gathered from the students' responses that related to the four areas of attention, relevance, confidence and satisfaction. The qualitative analysis arising from the data indicated that podcasts assisted many learners by helping them to understand the instructional content more quickly or better. The learners appreciated the additional information that the podcasts provided. The inter-correlation between the four IMMS factors is statistically significant at the 0.01 level with the strongest relationship being between learner attention and the relevance of the materials. The least strong relationship being between the confidence and satisfaction responses. The research comment that the positive qualitative results may arise from the fact that podcasts were a novel experience. The 'newness' influence, perhaps also related to the Hawthorne effect (Landsberger, 1958), may produce an increased attentiveness. The question of preferred learning styles (perception modalities) is raised in the discussion.

The lowest scoring area in learner responses is the important aspect of satisfaction. The qualitative responses suggest that file length may be a factor. Learners did not appreciate podcasts lasting for an hour and the download overheads may have been a distraction. A positive influence identified is, the teachers should refer to the podcasts in the lecture sessions. This would identify the relevance of the podcasts, raises their status as an integrated resource of the programme and indicates that they are not an optional extra. 
In this research (Bolliger et al, 2010) the podcast is used as an example a technology supporting learning; the research shows how empirical evidence and rigorous study enhances our understanding of the values of the technology. But the technology must not be the focus. It contains no psychology; it contains no inherent learning. The focus must be on the affordances of that technology and what it can do to enhance learning and to enable learning. As John Potter says in his podcast 'I would encourage them [teachers] to think about subjects and not technology. I would encourage them to think about learners, children and media and not technology. So, not to think about using a short video clip as an issue of technology but what is in the clip that is going to enhance the literacy learning in the classroom that day, or their knowledge of a different culture... But the technology doesn't drive it - the desire to make [the learning] be more about popular culture and media now is what drives and enhances that literacy lesson experience for the children' (Potter, 2010).

\section{E-safety in e-learning; safe-working in the virtual world}

Technology-enabled learning is not a singular act between a learner and a computer. There are many forms of learning through a computer and the powerful aspect of some of the approaches is the social communication and social constructivism that is enabled. With the ever-growing capacity of computers to connect people there is an increasing capacity for e-safety issues to arise. In the final chapter there is description of e-safety training in action and a commentary on the issues of the ways in which the health and well-being of learners can be protected but first, what does research tell us about the issues? There is a fear expressed by some educationalists that children can both harm others through their use of the computer (Oswell, 1998) and a fear that they can be psychologically harmed (Freeman-longo, 2000) through the growing concerns regarding pupils' access to adult-oriented materials. There are those that would use restrictions of access to reduce risk (discussed by Livingstone and Bober, 2005) and those that promote learners' resilience (Byron, 2008) to meet such challenges. Also, there is disagreement regarding the degree of inappropriate pupil behaviour taking place when they are online. Consequently, the level and the nature of risk that young people are exposed to are not determined.

In the following analysis of research, three areas are considered: what do teachers in training perceive to be the issues; what do the authorities believe is the solution and what do the children say? The first research to be considered investigates trainee teachers' knowledge and attitudes towards the issues of e-safety. The conclusions are based upon research across 4 United Kingdom higher education institutions and the full study includes: the expert evaluation of a number of e-safety resources; development of an online evaluation form; presenting e-safety sessions to 400 trainee teachers; presenting further resources online and capturing over 73,000 words of comments. The results show that some trainee teachers express degrees of naivety with regard to e-safety, both positive and negative comments are made and a range of trainee attitudes are expressed. The conclusions drawn from the work inform the way in which we should address issues of esafety. The elements selected below relate to the psychology aspects of the situation, those pertaining to motivation, understanding, reflection, morals and ethics (Woollard et al, 2009).

Whilst not all respondents are as passionate, some do make some sensible suggestions including: 'the responsibility of ICT technicians to block sites on the internet, Child Protection Officers supporting staff and of course many cite parents and carers for the part that they should play' (Woollard et al, 2007a, 18). They show an understanding of the need to protect pupils' emotional well-being and ability to reflect upon the topic constructively. The trainees make links between their subject specialism and e-safety in creative and thoughtful ways. When asked who they felt should be responsible for dealing with e-safety issues as a majority of the trainees answered in a variety of ways but with one voice, 'everyone' (Woollard et al, 2007a, 17).

The report concludes that there is a need for e-safety training to ensure teachers in training are best prepared to safeguard the pupils for whom they are responsible. The DVD Jenny's Story (Childnet, 2005) proved to be a 
most stimulating resource to focus attention on the issues of e-safety. The evaluation of the impact of Jenny's Story as a stimulus to promote discussion and raise awareness, was very compelling, with $84 \%$ of the trainees being wiser after the session. As one trainee put it, 'I think this was an excellent video to be shown. The only improvement is to ensure it is shown in as many schools as possible' (Woollard et al, 2007b:2). Implementing online portals to present advice for tutors, activities for trainees, some classroom resources and information for further study is seen to be an effective way forward.

The second area of research associated with e-safety is the Byron Review. In traditional research terminology, this is considered to be 'critique of the published' evidence. The work is of particular value because of the institutional standing of the author and process and the subsequent widespread dissemination of the findings. The impact of this research report is immense because it was requested by and presented to political leaders with influence; the report is widely distributed to and widely respected by the UK education community and the presentation is accessible. In addition, Tanya Byron commissioned three literature reviews on: the effects of video games and the internet on children; children's brain development; and child development (Goswami, 2008). These reviews informed the report and give the report a strong psychological and evidence-based tone. The psychology of the situation touches upon behaviour, ethical expectations and morals of the learners. The three important areas of the psychological dimension (Chapter 1, page xxxx or Figure 7) are: changing attitudes; development and maturity; and satisfaction and motivation. If learners are to be successful in the online environment they must be prepared and able to handle the technologies, be given the cognitive skills to assimilate information in the new forms and be resilient to the more vicarious aspects of the online world.

\section{changing attitudes}

As Tanya Byron reports, research is beginning to reveal that 'people act differently on the internet and can alter their moral code, in part because of the lack of gate-keepers and the absence in some cases of the visual cues from others that we all use to moderate our interactions with each other. This is potentially more complex for children and young people who are still trying to establish the social rules of the offline world and lack the critical evaluation skills to either be able to interpret incoming information or make appropriate judgements about how to behave online' (Byron, 2008:5). It is important for adults to learn from children and young people themselves, respond to their needs and 'empowering them to take responsibility for their own online behaviours' (Byron, 2008:109). An important aspect of changing attitudes is the need for clear ethical instruction and clear moral guidance. For example, the sexualisation of young people is a growing concern. 'sexting' is the activity of sending sexually explicit texts and/or images by mobile telephone. Often, it is used as confirmation of relationships but can be as acts of victimisation, cyber-bullying or simply for sexual gratification. This activity is leading to an increased sexualisation (Zurbriggen at al, 2007) and increased opportunity for grooming and paedophilia (Powell, 2007).

The learners' responses to exposure to inappropriate material and the impact upon their moral behaviour must have a bearing upon the pedagogic response. 'There is a good chance that young people will access unsuitable materials. They have, of course always been able to find print material which others might deem unsuitable. The difference with the web and email is that some of the material may come looking for them. They may be exposed to material, situations or communications that are undesirable or make them feel vulnerable. E-safety is everyone's responsibility' (North et al, 2005:100). An important element of that inappropriate material is the contact made by cyber-bullies.

\section{developmental aspects}

Tanya Byron reports on the evidence from the child development and brain development literature indicating that 'age-related factors and understanding the ways in which children learn can provide a very useful guide to identifying and managing potential risks to children when using the internet or playing video games... the development of a key part of the brain throughout childhood - the frontal cortex, which mediates their experience and behaviour (Byron, 2008:4). Computer-based game playing is colloquially said to be addictive. It is noted that young people spend more time socialising through the internet using internet messaging and social networking sites. This has lead to concerns about 'excessive use of these technologies by children at the expense of other activities and family interaction. As we increasingly keep our children at home because of 
fears for their safety outside - in what some see as a 'risk-averse culture' - they will play out their developmental drives to socialize' (Byron, 2008:3). Consequently, they may take risks in the digital world and in one where there is little control over the 24-7 access to materials that might negatively effect the younger, developing mind.

\section{satisfaction/motivation}

The developing technology presents the users with increasingly immersive experiences, increased vividness and more sophisticated interactions between online players. Although 'playing' online games can have a positive cognitive influence (Young et al, 2006) and a positive influence of social development (Yee, 2006). Players can collaborate and form constructive and long lasting relationships to the extent of developing 'second lives' (discussed more fully in the section ID, Id, avatar and persona). Marc Prensky gives an insight into why aspects of games playing are satisfying or motivating (Prensky, 2001c) including the motivational aspects of: fun, play, rules (providing structure and security), goals, outcomes and feedback, winning (ego gratification) and more. These are explored in the theory chapter. Tanya Byron observes that these (own selfdeveloped characters personalities, physical characteristics and skills) 'factors result in new issues related to potentially harmful or inappropriate experiences for children. A recent survey suggested that $25 \%$ of players of the massively multiplayer online role-playing games (MMORPGs) are under the age of 18' (Byron, 2008:156).

Tanya Byron acknowledges that debates and research in this area can be highly polarised. This is particularly evident in areas such as the impact of, say, violent imagery on the behaviour of young people. Research is a continuing theme through the report with commentary on the evidence but acknowledgement that there is insufficient research in this area. However, researching the effects of inappropriate material on children can be particularly problematic ethically. Research and teachers' actions in this area can develop our understanding. 'To help us measure and manage those risks [harm from video games and use of the internet] we need to focus on what the child brings to the technology and use our understanding of children's development to inform an approach that is based on the 'probability of risk' in different circumstances' (Byron, 2009:3). The mixed research evidence on the activities does not mean that the risks do not exist but it is likely that the context of the activity and the individual child's characteristics will have an large influence on the effects of the activity rather than the activity itself. For example, children from more deprived backgrounds may be more at risk online because of a lack of confidence with new technology or because their parents are less likely to be engaged with their children's use of the internet. These are important issues of social justice. Further information about the digital divide and the impact of social background, gender and age have on computer usage and online behaviour can be found at http://www.ukonlinecentres.com.

The final area of research associated with e-safety focuses on the attitudes towards and perceptions of risk in online activities by primary school aged children. The studies by Sue Cranmer, Neil Selwyn and John Potter gathers empirical data from over 600 children attending 5 different primary schools and creates a picture of the perceived issues of ICT. The researchers identify four research questions:

- 'How do pupils understand and talk about issues of safety and risk with regards to ICTs?

- How do these understandings differ by gender, age and school attended?

- How do concerns with safety and risk influence pupils' engagement with ICTs?

- What implications does this have for the ongoing 'e-safety' agenda in schools and home?' (Cranmer et al, 2009:130)

There are four very important aspects of this research that should be acknowledged:

- The focus of attention is on young children, aged 7 to 11 years whereas previous attention in the area of esafety has been on the behaviours and attitudes of older pupils and adolescents.

- The research endeavours to hear the 'pupil voice'.

- The research methodological approach uses a constant comparative (grounded theory) technique to analyse the qualitative data gained through questionnaire and focus group discussions. 
- The research method employed trained children to act as the researcher in focussing the discussion groups.

Their research leads them to conclude that teachers need to refocus the way in which e-safety is taught and they suggest that 'the introduction of media literacy programmes which embed safety guidance within a wider reflection on technology use. It is conceivable that current 'bolt-on' or stand-alone e-safety initiatives are seen by children as a 'dampener' on their enthusiasms for digital technologies. By embedding these messages within more positive approaches which seek to develop children's skills, knowledge and confidence with ICTs more generally, a more equitable balance of positive and negative is achieved' (Cranmer et al, 2009:140). They also identify that the pupils are affected by the exaggerated fears (Selwyn, 2009). Perhaps the tone of the professional dialogue around e-safety should be considered.

\section{Summary}

The range and diversity of research relating to technology-enabled teaching, independent online-learning and the technology itself is great. The resulting descriptions of practice and their efficacy are therefore often difficult to compare. Through the large-scale meta-analysis processes we begin to see the 'big picture', the trends and the patterns. There is strong evidence that technology is having an impact upon how well we teach both in terms of efficacy and in terms of entitlement and opportunity for all. There is growing evidence of the change in learning patterns and how learners learn. This chapter has introduced the key elements of research in the field of technology-enabled teaching: meta-analysis and critique and the key areas for investigation, the ways of learning, the context for learning and the technology of teaching.

\section{Activities}

Consider, in the light of the content of the chapter, the different areas of your own practice where there is the greatest impact upon the nature and efficacy of your teaching - the social, context or technology.

Consider the different approaches to research and which are more influential on your beliefs about the values of technology in teaching and learning.

Identify the values of meta-analysis and critique and how the conclusions of individual research projects might be better judged.

Identify the key issues of e-safety that relate to the learners for whom you are responsible. 


\section{THEORY}

By the end of this chapter you will be:

- able to identify the important theoretical areas related to technology-enabled teaching;

- aware of the diversity of theoretical constructs that underpin the use of technology in education;

- relate developmental theory of cognition to the appropriate use of technology; and

- identify the importance of personality theory in understanding activities of avatars in virtual worlds.

Technology-enabled teaching and learning is associated with a diverse range of underpinning theoretical viewpoints including: learning, personality, motivation or developmental theories focussing on the learner. Theoretical constructs relating to the teacher and teaching include the behaviourist design of software, stages of online interactivity of tutors and levels of teacher engagement in virtual worlds. The chapter begins by considering the developmental theories.

\section{Stages of cognitive development}

Jean Piaget (1896-1980) has been influential in establishing hierarchies of development guiding classroom design, curriculum content, teaching methods and the understanding of changes as children grow through to adolescence. His work focuses on brain development in childhood and how a child's thinking changes with maturation. His theory of cognitive development brings understanding of constructivist learning. It can be applied to the field of e-learning and perhaps bring a better understanding of what e-learning is all about.

Piaget proposed stages of cognitive development; these can be interpreted in terms of computer-based activities and exemplified by common classroom practice. In the following table, the stages (age ranges) have been selected to best reflect the changes in the potential of the child to participate in activities of computerbased learning and parallel Piaget's model of the developing brain and ways of thinking.

\begin{tabular}{|c|c|c|c|c|}
\hline Piaget Period & Age & Piaget's concepts: & computer-based activities: & Examples discussed: \\
\hline Sensori-motor & $\begin{array}{l}\text { up to } 2 \\
\text { years }\end{array}$ & $\begin{array}{l}\text { reflex activity, repetition, egocentrism, } \\
\text { object permanence, }\end{array}$ & $\begin{array}{l}\text { key, button and switch tapping; } \\
\text { responding to images, light, colour and } \\
\text { sound }\end{array}$ & $\begin{array}{l}\text { Voice and sound boxes used } \\
\text { by those with special } \\
\text { educational needs - an } \\
\text { older child operating as a } 2 \\
\text { year old }\end{array}$ \\
\hline $\begin{array}{l}\text { Pre-operational } \\
\text { (symbolic function) }\end{array}$ & 2 to 4 years & $\begin{array}{l}\text { representation (of objects/actions by } \\
\text { language and image), animism, }\end{array}$ & key press associated with activity; & MULCH; Beebot; \\
\hline $\begin{array}{l}\text { Pre-operational } \\
\text { (intuitive) }\end{array}$ & 4 to 7 years & $\begin{array}{l}\text { social speech, focus (centration), } \\
\text { judgement, basic rules }\end{array}$ & $\begin{array}{l}\text { sorting, binary tree, searching, rote } \\
\text { learning, }\end{array}$ & $\begin{array}{l}\text { Switch friendly games; } \\
\text { ROAMER; interactive } \\
\text { whiteboard, ReTreeval; }\end{array}$ \\
\hline $\begin{array}{l}\text { Concrete } \\
\text { operations }\end{array}$ & $\begin{array}{l}7 \text { to } 11 \\
\text { years }\end{array}$ & $\begin{array}{l}\text { conservation, seriation (ordering), } \\
\text { classification, logic, reversibility, number, } \\
\text { space, time and speed. }\end{array}$ & $\begin{array}{l}\text { presentations, sequencing, complex } \\
\text { search criteria, Boolean operators, }\end{array}$ & $\begin{array}{l}\text { ROAMER; Logo; DataSweet; } \\
\text { searching on the internet; }\end{array}$ \\
\hline Formal operations & $\begin{array}{l}11 \text { to } 15 \\
\text { years }\end{array}$ & $\begin{array}{l}\text { proportion, proposition (hypothetical), } \\
\text { double systems, equilibrium, probability, } \\
\text { elasticity and regulation. }\end{array}$ & $\begin{array}{l}\text { modelling, programming, algorithm, } \\
\text { representations, }\end{array}$ & $\begin{array}{l}\text { Scratch; spreadsheets; } \\
\text { simulations; expert systems }\end{array}$ \\
\hline
\end{tabular}

Figure 15 Stages of cognitive development, based on Piaget (1929/1964)

The computer-enhanced learning by infants up to the age of two is very much based on electronic toys of the 'touch and respond' type. Some devices respond to sound - clap and they play. For example, Leapfrog My Pal Scout toddler toy, 'is an interactive companion that helps children (toddlers) to learn with an entertaining twist... is an electronic learning toy... between the ages of six months to three years... music, lights, and singsong voice... can be personalized to your child... connect to the online... [includes] three 'AAA' batteries, one USB cable...' (Baby Toys, 2010). This could be interpreted as purely behaviourist in nature. The infant makes a gesture and is rewarded, like the pigeons in the many of Skinner's experiments. The infant's actions are reinforced and they occur more frequently until saturation occurs. The infant is acting at the sensorimotor stage.

As the infant develops into the pre-operational (symbolic) stage, there is more precision and an association between different responses and the reactions they cause. The basic programmable toys have a one-to-one

$$
--<30>--
$$


relationship between the buttons and their actions. For example, a favourite toy of my children in the 1980 s was MULCH a robot gardener. It has 9 buttons, one for each action: lights flash, turn in a circle, dance (turning left and right in rapid succession), forward, backward, sing (a simple monochromatic tune) and GO. At 3 years of age, it was press and see the response; from 4 years, it was putting the actions together in a sequence.

From 4 years to 7 years children are in the pre-operational (intuitive) stage and are able to put together sequences of events. It is common practice in early years and infants classes to use devices like the Valient Roamer (Piper, 2000; Valient, 2010). To make the Roamer move the child enters a sequence of instructions. The 3 key presses [^] [5] [GO] makes the Roamer go forward 5 paces (5 Roamer lengths). It would be expected that 7 year-olds would be able to construct sequences of instructions with iteration and calls to previously made procedures.

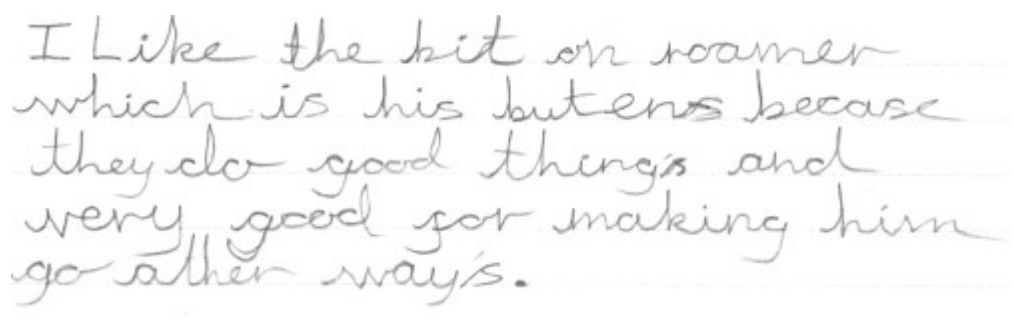

Figure 16 Reflections of a 6 year-old on using a Roamer

'The evidence would certainly indicate that it is an excellent tool for use within the classroom. The children enjoy lessons using Roamer (as based on my own observations) and, used imaginatively, Roamer can assist in the teaching and learning of many mathematical concepts. Introducing Roamer into mathematics lessons can provide opportunities for investigation, encourage mathematical discussion and generally make mathematics more practical and enjoyable' (Piper, 2000).

From the motivational and emotional perspective of learning, at this stage children have more difficulties separating pretence from reality, especially scary pretence (Harris et al, 1991). Content is potentially more frightening for younger children and is likely to have a more significant impact on their ability to process it without distress. 'Just as with other kinds of media content, we need an age-related approach when thinking about appropriateness of content within video games for children, with younger children protected from extreme content that may cause them harm' (Byron, 2008:151). Innocent games such as Granny's Garden can have an effect upon children. (See the 'emotional engagement' section of the pedagogy chapter.)

The pre-operational intuitive stage accommodates the organisation of objects into sets following basic rules. The learners can explore structures but for them to independently classify objects and create sequences based on the individual object's properties means they have moved to the concrete operations stage. The cognition behind the physical activities of classifying, sorting, sequencing are supported by computer software. For example, ReTreeval (Kudlian, 2008) is designed to make the connection between prose questions such as:

is it blue? what shape is it?

and the methodical organisation, based on a tree structure, in a database management system. 


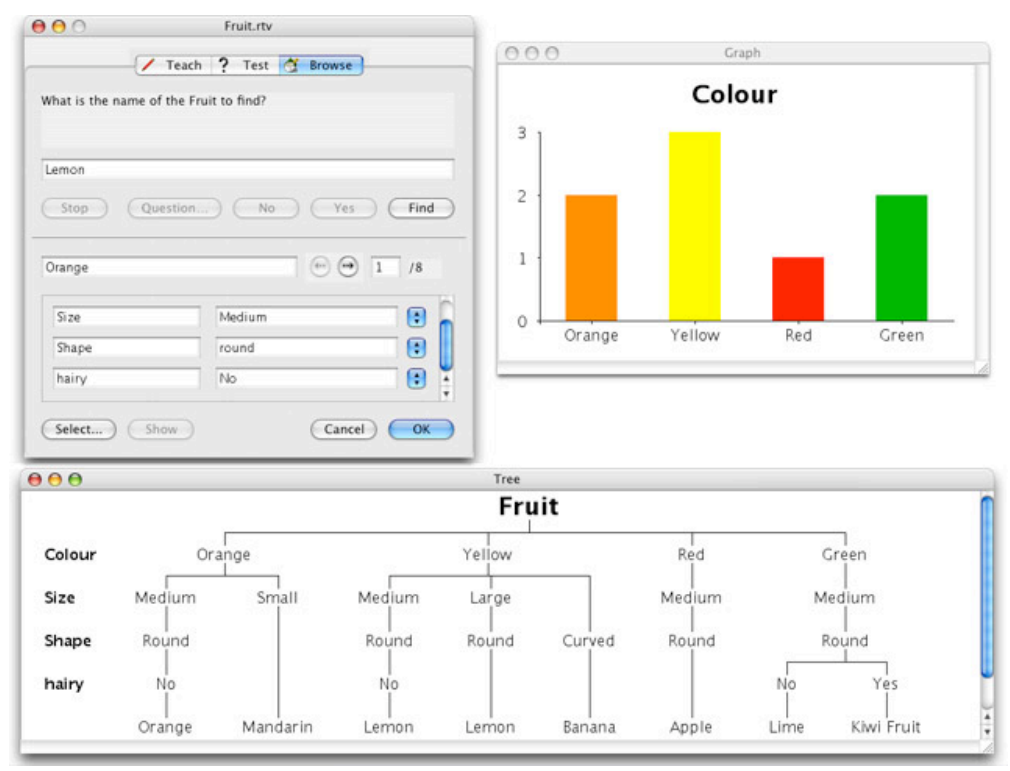

Figure 17 ReTreeval software from http://www.kudlian.net for creating tree data structures

The other aspects of the concrete stage are seriation (ordering), classification and logic. These are also supported by data handling software. Charting programs enable children to enter data and immediately see the graph, in the form of bar charts, pie charts, line graphs, histograms or scattergrams. Flat file databases give learners the opportunity to associate several characteristics (fields) with each object (record). Then by sorting and searching they can discover patterns.

The highest stage of Piaget's cognitive development, formal operations, is reflected in the use of basic officetype software but in increasingly more sophisticated ways. The most flexible application is the spreadsheet.

Proportion - using a spreadsheet 'count if' function on an area of values/qualities and then charting the totals for each value/quality gives a visual and interactive display of proportionality. Knowledge, represented as an array of facts, is converted to visual imagery, represented by a pie chart.

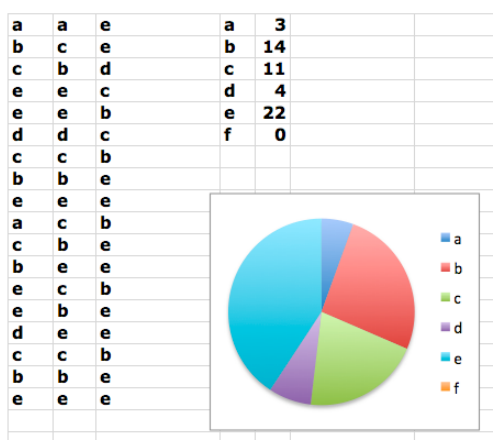

\section{Figure 18 Using technology to better explore proportion}

Double systems - the 'classification of elements in a double entry table' (Inhelder and Piaget, 1958:312). The simplest forms are scattergram, Carroll diagram, logic table and Venn diagram. The scattergram has for the each axis a variable measure and the entry is a star. The pattern formed by those stars indicates the relation (correlation) between the variables on the axes. The Carroll chart has a states and the not-state on the axes and the entry in the table are items meeting that state. The logic table has is true or false (logic) or a statement of the inter-connection. The Venn diagram has overlapping circles with items falling into the overlap if they are members of both circles (sets). These different forms of pictorial graphics are needed to represent the different way in which information can mentally be visualised. Some of these technologyenabled devices can aid the Gestalt (Ellis, 1938) mental visualisation process. 


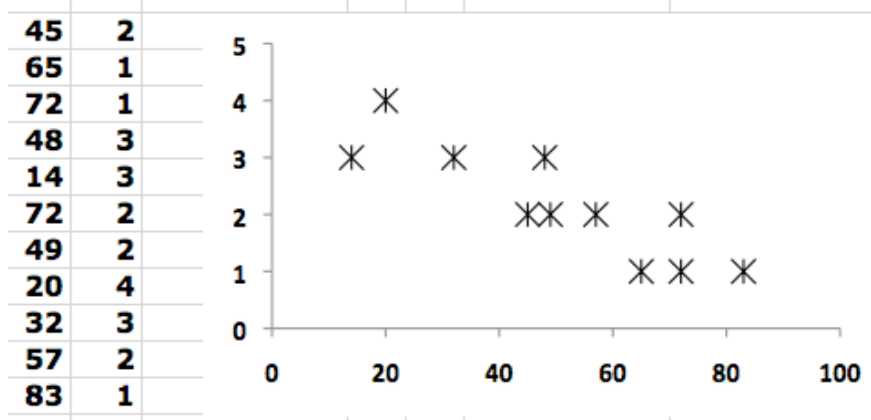

Figure 19 Scattergram showing the relationship between two values from each member of a set

Equilibrium - one aspect of equilibrium is the intersection between two formulae, for example, the formulae for the income from sales of 1 to many items and the formula for the costs of manufacture of 1 to many items. When these are plotted together on a chart they show the point of break-even. Another graphical representation easily achieved using technology is plotting the cooling curves of hot substances in a cooler environment such as 'in a science experiment, the temperature of a cup of coffee is measured over half an hour', (DfES, 2004c:15). These two examples barely scratch at the surface of the equilibrium construct (Inhelder and Piaget, 1958) which includes: equality (:140); representation (:187); stability (:258); physical (:319); psychological (:258). However, there are clear examples where technology-enhanced teaching is more effective in portraying the concepts of, in these cases, commerce and physical sciences. The computer imagery is acting as a metaphor for the concept. The intersection of two lines at a precise point on the screen is a visual metaphor representing breakeven point on a profit/loss chart, which is a theoretical construct.

Proposition (hypothetical) - asking the 'what if' question when exploring a model. The cognitively most sophisticated and engaging activity with a computer can be considered to be modelling. From Learning and Teaching Using ICT, 'Modelling is an important aspect of the ICT curriculum and it provides important strategies for helping students understand scientific concepts and relationships. Students can use ICT to create models and explore understanding by asking 'What if..?' questions. They can modify rules and variables to explore the relationships within the model, predict outcomes and test hypotheses. The models can be presented as spreadsheets of data. Alternatively, the numbers can be embedded into multimedia presentations and interactive applications, for example, wave simulation programs that allow the students to explore amplitude, frequency and direction when combining, passing through a refraction grating or being reflected off a solid surface' (Woollard, 2007a:172).

Modelling has two aspects:

- modelling is the use of models - exploration and investigation of simulations, spreadsheets, expert systems and charting programs; and

- modelling is the creation of models through designing spreadsheets, writing computer programs or authoring in a computer environment.

Models are representations of a real world situation by variables, formula and relationships usually in a spreadsheet or more graphically through a microworld or simulation. The learner is able to set up situations and see the consequences of their decisions. For example, The Model Shop from Sherston Software poses the challenge 'Simulation Street is in danger of being destroyed, and only computer modelling skills can save the day! Can your pupils help Josie, armed only with her trusty laptop, to sort out everyone's problems?' (Sherston, 2010). Learners use higher level thinking skills to investigate and then hypothesise.

Jean Piaget's construct of developmental stages has a clear parallel with the progression in the use of computer-based teaching devices.

\section{An educational software paradigm}

Behaviourism is a philosophy, theory and pedagogy supported by empirical data obtained through careful and controlled scrutiny and measurement of observable behaviour under laboratory conditions or within welldefined social environments such as the classroom, work place, community and home. 
Behaviourism asserts that there are direct parallels between animals and humans in the way in which learning appears to occur and that valuable research can be carried out on animals as well as humans.

Behaviourism asserts that from conception the mind is influenced by the environment and experiences and that the environment, experiences and the actions of other people influence a person's motivation and behaviour.

Behaviourism asserts that all behaviour, no matter how complex, can be reduced to a simple stimulus response association and new behaviour occurs through: classical or operant conditioning; or the modification of old behaviour through rewards and punishments; or imitation of observed behaviour called modelling. Rewards are more effective than punishments.

Behaviourism accepts that some rewards are intrinsic associated with internal senses of gratification (pleasure), well-being (absence of need) or moral correctness (righteousness) and that the outcomes of some internal processes (such as learning) evoke those rewards.

Behaviourism encompasses aspects of affective domain that are reflected in the physical domain (interest, curiosity, motivation, cooperation, attitude, belief) and that these behaviours are influenced by reward and punishment.

\section{Figure 20 A formal description of behaviourism (Woollard, 2010:21-22)}

Many approaches to computer-based teaching and training are founded on this philosophy. There is a rich and valued history of effective teaching with computers underpinned by the behaviourist approach.

B.S. Skinner's programmed learning theory (Skinner, 1954) lead to the development of the teaching machine based upon the strategies of task analysis, the sequencing of learning and the presentation of the concepts through small steps with positive reinforcement as each step is successfully negotiated. This description is taken from Walden Two. 'In this device, [teaching machine] a human learner is given a logically connected series of questions or problems, to each of which there is one correct answer from among the alternative answers offered by the machine. If the learner selects a wrong answer, the machine provides an explanation of the error and directs the student back to a clarifying point in the sequence. If the learner selects the right answer, the machine tells him that he is right and sends him on to the next question' (Skinner, 1968:6-7).

This approach remains both efficient in presenting teaching materials and effective through motivating and enabling the learners. It is particularly applicable where the computer-enabled learning is by a single learner working without the direct (synchronous) support of a tutor or the social support of fellow learners.

During the 1980s the media-enhanced applications of HyperCard and presentation software enabled content designers to enrich the learning experience. Real places and events could be represented on screen by low fidelity video imagery of the real or simulated graphics to represent the real. This enabled the learner to be more engaged in the process and the rewards can be more motivating. At the highest level of sophistication of computer-based modelling are flight-training simulators where the fidelity approaches $100 \%$. From a technical viewpoint, the capsule that contains the flight deck simulator, the screens that show the images and the location of the apparatus are far from being a real aeroplane. However, the immersive effects of the indicative visual imagery, the reinforcement of the kinaesthetic through switches and the physical orientation/sensation, the narrative of the experience and the emotional engagement in the process means that trainee pilots experience a near $100 \%$ fidelity. The psychological involvement is so great that trainee and experienced pilots need to be debriefed and pastorally supported after making a mistake whilst 'flying the aircraft'. In the classroom, the fidelity is far lower but can still achieve immersion. (See the 'emotional engagement' section of the pedagogy chapter.)

The look-and-say phonics approaches, the chanting of times tables and the rote learning of facts and figures up until the 1970s had a big influence upon the design of computer software for the early classroom-based computers. Then, technology-enabled learning focussed on spelling, numeracy and facts and figures. There were right and wrong answers. Buzzes, bells and simple graphics rewarded the right answers. Wrong responses were greeted with a repeated question. Scoring and league tables were features of the positive feedback and encouragement built into the programs. 
Although programmed learning machines are no longer used, they are emulated in the structures of some computer-based applications such as the integrated learning systems (ILS), In the 1980s, they were developed to provide individualised, measured and controlled teaching experiences in the basic skills of numeracy and literacy. They remain an effective approach to this day being based on networked computers providing instructional content as well as assessment and learning management tools. Instruction is organised around specific objectives and the software is based on a mastery learning approach to instruction. The principles are based on the implications of reinforcement theory (Markle, 1969; Skinner, 1968) and require the curriculum to be presented as a series of frames. A current example is SuccessMaker ${ }^{\circledast}$ (Pearson, 2009).

\section{Stages of online interactivity}

Understanding the value of computers in teaching and learning and the widespread access to internetconnected computers came together in the late 1990s. Models of working were being established and computer-mediated activities in education started to become collaborative, interactive, focussed and analysed. Research by Gráinne Conole (Conole, 2007; Conole and Oliver, 2007), Diana Laurillard (Laurillard, 2002), Bridget Somekh (Somekh, 2007), Etienne Wenger (Wenger et al, 2002; Wenger et al, 2009) and Gilly Salmon (Salmon, 2000), moved the agenda of online learning to the social dimension. The term 'communities of practice' (COP) has been established to describe the interaction between people who have a common goal in learning either formal or informal. Etienne Wenger describes 'communities of practice are groups of people who share a concern or a passion for something they do and learn how to do it better as they interact regularly' (Wenger, 2006). He describes the construct of community of practice as requiring three elements: domain, community and practice. The domain is the focus, the community is the group of identified people participating and the practice is collective of the engagement activities of those people. 'They develop a shared repertoire of resources: experiences, stories, tools, ways of addressing recurring problems - in short a shared practice' (Wenger, 2006).

One theoretical model that emerged brought understanding to the process of individual's maturity in the process of using computers in learning. Gilly Salmon created a model through detailed analysis of participants' online conversations. 'This analysis [coding the statements of participants] led me to revise the categorizations of some messages, and to a greater sense of the sequence of activities pursued by the online participants' (Salmon, 2000:25). The resulting five-step model is a useful way of analysing and describing an elearner's maturation in a number of learning situations. It describes the increasing level of interactivity through the stages of:

- access and motivation;

- online socialisation;

- information exchange;

- knowledge construction;

- [learner] development.

The model also shows the balance between the activity of what Gilly Salmon coined, the 'e-moderator' and the activities of technical support (Salmon, 2000:26). The figure below applies the Salmon model to the stages through which learning avatars develop in an immersive virtual world. There are direct parallels with the Social Domain of the Blended Taxonomy (Scopes, 2009) which includes personalising, contextualising, communicating, affiliating, networking and channelling and is described later in this chapter.

\begin{tabular}{|c|c|c|c|c|}
\hline Access and motivation $\gg$ & Online socialisation >> & Information exchange >> & Knowledge construction >> & Learner development \\
\hline $\begin{array}{l}\text { by: } \\
\text { building a platform } \\
\text { associated with an island } \\
\text { and adding the facilities of: } \\
\text { SLurls; notice cards; } \\
\text { Welcome Points; dexterity } \\
\text { training }\end{array}$ & $\begin{array}{l}\text { by: } \\
\text { ensuring identities are } \\
\text { known; using IM and } \\
\text { local chat; creating } \\
\text { groups; creating mail } \\
\text { lists; }\end{array}$ & $\begin{array}{l}\text { by: } \\
\text { creating notice boards; } \\
\text { easels; presentations and } \\
\text { setting targets including } \\
\text { peregrination, treasure } \\
\text { hunts and guided tours }\end{array}$ & $\begin{array}{l}\text { by: } \\
\text { developing conferencing } \\
\text { facilities/skills; scheduling } \\
\text { events and meetings; } \\
\text { creating interactive learning } \\
\text { resources including out-of- } \\
\text { world blogs, wikis and } \\
\text { forum }\end{array}$ & $\begin{array}{l}\text { by: } \\
\text { building networks; } \\
\text { promoting friendships } \\
\text { outside the group; } \\
\text { supporting exploration; } \\
\text { celebrating } \\
\text { achievements... }\end{array}$ \\
\hline
\end{tabular}




\begin{tabular}{|c|c|c|c|c|}
\hline $\begin{array}{l}\text { and so: } \\
\text { enabling access and } \\
\text { stimulating motivation } \\
\text { through successful } \\
\text { navigation and providing a } \\
\text { sense of safety (home). }\end{array}$ & $\begin{array}{l}\text { and so: } \\
\text { promoting online } \\
\text { socialisation; creating } \\
\text { the foundations for } \\
\text { collaboration and } \\
\text { cooperation; and } \\
\text { developing socialisation } \\
\text { skills. }\end{array}$ & $\begin{array}{l}\text { and so: } \\
\text { enabling learners to gather } \\
\text { information; report their } \\
\text { findings and be aware of } \\
\text { others' work. }\end{array}$ & $\begin{array}{l}\text { and so: } \\
\text { enabling shared and agreed } \\
\text { constructs of learning. }\end{array}$ & $\begin{array}{l}\text { and so: } \\
\text { establishing full } \\
\text { immersion in the virtual } \\
\text { world, confidence in } \\
\text { exploration and } \\
\text { competence to } \\
\text { assimilate and } \\
\text { communicate } \\
\text { information. }\end{array}$ \\
\hline
\end{tabular}

Figure 21 Five-stage model of learning and socialisation in a virtual world, based on Salmon (2000) and Scopes (2009)

In the final stage 'participants become responsible for their own learning through computer mediated opportunities and need little support beyond that already available' (Salmon, 2000:35). Independent learning and a sense of value and self-control liberates many and secures their life-long learning through the media of computers. In the more detailed account of the five-stage model three separate activities of 'advice on technical support... helping participant to learn [motivating] and... e-moderating' (Salmon, 2000:115-9).

\section{Learning in cyberspace}

The final theoretical consideration is the concept of cybergogy. As discussed in the section 'Towards a definition of e-learning', there is a very general use of the word cybergogy that encompasses all forms of pedagogy that are technology-enabled. However, there are advocates of the idea that cybergogy only applies to teaching and learning within a virtual world since these, as an emerging platform for teaching and learning, require a more specialised instructional design approach if they are to be allowed to demonstrate their potential to splice e-teaching away from classical methods of online delivery of education and training. It is this aspect of pedagogy that is now described. The following table identifies the terminology and indicates where some words are used synonymously and where there are nuances of difference in meaning.

\begin{tabular}{|c|c|}
\hline Cybergogy & The pedagogy of the virtual world \\
\hline Avatar & $\begin{array}{l}\text { A digital representation of himself, herself or other self in the form of a three-dimensional } \\
\text { animated agent whose actions, interactions and decisions are under the control of the learner. }\end{array}$ \\
\hline Virtual world & $\begin{array}{l}\text { A visual and audio representation of a computer generated persistent location wherein avatars can } \\
\text { interact with the environment and with other learner's avatars. }\end{array}$ \\
\hline 3Di & $\begin{array}{l}\text { 3-dimensional immersive application that affects human senses via visual and auditory means to } \\
\text { create an ambience. }\end{array}$ \\
\hline Microworld & $\begin{array}{l}\text { First coined in the 1970s, a virtual world that can be explored with activities like Granny's Garden } \\
\text { and LOGO programming but without the user avatar. }\end{array}$ \\
\hline $\begin{array}{l}\text { Metaverse } \\
\text { Flatland }\end{array}$ & $\begin{array}{l}\text { The network of 3D virtual worlds that is expanded when new 3D worlds are added. Term coined in } \\
\text { Snow Crash by Neil Stephenson (1992) }\end{array}$ \\
\hline 3DLE & $\begin{array}{l}\text { A pejorative term for the } 2 \mathrm{D} \text { presentation of learning materials such as conventional learning } \\
\text { platforms, the } 2 \mathrm{D} \text { web and VLEs. }\end{array}$ \\
\hline Second Life $\mathrm{T}^{\mathrm{TM}}$ & A virtual world designed specifically with the goal of learning. \\
\hline Learning archetype & $\begin{array}{l}\text { A social-centric virtual world supporting leisure, business and educational activity. Not necessarily } \\
\text { designed for learning, some users are actively customising parts as a learning platform. }\end{array}$ \\
\hline Learning don & $\begin{array}{l}\text { Pedagogic metaphors and fundamental tools of cybergogy; these are classifications of activities } \\
\text { that maximise the essence of a virtual world in as much as it's ability to facilitate learning } \\
\text { experiences delimited by physical world constraints. }\end{array}$ \\
\hline & Aspects of sentience which can be addressed in combinations to provide learning experiences \\
\hline
\end{tabular}

\section{Figure 22 Terminology of cybergogy}

Current academic research in the area of virtual worlds focuses upon the impact of the immersive nature of virtual world experience (Book, 2006; Doyle, 2010; De Lucia et al, 2008; Malaby, 2007), the developing curriculum application (Mallan et al, 2010) and the implications for global access (Hunsinger and Krotoski, 2010). This section describes a pedagogy that is specifically designed for the virtual world, called cybergogy, based upon the work of Lesley Scopes (Scopes, 2009) that was acknowledged as a detailed approach by Karl Kapp and Tony O'Driscoll in their book 'Learning in 3D' (Kapp and O'Driscoll, 2010). It is structured on the premise of social constructivist view of learning where knowledge is constructed and internalised by the 
learner and is sustained by social processes. The model of cybergogy in the following chapter is based upon the development of these ideas.

\section{ID, Id, avatar and persona; the changing face of self.}

An avatar is a person's representation of himself or herself within a computer system. The definition of avatar begins by stating what it is not - it is not a real person. Jeremy Bailenson and Kathryn Segovia use the term 'doppelganger' (Bailenson and Segovia, 2010:175) to indicate both the connection but also the separation of self from the avatar. The rules, principles and theories of human psychology do not automatically apply to the behaviours of the avatar but, with an ever-increasing fidelity of representation and with an ever-increasing immersive nature of the virtual environment, we are witnessing characteristics of behaviour of avatars that have striking parallels with the behaviours of humans in real-world situations and, importantly, the behaviours and characteristics of the avatars are not the same as the person driving the avatar. This section explores a major theory of personality and then considers other views in relation to the appearance, behaviour and apparent motivations of avatars in the immersive 3D environment.

The human body carries out three functions in the social world - communication, representation and peregrination. It is through our bodies we communicate with others by gesture, action and word. It is through our bodies and the way by which we dress and adorn our bodies that we represent ourselves and our status within the society in which we live. And, by means of our body we move about our environment, going to places and meeting people. Avatars in learning environments have three parallel functions of supporting communication, representation and peregrination. The first characteristic of the avatar to be determined is their ID or identification. In the popular virtual world Second Life ${ }^{\mathrm{TM}}$ (Linden Lab, 2010), the second name has to be chosen from a relatively narrow set of names on offer at the time of 'birth' (registration). An avatar's age is given in years and months from the moment of becoming a resident. The owner then gives a first name of their choice. The only connection between the real person and the avatar is the email address required by Linden Labs as some form of authentication. For most users there is a feeling of connection between themselves and their avatar and it will be a representation of themselves and their id. The next stage is usually to modify the appearance of the avatar, and when this is under the control of the learner, can begin the process of personalisation and moving the ID of the avatar closer to the Id the learner wishes to present or subconsciously presents. 


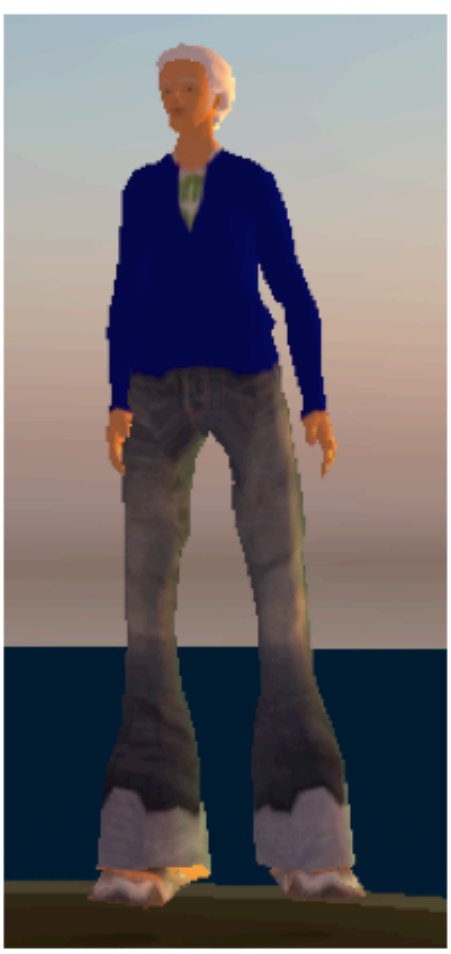

\section{Communication}

The avatar is the focus of all communication. People can only 'hear' the avatar if they are physically close, the volume decreases as they walk away; others can only see the local chat if they are in the same environment, and IM at a distance is identified by the name of the avatar, not the person.

Communication is also in the form of gestures such as whistle, clap, nod and shake.

\section{Images: Second Life ${ }^{\mathrm{TM}}$ \\ Avatar: Stradd Ling}

\section{Representation}

The avatar represents the person without there being direct communication. It is what they look like in profiles and when present in the learning environment.

The psychology associated with 'judging on appearance' comes into play.
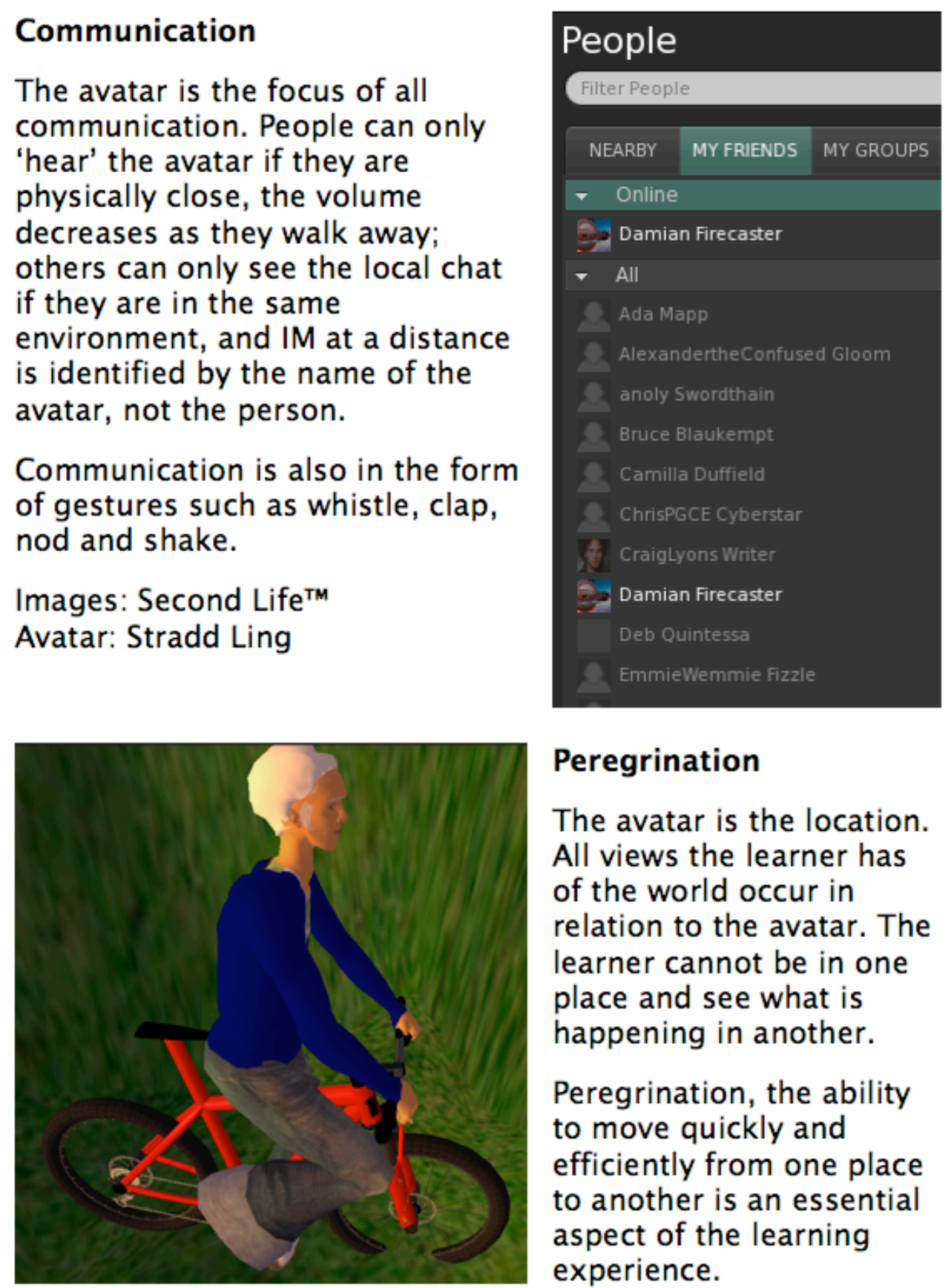

\section{Peregrination}

The avatar is the location. All views the learner has of the world occur in relation to the avatar. The learner cannot be in one place and see what is happening in another.

Peregrination, the ability to move quickly and efficiently from one place to another is an essential aspect of the learning experience.

Figure 23 The three functions of avatars.

Sigmund Freud proposed a number of life instincts that determine the behaviour of a person and that these are reflected as the persona. These theoretical constructs included the libido, related to the sexual instinct required for the reproduction and therefore, future success of the species. Some relate to the survival of the individual and are related to the lower order Maslow 'needs' and instincts. Others include the basic drives (or primary processes) such as pleasure and passion. These are collectively called the Id. The Ego is the more pragmatic aspect of subconscious motivated by operating in relation to the outside world through the 'akust' (cap of hearing). The drives of the Id are modified by the impact of the external world through the perceptual consciousness and cap of hearing. They are also reduced by, what Freud calls verdrängte, repression. 


\section{Ego}

\section{repressed}

Id

Figure 24 Classical hierarchical diagram, based on Freud (1960)

As people reinvent themselves through their avatar we can suppose that the avatar will be subconsciously affected by the Id through the Ego. That is, the degree to which the individual's desires are impacted upon by social conventions of the virtual world, repression of basic desires and the pragmatism of the Ego to succeed in the long-term. Tansley, in his book The New Psychology and its relation to life, calls these the 'herd complex', the 'sex complex' and the 'ego complex'. Tansley makes a clear statement about human desire and the 'importance and universality of the processes by which the mind seeks, more or less successfully, to escape from the discomforting realization of its own weakness and from the conflicts engendered by opposed instincts, as well as from the disharmony of a chaotic world' (Tansley, 1920:183). As we see people attracted to the virtual worlds and developing and invest in their avatars, we need to be aware of the conscious and subconscious motivations that result in avatars that sometimes represent the learner accurately, imaginatively, ideally and controversially. Mark Meadows in I, Avatar makes the claim that '75 percent of Internet users feel safer speaking their mind when they use an avatar' (Meadows, 2010:36). Perhaps this is an indication that the Ego is being more strongly driven by the Id when the Ego is working in the less oppressive environment of the virtual world. Current work by Howard Gardner, including the GoodPlay Project, explores the development of ethics by young people and how 'ethical minds' are developed in the new media. He recognises identity, privacy, ownership and authorship, credibility, and participation as key elements of the developing self (Gardner, 2008). Another way of examining the way in which avatars behave is to consider their moral characteristics identified through their behaviours. Lawrence Kohlberg's stages of moral development, developed over his lifetime, is based on a similar developmental structure to that of Jean Piaget's cognitive stages. The theory postulates six identifiable developmental stages of growth in which the person is better able to handle moral dilemmas based on the concept of justice and ethics, the further they proceed through the stages.

\begin{tabular}{|l|l|l|l|}
$\begin{array}{l}\text { Kohlberg's stages of } \\
\text { moral development }\end{array}$ & $\begin{array}{l}\text { Behaviours in the flatlands of social } \\
\text { networking, chat room, forum and virtual } \\
\text { learning environments }\end{array}$ & $\begin{array}{l}\text { Additional behaviours in the 3D } \\
\text { immersive environments }\end{array}$ & $\begin{array}{l}\text { Cautions for the e-tutor, e-trainer } \\
\text { and e-teacher }\end{array}$ \\
$\begin{array}{l}\text { Level 1 } \\
\text { (Pre-Conventional) } \\
\text { Stage 1. } \\
\text { Obedience and } \\
\text { punishment }\end{array}$ & $\begin{array}{l}\text { following instructions exactly such as 'Zip it, } \\
\text { block it, flag it'; } \\
\text { providing full and correct identity; } \\
\text { disclosing personal information on request; } \\
\text { reading and being conscious of 'terms and } \\
\text { conditions'; }\end{array}$ & $\begin{array}{l}\text { making the avatar match } \\
\text { themselves; } \\
\text { being and doing in the virtual } \\
\text { world as they think they do and } \\
\text { be real world; }\end{array}$ & $\begin{array}{l}\text { learners may disclose personal } \\
\text { information and put themselves } \\
\text { at risk; }\end{array}$ \\
$\begin{array}{l}\text { Level 1 } \\
\text { (Pre-Conventional) } \\
\text { Stage 2. } \\
\text { Self-interest }\end{array}$ & $\begin{array}{l}\text { thoosing the option best for them; } \\
\text { thinking that breaking some rules may be } \\
\text { acceptable; }\end{array}$ & hiding behind the avatar name; & $\begin{array}{l}\text { These learners may do things } \\
\text { thinking they are protected by the } \\
\text { false identity or avatar. }\end{array}$ \\
\hline $\begin{array}{l}\text { Level 2 } \\
\text { arguing that someone can be good if when }\end{array}$ & making the avatar do things that & These learners may become \\
\hline
\end{tabular}




\begin{tabular}{|c|c|c|c|}
\hline $\begin{array}{l}\text { (Conventional) } \\
\text { Stage } 3 . \\
\text { Interpersonal accord } \\
\text { and conformity }\end{array}$ & $\begin{array}{l}\text { they break rules they do it for good reasons; } \\
\text { disclosing others' and their own mis- } \\
\text { demeanours because they feel they are right; } \\
\text { rationalised and therefore condoning rule } \\
\text { breaking if they feel it fits within the ethical } \\
\text { rules (their morals); } \\
\text { not fully complying to rules they see as unfair, } \\
\text { for example, copying text for their } \\
\text { assignments; }\end{array}$ & $\begin{array}{l}\text { some others may feel is wrong; } \\
\text { learner may suffer abuse or } \\
\text { disapproval from residents if they } \\
\text { do not conform, for example, } \\
\text { placing themselves physically } \\
\text { between two avatars in } \\
\text { conversation; }\end{array}$ & $\begin{array}{l}\text { vulnerable because they } \\
\text { knowingly take risks. } \\
\text { These learners may become } \\
\text { vulnerable because they break } \\
\text { local rules that do not comply } \\
\text { with their morals or the ethical } \\
\text { context they usually work in. }\end{array}$ \\
\hline $\begin{array}{l}\text { Level } 2 \\
\text { (Conventional) } \\
\text { Stage } 4 . \\
\text { Maintaining social- } \\
\text { order }\end{array}$ & $\begin{array}{l}\text { working towards the notion of a good society; } \\
\text { supporting procedures put in place to protect } \\
\text { (Zip it, block it, flag it and CEOP Report button) } \\
\text { seeing the need to protect individual rights; } \\
\text { defending others within online communities; } \\
\text { settling disputes through democratic } \\
\text { processes; participating in open (chat room) } \\
\text { debate about moral dilemmas; }\end{array}$ & $\begin{array}{l}\text { building rules for their } \\
\text { communities; } \\
\text { developing a policing strategy; }\end{array}$ & $\begin{array}{l}\text { These are competent e-learners; } \\
\text { they will be working in safe ways } \\
\text { and ensuring that others are safe; }\end{array}$ \\
\hline $\begin{array}{l}\text { Level } 3 \\
\text { (Post-Conventional) } \\
\text { Stage } 5 . \\
\text { Social contract } \\
\text { orientation }\end{array}$ & $\begin{array}{l}\text { challenging the conventions when they feel the } \\
\text { conventions are not in the interest of all; } \\
\text { protecting the oppressed minority; }\end{array}$ & & \\
\hline $\begin{array}{l}\text { Level } 3 \\
\text { (Post-Conventional) } \\
\text { Stage } 6 . \text { Universal } \\
\text { ethical principles }\end{array}$ & $\begin{array}{l}\text { expressing a principled conscience in online } \\
\text { chats; }\end{array}$ & & \\
\hline
\end{tabular}

Figure 25 Moral development and response to ethics in learning environments, based on Kohlberg (1975)

There are important implications arising from the consideration of Lawrence Kohlberg's stages of moral development (Kohlberg, 1975:671) with regard to pedagogy and technology-enabled learning. The least mature learners may disclose personal information and put themselves at risk and the learners may do things thinking they are protected by the false identity or avatar. More mature learners may become vulnerable because they take risks or break local rules that do not comply with their morals or the ethical context in which they usually work.

Another way of analysing personality is by considering the outward expressions, assertions and behaviours or avatars. The Big Five is a popular procedure for classifying personality types (John and Srivastava, 1999). It was originally derived in the 1970's by psychologists at the National Institutes of Health and independently by Warren Norman and Lewis Goldberg. They established through a grounded theory approach (building a theory from data and then collecting and re-analysing more data until the theory does not change) that most human personality traits can be boiled down to five broad areas regardless of language or culture represented by these constructs: closed-minded - open to new experiences; disorganised - conscientious; introverted extraverted; disagreeable - agreeable; calm/relaxed - nervous/high-strung. They are often referred to as the OCEAN model of personality, based on the acronym of the names of the five dimensions.

The value of this, or any other personality construct, in helping us understand the behaviours and motivations of avatars in virtual worlds is expressed by this observation on personnel selection by Lewis Goldberg's writing, 'Back in the days when we had no personalities [personality tests], it made no sense to use personality measures in personnel selection [identifying avatars]. Now that we have regained our personalities, evidence has been accruing about the utility of personality measures as predictors of diverse criteria. Recently... reviews of the literature have concluded that personality measures, when classified within the Big-Five domains, are systematically related to a variety of criteria of job performance [avatar role]', (Goldberg, 1993: 31). He goes on to discuss the merits of the 'conscientiousness' trait with regard to job performance. In the field of technology-enabled learning, conscientiousness is likely to be an important trait to identify, however, the values of openness are also important if the avatar is to represent an imaginative, creative and lateral thinker. The social element of online learning situations also makes the agreeableness trait an important factor in successful collaborative and cooperative learning.

$$
\text { - - < } 40>\text { - - }
$$




\begin{tabular}{|l|l|l|l|}
\hline O & openness & $\begin{array}{l}\text { original, inventive, creative, curious, complex, } \\
\text { adventurous, interest in art/aesthetics/emotion }\end{array}$ & $\begin{array}{l}\text { conventional, consistent, down to earth, curious, } \\
\text { narrow interests, uncreative }\end{array}$ \\
\hline C & conscientiousness & reliable, well-organized, self-disciplined, careful & disorganized, undependable, negligent \\
\hline E & extraversion & $\begin{array}{l}\text { surgency, seeking stimulation, outgoing, energetic, } \\
\text { sociable, friendly, fun loving, competitive, } \\
\text { talkative, proactive, dominating, self-confident, } \\
\text { decisiveness, frankness, quick to positive } \\
\text { emotions, cheerful, happy }\end{array}$ & introverted, reserved, inhibited, quiet, \\
\hline A & agreeableness & $\begin{array}{l}\text { friendly, compassionate, good natured, } \\
\text { sympathetic, forgiving, courteous, cooperative }\end{array}$ & $\begin{array}{l}\text { competitive, outspoken, critical, suspicious, callous, } \\
\text { rude, harsh, antagonistic, irritable }\end{array}$ \\
\hline N & neuroticism & $\begin{array}{l}\text { feeling of vulnerability, nervous, anxious, high- } \\
\text { strung, insecure, worrying, tense, quick to fear, } \\
\text { anger and dislike, depressed }\end{array}$ & secure, calm, relaxed, hardy \\
\hline
\end{tabular}

Figure 26 Traits of personality of the Big Five taxonomy

More recent research in the field of avatar behaviours considers have they 'touch' each other (haptic interaction) in the virtual world. A haptic interface is a force reflecting device that allows a user to touch, feel, manipulate, create and/or alter simulated 3D objects in a virtual environment. Those objects can be other avatars. Jeremy Bailenson examined the manners in which avatars touch digital representations of other avatars (Baileson and Lee, 2007) comparing it to the manner in which they touch digital representations of objects. He observed that avatars use less force when touching other avatars than objects, and those avatars touched the face with less force than the torso area. He also notes that male digital representations were touched with more force than female representations by avatars of both genders. These haptic studies add one more facet to the world of avatars that need a deeper theoretical understanding so that the pedagogy is better established. They show that there are correlations between behaviours of avatars and human behaviours. However, we also know people act differently online than they do in physical settings. They do and say things online that they would not do offline; adults and children, who are already vulnerable in the online environments, put themselves at greater risks. They do not necessarily behave in deed and word including:

cyber-flirting (Whitty, 2003);

risk taking (Byron, 2008:56);

meeting offline (Livingstone and Helsper, 2007);

role/gender experimentation (Richards, 2009);

virtual physical contact (Bailenson and Yee, 2007);

false memories in children (Segovia and Bailenson, 2009); and

truth and lying (Whitty and Joinson, 2008).

\section{Summary}

The theoretical basis for supporting the use of technology in education arises from a diverse range of disciplines including cognitive development psychology, personality theory and motivation theory. The learning theories find their influence in many areas of technology-enabled teaching: behaviourism with feed back, reward and task analysis of the curriculum, constructionist through authoring and programming in computer environments, constructivist through social networking and Web 2.0 applications and cognitivists through mind tools, information processing and problem solving. Other theoretical approaches describe the underpinning ideas of pedagogy, andragogy and cybergogy. This chapter has introduced the key areas of theory in the field of technology-enabled teaching: stages of cognitive development, the design of software, the value of interactivity, engagement and immersion and the role of self in the way in which learners behave online.

\section{Activities}

Consider, in the light of the content of this chapter, the different theoretical viewpoints and which you consider the most influential on your practice: learning, personality, motivation or developmental theories? 
Consider the model of online interactivity (Figure 21) and determine your personal level of engagement with technology in teaching; if you are working in a virtual world then consider the degree of that engagement.

Consider how you represent yourself (or will represent yourself) in a virtual world; what do you feel will be the differences between who you are and the impression that your avatar, its actions and communication will give? 


\section{PEDAGOGY}

By the end of this chapter you will be able to:

identify the factors that influence pedagogy, particularly that associated with the use of technologies;

understand the value of technology in supporting critical, creative and lateral thinking;

appreciate the value of games and associated activities;

describe the affordances associated with virtual learning environments; and

describe the affordances of virtual worlds.

There are three pedagogies, that is, there is the traditional pedagogy of the classroom; there is the pedagogy for the adult called andragogy and; there is the pedagogy of virtual worlds called cybergogy. In this series of books on psychology for the classroom, this chapter usually reflects upon pedagogy with some important references to andragogy. This chapter focuses upon pedagogy as it relates to technology-enabled teaching and cybergogy as it relates to learning in virtual worlds. The first part of the chapter identifies and describes the key factors relating to the success of technology in teaching: belief, motivation, immediacy and different aspects of engagement. The virtual learning environment is a key feature of teaching with technology and has an important role in pedagogy. The second part identifies the affordances and challenges to teaching of the VLE including the routes of communication, social interactivity, engagement and assessment. Finally, an analysis of cybergogy in the virtual world is presented.

\section{Using learning technologies}

Pedagogy arises from considering theories related to learning and developing models for teaching. Pedagogy also arises through practice; the methods of and approaches to teaching develop through the processes of trial and improvement, practice and reflection. The diagram below identifies the important factors that impact upon pedagogy and what we see happening in the classroom and in technology-enabled teaching.

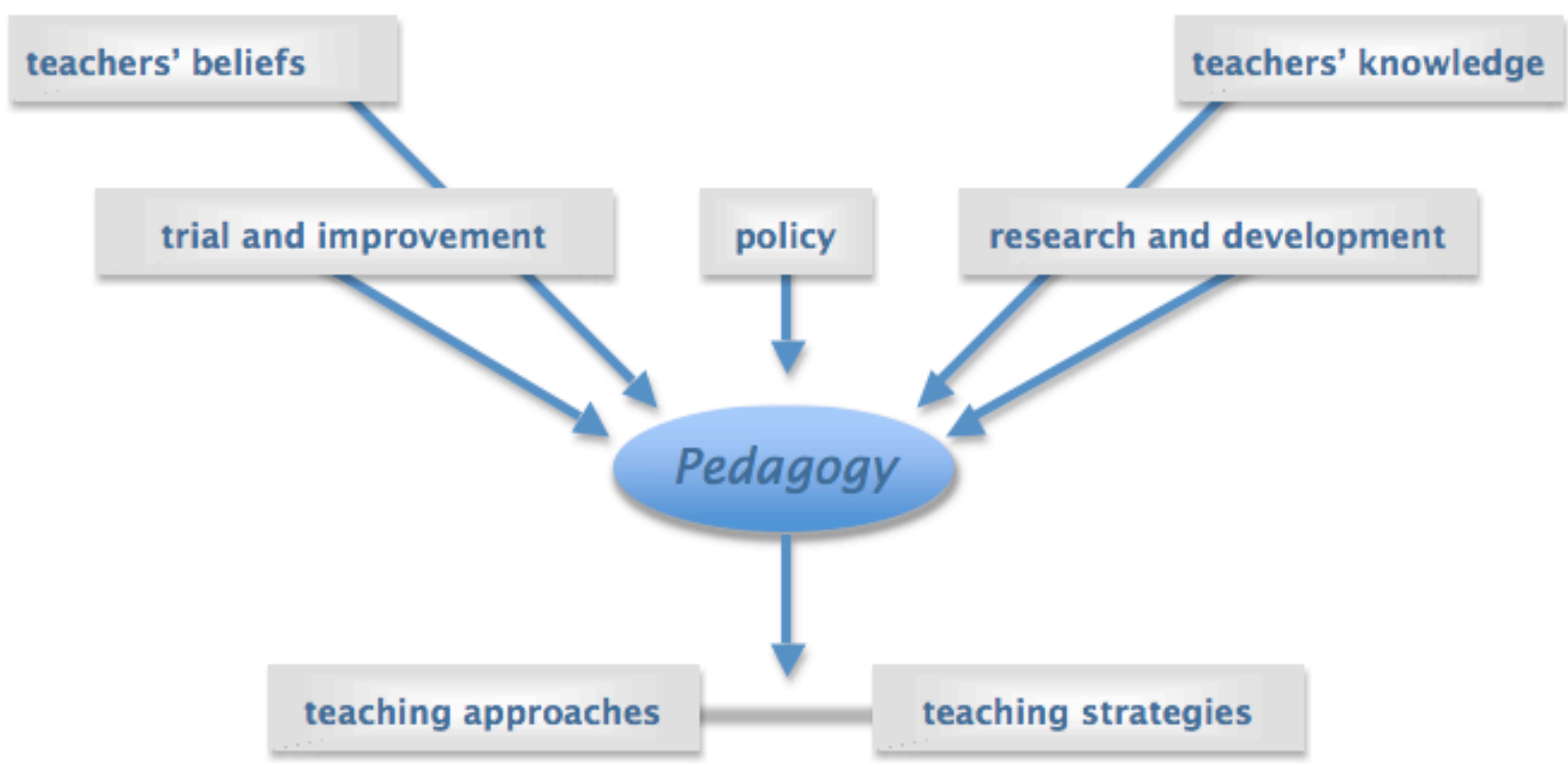

Figure 27 Pedagogy arising through theory, policy (politics) and practice

In traditional classrooms, the pedagogy underpins the strategies adopted by teachers. The nature of the classroom environment, the activities, the resources for learning and the regulation of activities and learning, all reflect the underpinning pedagogy. Mortimer (1999) describes the different ways in which pedagogy has been viewed in the recent past: types of teacher and styles of teaching; the teaching environment and contexts for teaching; teaching and learning as a collaboration between teacher and learner; and a policy/stakeholder view of teaching. In the recent past, the development of pedagogy with ICT is both 
blighted and stimulated by the continual change that technology brings to teaching and the political involvement. That outside involvement, in both how teachers teach and what teachers teach, stems to a large extent from the UK Education Reform Act (OPSI, 1988) that dictates the curriculum. It gives a rationale for observing and measuring practice through agencies such as local education authorities, curriculum and assessment councils and the Office for Standards in Education (Ofsted).

Gráinne Conole and co-writers postulate the concept of the micro dimensions of e-learning. They identify areas of technology-enabled teaching and learning that include the organisational, technical, pedagogical and socio-cultural aspects including: interdisciplinary, access and inclusion, change, commodification, interactivity and social interaction and political aspects. The pedagogical aspects they identify include understanding and developing the:

- skills of teachers;

- skills of students;

- nature of online communities;

- different forms of communication;

- different forms of collaboration;

- modularisation, flexibility and interactivity;

- use of mobile learning (Conole and Oliver, 2007:8).

When we consider technology-enabled learning, the technology artefacts tend to dominate the experience of the learners. The technology impacts upon the environment, the types of activities undertaken, the resources that may be used and frequently, takes from the teacher and learner the regulation of learning. Bring the focus away from the technology and towards the theories, Terry Mayes and Sara de Freitas describe the pedagogy of technology in three broad perspectives: associative, cognitive and situative (Mayes and de Freitas, 2007). Their analysis can be simplistically interpreted as arising from the principles of behaviourism, cognitivism and social constructivism but, as stated in the introduction to this book, there are many more theories underpinning technology-enabled teaching and learning and the resulting pedagogies.

It is important to ask why some teachers adopt the use of computers in the classroom so enthusiastically and why that enthusiasm continues despite the ever-changing and rapidly changing frailties of technology and the challenges and difficulties associated with using computers in the classroom. The early adopters (Rogers, 1983) were 'seeing' the affordances (Kennewell, 2001) of the technology and balanced the cost/benefit positively whilst others described as laggards 'suspicious of change' (Rogers, 1983:250) took a more negative stance and some were assertively negative (Luddites). In the early 1980's there were several key reasons identified for the efficacy of computers in the classroom. They included the motivational effect of the 'new' technologies, the non-judgemental nature of computer feedback and the immediacy of response of the computer. These factors continue to be important in the use of technology in teaching.

To a large extent, those generic reasons remain key to the continuing success of technology-enabled teaching. Avril Loveless reflects that 'technology doesn't change pedagogy - people do' but also states that the increased use of technology in teaching is causing educationalists to rethink their models of pedagogy (Loveless et al, 2001:63). She proposes that the teachers' influence and use of technology relates to their:

- approaches to teaching

- beliefs about the subject matter;

- subject knowledge;

- pedagogic content knowledge;

- craft skills in organisation and management;

- personal characteristics and perceptions of the current situation;

- teaching behaviours; and 
- context in which they are teaching (Loveless et al, 2001:68).

\section{belief}

In the introduction to her book 'Children Using Computers', Anita Straker reflects on the pervasive nature of IT in society and the implications for teaching. 'Whether we like it or not, it is here to stay' (Straker, 1989:2). In those days there were two sorts of advocates of computing - those teachers who saw the new technology and said 'how can we use this in our teaching'; the others would say 'we have a challenge in our teaching - is it possible to use a computer to meet that challenge?' Those teacher beliefs have strong influences over the developments in ICT for teaching and learning; Rosie Turner-Bisset describes it, 'Beliefs about a subject are informed by one's knowledge of substantive and syntactic structures of the subject. The same is true in education and teaching. If one believes education to be training, this belief shapes one's thinking, discourse and actions within education' (Turner-Bisset, 2001:10-11).

The first way-of-thinking, assuming that the technology should be used because it is there, results in many innovative practices being tried and perhaps later discarded because they did not result in good and sustainable practice. For example, the laser disc mass-data storage technology of the late 1980's enabled the distribution of the Domesday Project which celebrated the 900th anniversary of the Domesday Book (1086) and contained thousands of photographs, articles and maps of Great Britain in a searchable and graphical format, running through the classroom computer. 'The BBC Domesday project is a high profile example of 'digital obsolescence' where technology has changed to the point that this once prestigious project has essentially disappeared less than a quarter of a century after it was completed' (Grant, 2009). The initial, obvious affordances of the system soon were rejected in the light of experience of the difficulties of access.

The second way-of-thinking 'we have a challenge in our teaching' created successful case studies and exemplars of practice. When scalable, the initiative enabled the wider use of ICT in teaching and learning. However, what works as an idea for a teacher or small group of teachers, may not work for everyone. This way-of-thinking also caused the development of software applications and methods of working that too were not sustainable. It becomes a teacher-belief whether they see the imaginative application of new technologies (because they are new) as a valid way forward or they only consider the use of an ICT initiative if they feel that it meets a pre-identified need. Teacher-beliefs are strong influences in the adoption of ICT in teaching and learning.

\section{motivation}

Computers were seen to be motivating. 'Anyone who has watched children working with a computer is impressed by the increase in their motivation and concentration' (Straker, 1989:3) is in stark contrast to the observations that children have lost the power of concentration as a result of their continuous use of computer-based technology. There is no doubt that computer-based activities can be engaging to the level of compulsive, exclusive, dominating and health-threatening. This aspect of what computers and the engagement with the processing and screen imagery effects both the game enthusiasts, those involved with social networking and those involved with programming.

In the 1980s, the motivational impact of computers related to a large extent to newness of the moment, coined the 'white heat of technology'. Computers were special and therefore seen by pupils as being worth 'doing'. Many pupils associated computers with games like the newly emerging Space Invaders and Pong which combined a narrative such as, stop the invaders or play an opponent, with quickness of reaction and finesse of hand. These genres were easily adopted by educational software developers to add competition, quickness of reaction or game rewards to the teaching elements such as spelling or mental arithmetic or knowledge questions.

Computers were seen to be non-judgemental. Pupils did not seem to be reacting badly to the computer when it corrected their mistakes - it was not personal. There seemed to be an acceptance of the decision and a motivation to get it right the next time. The 'punishment' for getting it wrong, withdrawal of the reward or a negative image such as a sad face, was accepted by the pupil. Even when the 'punishment' was a rewarding loud sound (raspberry) or appealing animation, there appeared an endeavour to get it right next time. 'Online assessment tests can provide immediate feedback in a non-judgemental way' (JISC, 2004:26). Terry Freedman 
commented on the role of ICT in the light of the Every Child Matters agenda, 'teachers take advantage of the non-judgemental character of ICT to help children develop higher self-esteem' (Freedman, 2005:15).

\section{emotional engagement}

In 1986, my nephew came around to play with my children on our newly acquired BBC Master computer; we had a new game called Granny's Garden.

Granny's Garden by 4Mation was developed as an educational adventure game or microworld in which the user had to find six missing children: Esther, Tom, Anna, Jessica, Clare, and Daniel from the clutches of the Wicked Witch and return them to the King and Queen of the Mountains. There were logical puzzles and some guesswork - one wrong step in the forest and the witch would get you; with an eerie tune you were sent back to the start. 'Granny's Garden remains a firm favourite with teachers and children alike. Over the years it has obtained 'classic' status and is considered by many to be the definitive educational software problem solving adventure for young children. The program has been updated to include a SCORM version for use in VLEs and remains as educationally useful as ever (4Mation, 2010).

The narrative of the story began, 'You are trying...'; it was 'you' who was trying to find the lost children; it was 'you' who the wicked witch would perhaps catch. After 10 minutes or so of quiet play there was a sudden scream and then many tears from my nephew. The witch had caught him. In today's language we would say, 'the immersive nature of the simulation engaged both the physical and the emotional senses'. This is an early example of the computer's ability to represent a world and the user's existence in that world in such a way that the virtual experience becomes as real (in terms of perceptions) as the real world. If it was named as esafety in 1986, then e-safety would have related to teachers needing to present stories to children so that they are inspired and excited but not worried or frightened. Teachers would be required to consider the social and emotional aspects of learning.

\section{immediacy}

As discussed above, many pupils were attracted by the interactive nature of the games and educational software. Simply the speed and the challenge to respond quickly, more quickly than their opponents or more quickly than the computer appeared to react, may have provided the motivation to complete the activities. The computer had a high degree of patience and did not get frustrated over delays in answering questions the learner was in control of the pace of learning and not the teacher. The relevance and the timeliness of the feedback provided a pedagogically sound teaching method; the pupils know immediately if they are right or wrong because the computer provides a strong reinforcer of appropriate behaviour. In the speed-response and accuracy-response educational games there are strong connections with behaviourist approaches to learning. Keywords drawn directly from behaviourism and related directly with computer assisted learning activities include: observable behaviours, social environments, experiences, motivation, stimulus-response, conditioning, behaviour modification, modelling, rewards, punishments, and affective domain.

More recent reflections on the reasons why computer-enabled teaching can be effective are drawn from the JISC report - Effective Practice with e-Learning A good practice guide in designing for learning. It identifies key benefits that directly parallel those of a generation previously. They reiterate learner control in 'self-paced' learning, the motivation effect of the graphics using the term 'media-rich resources', the value of quizzes and formative assessment through 'self-test', the immediacy of the interaction with 'immediate feedback' and the 'non-judgemental way' that computers communicate attainment and errors to the learner.

Online resources can support different learning styles and provide self-paced learning. Media-rich resources in different formats can provide more efficient learning when linked to face-to-face sessions in a blended learning programme. Online quizzes give learners opportunities to self-test prior to summative assessment. Online assessment tests can provide immediate feedback in a non-judgemental way Individual learners can be more easily supported through differentiated resources (JISC, 2004: 26)

\section{action engagement}

There is an uneasy relationship between games and learning. On the one hand, there is a celebration of the game/play values to learning. On the other hand, a distant is placed between the play/entertainment

$$
--<46>--
$$


elements and learning by using the term 'serious' as in 'serious games'. However, it is plain to see that games engage the player, games engage the learner and engagement is a good measure of learning potential.

Marc Prensky identified 12 ways in which games appeal (Prensky, 2001c). Games give us enjoyment and pleasure (fun) through intense and passionate involvement (play). There is structure (rules), motivation (goals/win states), activity and outcomes. The latter, outcomes, Prensky relates to feedback and learning. Games are adaptive, require problem solving, promote interaction and develop emotion through narrative. Some computer games are long and complicated but still engage because of the higher-level elements of motivation, emotion, interaction and interactivity. The features of computer games that encourage people to engage relate directly to those of cognition and learning (Gee, 2003). Game-based learning is the result of combining the 'game' characteristics with the learning 'context' or 'curriculum'. The model proposed by Rosemary Garris adopts an 'Input Process Outcome' sequence (Garris et al, 2002). It is proposes that an educational game is designed by integrating the teaching content with the game's characteristics. Secondly, the game program creates a learning cycle in which learners exercise their judgement and perform; meanwhile, the system provides feedback to learners. Good educational games, like good teaching, should give evaluation and feedback to improve the learners' study. 'Identifying significant mediating variables is an important step in understanding the attraction of games and the effectiveness of instruction. Analyses of training effectiveness have revealed a number of variables that mediate training outcomes. Three such attitudinal constructs are locus of control, self-efficacy and valence (Garris et al, 2002:13). The locus of control is the willingness or ability of participants to engage in the process; the self-efficacy determines what activities the user will pursue, the effort they will make and the persistence they have to overcome the challenges; the valence is the attractiveness of the outcomes.

When learners engage in this cycle and are motivated to succeed. That success is achieving the goals, rewards and recognition of the game or achieving the learning outcomes. A fully educational game is when game outcome and the learning outcome are one and the same. Good educational games have to construct a cycle which motivates learners to learn continuously - they are learning in a highly contextualised environment and this form of learning relates to the situated learning theory (Brown et al, 1989; Bruner, 1990; Lave and Wenger, 1991; Jarvis, 2004).

\section{cognitive engagement}

A very early consideration of the impact of audio-visual resources on learning is that of Edgar Dale who proposed a hierarchy of engagement in the learning process from the least engaging, reading about something, to the most engaging, actually carrying out the task by doing the real thing. His ideas present a realistic challenge to teachers and designers of technology-enabled learning experiences and can be used as a touchstone regarding pedagogic value.

reading

hearing words

looking at pictures

watching a moving image

looking at an exhibit of the artefact

watching a demonstration of the activity

seeing the activity being carried out on location

seeing and discussing the activity with other learners

preparing and giving a spoken presentation about the activity 
Figure 28 Hierarchy of engagement, based on Dale (1969)

When software-driven tasks are designed to present information in a predetermined, pre-structured and didactic way, they lead to efficient knowledge transfer. When those tasks enable learners' achievements to be presented and assessed then they lead to effective learning through feedback. When those tasks are drill and practice, they heighten response and accuracy and lead to more skilled learners. When the tasks enable collaboration and communication they lead to socially constructed learning that is both engaged and secure.

In contrast, when learners use software that engage them in critical thinking about what they know then they are using mindtools. Mindtools are at the heart of Papert's ideas when he proclaimed that computers would transform education. Mindtools are computer applications that engage the learner in analysing the information, they scaffold different forms of reasoning; they make learners think about what they are learning.

An important aspect of using a computer in this way is programming. When programming, the learners has to convert their ideas into computer formats. It is that intellectual process that:

- engages the learner with the material;

- requires them to analyse the material; and

- requires them to represent it in another format usually as a sequence of events or a set of rules.

Programming is an important way in which the computer enables this process of engagement, analysis, transformation and representation. But programming is not the only way in which computers can support this form of learning. They can facilitate the learner represent their ideas and understanding as visual representations (such as concept mapping), manipulating virtual environments (such as game authoring), causing actions (through avatar control). Papert's ideas have developed a flavour of constructivism called constructionism. The theoretical basis of constructivism is that knowledge is built by the learner and not supplied by the teacher; the learner is actively engaged in interpreting and analysing. In social constructivism there is negotiation of meaning to develop common understandings. In constructionism, the understanding is derived from the learners' construction of new devices, ideas, knowledge, representations and sharing those with others. Mindtools facilitate that knowledge construction.

Mindtools do not simply enable construction; mindtools support engaged, critical, constructive and reflective thinking. Although the terms are frequently used interchangeably, it is useful to differentiate between those thinking activities that analyse with a degree of criticality, those thinking activities that lead to new ideas and those thinking activities that reflect upon or evaluate.

\begin{tabular}{|c|c|c|}
\hline Critical/Descriptive & Constructive/Creative & Reflective/Evaluative \\
\hline $\begin{array}{l}\text { measuring against criteria } \\
\text { determining reliability } \\
\text { recognising errors/misconceptions } \\
\text { abstracting } \\
\text { categorising } \\
\text { testing hypotheses } \\
\text { identifying purpose }\end{array}$ & $\begin{array}{l}\text { sequencing and algorithm } \\
\text { recognising patterns } \\
\text { connecting - making links/connections } \\
\text { devising principles from experience/facts } \\
\text { reorganising and representing } \\
\text { representing in another form, finding alternatives } \\
\text { elaborating, developing, changing the purpose } \\
\text { imagining, designing } \\
\text { inferring }\end{array}$ & $\begin{array}{l}\text { drawing inferences } \\
\text { identifying implications } \\
\text { deliberating/judging } \\
\text { prioritising } \\
\text { comparing/contrasting } \\
\text { determining } \\
\text { usefulness/appropriateness } \\
\text { relating to the personal } \\
\text { relating to others }\end{array}$ \\
\hline
\end{tabular}

\section{Figure 29 Analysis of critical thinking}

Mindtools are resources that support learning and have these three important features: 
- they can represent knowledge, relationships or systems;

- they are generalisable to different topic, theme, subject or curriculum areas; and

- they foster some form of engagement through critical thinking.

\begin{tabular}{|c|c|c|c|c|}
\hline & $\begin{array}{l}\text { represents } \\
\text { knowledge }\end{array}$ & $\begin{array}{l}\text { represents } \\
\text { relationships }\end{array}$ & $\begin{array}{l}\text { represents } \\
\text { systems }\end{array}$ & Examples: \\
\hline word processor & $\checkmark$ & & & $\begin{array}{l}\text { using a 'shared' document to develop a narrative; creating a } \\
\text { template that can be used for many applications; changing } \\
\text { styles to meet audience needs }\end{array}$ \\
\hline spreadsheet & $\checkmark$ & & $\checkmark$ & $\begin{array}{l}\text { modelling real life scenarios such as theatre ticket sales or } \\
\text { profit/loss scenarios }\end{array}$ \\
\hline $\begin{array}{l}\text { database manager } \\
\text { (particularly relational } \\
\text { databases) }\end{array}$ & $\checkmark$ & $\checkmark$ & & $\begin{array}{l}\text { identifying fields that represent in the same structure many } \\
\text { disparate objects }\end{array}$ \\
\hline presentation package & $\checkmark$ & & & $\begin{array}{l}\text { sequencing or structuring knowledge to show understanding; } \\
\text { using visualisations to represent the construct being presented }\end{array}$ \\
\hline wiki, blog or forum & $\checkmark$ & & & $\begin{array}{l}\text { presenting shared understanding; negotiating representations } \\
\text { of knowledge; building knowledge through contributions }\end{array}$ \\
\hline concept mapping software & $\checkmark$ & $\checkmark$ & $\checkmark$ & $\begin{array}{l}\text { creating spider diagrams } \\
\text { Mind Mapping }^{\mathrm{TM}}, \text { Inspiration }^{\mathrm{TM}}, \text { Kidspiration }^{\mathrm{TM}} \text {, }\end{array}$ \\
\hline programming language & & & $\checkmark$ & LOGO, Scratch and Greenfoot \\
\hline virtual world activities & & & $\checkmark$ & $\begin{array}{l}\text { programming avatars (Kodu, 2010; Kar2ouche, 2010); } \\
\text { designing environments (Habbo, 2010); adapting behaviours } \\
\text { to other situations (Second life }{ }^{T M} \text { ) }\end{array}$ \\
\hline
\end{tabular}

Figure 30 Mindtools - functions and examples

\section{creative and critical thinking}

The competent and confident e-learner must have a degree of capability in handling information in the online environment. Edward de Bono wrote extensively about lateral thinking and the processes of generating novel solutions to problems. Although De Bono does not acknowledge any theoretical antecedents for his work on lateral thinking, it seems closely related to the Gestalt theory of Wertheimer which founds its ideas of thinking and perception on a set laws of organisation or grouping of ideas. Thinking and understanding is related to visualisation including the proximity, similarity, completeness (closure) and simplicity. For example, when trying to conceptualise the ideas about e-learning the visualisations might include:

- the proximity of the relationship between asynchronicity/synchronicity with the cognitive/constructivist views of learning as reflected in Figure 8;

- the similarity of the personality and behaviours of an avatar with the personalities and behaviours of 'real' human beings;

- the complete dimension of the evaluation of e-resources is represented by the 6 areas of changing behaviour, constructing understanding, social construction, changing attitudes, developing maturity and satisfaction/behaviour - see Figure 6;

- the simplicity of structures such as the brain diagram to represent the inter-relationship between Id and Ego in the Freudian interpretation of personality - see Figure 23;

Edward De Bono observed that 'western thinking' is concerned with analysis, judgement and argument. He contests that 'there is another whole aspect of thinking that is concerned with 'what can be', which involves constructive thinking, creative thinking and 'designing a way forward"' (de Bono, 1985:2). His work has influenced the education of young children through, for example, 'Six Thinking Hats'.

For older e-learners de Bono has identified four critical factors associated with lateral thinking:

- recognise the dominant ideas that polarise perception of problems/situations;

- searching for different ways of looking at problems/situations;

- relaxing the rigid control of thinking; and 
- the use of chance to encourage other ideas.

The primary school e-learner can benefit from being encouraged to think about the thinking strategies.

\begin{tabular}{|c|c|c|c|}
\hline Using the Six Hats & makes the learner consider... & and tutors/trainers/teachers are & resulting in... \\
\hline $\begin{array}{l}\text { The Red Hat } \\
\text { Feelings and emotions }\end{array}$ & $\begin{array}{l}\text { use intuition, feelings, and } \\
\text { hunches }\end{array}$ & $\begin{array}{l}\text { encourage learners to try and not be afraid, ensure } \\
\text { they have they have the knowledge to back track } \\
\text { (Control Z, browser back/forward buttons, } \\
\text { breadcrumbs and history) }\end{array}$ & $\begin{array}{l}\text { confident and sensitive } \\
\text { users of technology }\end{array}$ \\
\hline $\begin{array}{l}\text { The Black Hat } \\
\text { Critical } \\
\text { judgement }\end{array}$ & $\begin{array}{l}\text { be cautious and prepared for } \\
\text { difficulties; } \\
\text { be aware that things might go } \\
\text { wrong }\end{array}$ & $\begin{array}{l}\text { caution learners on e-safety rules and staying safe } \\
\text { strategies; but developing pupil resilience to } \\
\text { inappropriate material and actions (Byron, 2008) }\end{array}$ & $\begin{array}{l}\text { confident and resilient } \\
\text { users of technology }\end{array}$ \\
\hline $\begin{array}{l}\text { The Yellow Hat } \\
\text { Positive } \\
\text { values }\end{array}$ & $\begin{array}{l}\text { identify values and benefits; } \\
\text { identify why something might } \\
\text { work }\end{array}$ & $\begin{array}{l}\text { making the learners aware of functionality and } \\
\text { affordances - what the systems can do and what the } \\
\text { systems enable us to do. }\end{array}$ & $\begin{array}{l}\text { competent users of } \\
\text { technology }\end{array}$ \\
\hline $\begin{array}{l}\text { The Blue Hat } \\
\text { The big picture }\end{array}$ & manage the thinking process & $\begin{array}{l}\text { using technology as a natural part of the teaching and } \\
\text { learning process }\end{array}$ & \\
\hline \multicolumn{4}{|c|}{$\begin{array}{r}\text { becoming the: competent; confident; } \\
\text { effective; efficient; imaginative; } \\
\text { resilient; and sensitive } \\
\text { e-learner. }\end{array}$} \\
\hline
\end{tabular}

\section{Figure 31 The six hats and e-learning skills, based on de Bono (1985).}

The competent and confident e-learner adopts the appropriate strategy according to the situation being encountered. The provisionality of online environments continually presents the learner with novel and challenging visuals and opportunities and to be competent, the e-learner has to possess strategies to deal with them. Lateral thinking offers important strategies. At the highest level the e-learner makes decisions driven by strategies based on secure knowledge, driven by ambition and will, based on appropriate caution and care, using imagination and creativity within an overall strategic plan. The beginner e-learner needs guidance and tuition in the strategies. For the teacher, the first stage is to use the Six Hats each in isolation creating learning situations that are best tackled by the target 'hat'. Lateral thinking and the release of imagination to solve problems are important elements in creativity (Wickens, 2007), prediction and the application of interpolation and extrapolation (Woollard, 2007b). Aspects of lateral thinking that are useful strategies for our pupils to adopt include being able to:

- develop concepts to breed new ideas and sharpen or change your focus to improve your creative efforts;

- break free from the limits of accepted ways of operating by challenging conventions and mores;

- use unconnected ideas and introduce elements of randomness to open new lines of thinking;

- harness the energy of provocation and move the thinking to constructive and useful ideas;

- select the best of early ideas and shape them into useable approaches and, in particular, apply those ideas to new situations.

Edward de Bono's book 'The five-day course in thinking' (1969) provides a good opportunity to show how computers can enhance learning. The problems, particularly the blocks examples, require the learner to physically or mentally manipulate blocks into different positions to meet particular conditions. By using a computer screen and mouse, the exercises can be mediated by manipulating simple diagrams. The T-junction solution (De Bono, 1967: 103) is one that comes much more easily (for some people) when 'physically' 
manipulating the images (within the virtual environment of the computer screen) than trying to follow the process with mental imagery (in the head).

In contrast, his book 'How to have creative ideas' (de Bono, 2007) is not suitable for computerisation. In essence, the exercises are based on the use of randomly selected words with the learner imaginatively identifying connections and contrasts between individual words and groups of words. The answers are based on semiotic, word shape and phonic characteristics of the words. For an answer to be correct may depend upon the history, context or feelings of the respondent and so be correct for him or her but not correct for anyone else. 'The fact that there are no right answers does NOT mean that any answer will do. The answer must satisfy the requirements of the exercise' (de Bono, 2007:12). This is particularly challenging for conventional computer programming that can deal with very fast responses to 'does the response match one of the correct answers?'

In conclusion, Edward de Bono's ideas on lateral thinking provide important guidance for supporting the elearner develop his or her skills and aptitudes to handle the technology-enabled learning process. His ideas can be the basis for some computer-based activities but the nature of lateral thinking often generates many right answers that are difficult to codify within a fixed-state computer program.

\section{Using virtual learning environments}

The virtual learning environment (VLE) is the dominant domain of technology-enabled learning for the start of the millennium. The decade has seen the progress from the first introductions of VLEs right through to the legislative requirement for all UK schools to adopt a VLE. The VLE is an important conceptual and theoretical paradigm to be understood. For the e-learner the VLE is as important as the classroom is for the traditional learner in school. The VLE embraces the technologies of Web 2.0 and presents them in a unified way within the protection of a secure, closed location.

The use of virtual learning environments has become ubiquitous in UK education from the youngest entering school to the oldest leaving university. In infant schools, teachers are using VLEs such as the Hampshire Wizkid to offer 'another style of learning (e-learning) which our pupils will meet later in their education... sits alongside traditional classroom teaching methods giving an opportunity to children who enjoy learning this way' (Freegrounds, 2010). Teachers can make available resources for the children to use in school, at the local library and at home. The systems have the full range of online resources including 'messaging facilities similar to email, chat areas and forums for discussion [where pupils] can develop their skills in this safe and closed environment with just their teachers and other pupils' (Freegrounds, 2010). The systems offer continuity between primary and secondary education. In some primary schools the systems are used as a communication channel with parents. Secondary schools use them to regulate learning, both in the classroom by being the source of learning objectives, teaching materials and assessment, and when pupils are working outside the classroom, prescribing homework, enabling the submission of homework, online tests for formative assessment and communication between pupil and teacher. In higher and further education they are used to 'manage' the education provision; the gateway to all courses is through the VLE. It is the standard method of distributing course information, teaching and learning resources, calendar and event information; focus for self-assessment and summative assessment activities and the route by which reporting of student performance is made. The virtual learning environment is having a dramatic impact on the learners' experiences, the strategies adopted by teachers and the development of the underlying pedagogy.

An early analysis of the use of a VLE to support learning adopted Mayes's conceptual framework (Mayes and Fowler, 1999) to describe the learning cycle which passes through the three aspects of: conceptualisation; construction; and dialogue. At the conceptualisation stage the learner is exposed to new ideas or concepts through online experiences - those experiences involve orientation, exploration and experimentation. The construction stage involves the learner applying the new understanding/concepts in meaningful tasks including selecting, linking and classifying material. The third stage, dialogue, involves the learner communicating their knowledge and understanding to others through discussion, reflection and reification - it is here that feedback from teachers and peers takes place and misconceptions may be identified. Michael Gardner describes the fundamental facilities of a generic learning platform and identifies that utilising a commercial product is attractive because 'it could provide a single service platform which could be used to 
provide tailored services to different market sectors [learners]' (Gardner and Ward, 1999:19). The architecture is described in technology terms; this is reflected in psychology/learning terms in the table below.

\begin{tabular}{|l|l|}
\hline Technology & Psychology \\
\hline $\begin{array}{l}\text { description of roles, personal information about } \\
\text { learners/tutors }\end{array}$ & identifying of self, security, personal well-being \\
\hline virtual classroom/meeting place, audio conferencing & starting to build a sense of community \\
\hline private information spaces, file stores, the cloud & protecting the learner in the sensitive aspects of learning personal well-being \\
\hline shared diary & ensuring online synchronous collaboration social constructivism \\
\hline modular coursework access, check points & structuring learning, supporting learning, regulating learning, feedback \\
\hline email and discussion forum & asynchronous learning, representing understanding \\
\hline spreadsheets, concept mapping, presentation software & mind tools for cognitivist activities \\
\hline personalised home pages & raising esteem and developing personal well-being \\
\hline
\end{tabular}

Figure 32 Learning platform architecture and learning processes, based on Gardner and Ward (1999)

Online, distance-learning approaches cannot be successful without the learners having easy access to the full structure and resources of the learning programme. Although this can be achieved by providing open access to all the resources through the worldwide web (for example, the teacher training programme for ICT teachers at the University of Southampton - http://www.pgce.soton.ac.uk/IT) many provisions require a degree of protection of resources and monitoring of access. The affordances of VLEs best meet those needs.

The nature of knowledge in the technology-enabled learning environment is changing. As a consequence, the way in which learners both perceive and acquire knowledge is also changing. The text book was the very lifeblood of education up until the late 1990. 'The textbooks have been terminated by Arnold Schwarzenegger, the bodybuilding state governor who says they are "outdated" and too expensive' (Times Online, 2009). The virtual learning environment is proving to be the computer-based equivalent.

It is the design models for the VLE's that now underpin the teachers' strategies. The following list is based upon and extended from the work of John Cook and his analysis of the design of learning technologies (Cook et al, 2006:55). It is important that the teaching intentions are well matched to the learning technology employed. In the examples presented, the nature of the learning is matched to the affordances of the technologies. The third column reflects the typical impacts and changes that the introduction of technology has upon the learning environment. The statements do not avoid a focus on the negative and it is evident through considering the practices described below that there are positive and constructive impacts which make the introduction of technology-enabled learning a valid exercise. By focusing on the negative implications, the process can identify the areas where additional activity could be introduced to compensate for the perceived disadvantages.

\begin{tabular}{|l|l|l|}
\hline Nature of the learning & Learning technology & Characteristic impacts \\
\hline Online, distance & VLE, MLE, WWW & $\begin{array}{l}\text { the computer screen becomes the sole medium for learning; } \\
\text { the tutor leads the learning by means of the technology - } \\
\text { described by Laurillard (2002) as the narrative of her } \\
\text { conversational model. }\end{array}$ \\
\hline Group and team work & $\begin{array}{l}\text { social networks, asynchronous } \\
\text { interaction through blogs, wikis and } \\
\text { email, synchronous through internet } \\
\text { messenger, chat rooms and CMC }\end{array}$ & $\begin{array}{l}\text { the learner becomes an ID; they are represented only by } \\
\text { their words - how they respond verbally in 1:1, many:many, } \\
1: \text { many and many:1 relationships }\end{array}$ \\
\hline $\begin{array}{l}\text { Assessment } \\
\text { (summative/formative) }\end{array}$ & $\begin{array}{l}\text { CAA, item banks, e-portfolios, patchwork } \\
\text { evidence becomes electronic; } \\
\text { more immediate feedback; less time to reflect upon } \\
\text { submission; } \\
\text { feedback is separated from the learner-teacher relationship; } \\
\text { assessment is separated from the learner-teacher } \\
\text { relationship }\end{array}$ \\
\hline Motivating and engaging & $\begin{array}{l}\text { multimedia, virtual reality, game-play, } \\
\text { virtual worlds }\end{array}$ & $\begin{array}{l}\text { disenfranchisement/disadvantage by those that do not 'buy } \\
\text { into' the medium }\end{array}$ \\
\hline Discovery and exploration & hypermedia, simulations, microworlds, & \begin{tabular}{l} 
takes away 'real' activity - reduces the kinaesthetic to finger \\
\hline
\end{tabular}
\end{tabular}




\begin{tabular}{|l|l|l|}
\hline & game-play & movements \\
\hline Personalisation & $\begin{array}{l}\text { adaptive software, adaptive } \\
\text { environments; } \\
\text { portfolio systems }\end{array}$ & $\begin{array}{l}\text { disenfranchises/devalues the teacher; } \\
\text { removes the physicality of the product of learning }\end{array}$ \\
\hline $\begin{array}{l}\text { Informal, self-directed, } \\
\text { open, independent, } \\
\text { flexible }\end{array}$ & $\begin{array}{l}\text { mobile learning, open-access WWW, } \\
\text { ubiquitous computing }\end{array}$ & physically isolates the learner from other learners \\
\hline
\end{tabular}

Figure 33 Teaching strategies and learning technologies

\section{social interaction}

Social interaction is a most important aspect of learning regardless of the theoretical model that underpins the pedagogy; the behaviourist requires the interaction for the positive reinforcement and the social conditioning; the social constructivist learning and understanding is the expression through language of that understanding; and the cognitivist see the product of the thinking and thinking strategies through the interactions of the learner.

In the classroom communication between teachers and pupils and between pupils and others is complex. A systematic analysis of the social interactions can be made (Edwards and Westgate, 1994; Kollias and Vosniadou, 2002; Bloome et al, 2005). In the technology-enabled environments similar analyses can be made (Martínez et al, 2003; Mercer et al, 2004). The following diagram illustrates the basic routes of communication; it can be used to illustrate and explain the functionality of the technology and the affordances that technology can bring to the teaching and learning process.

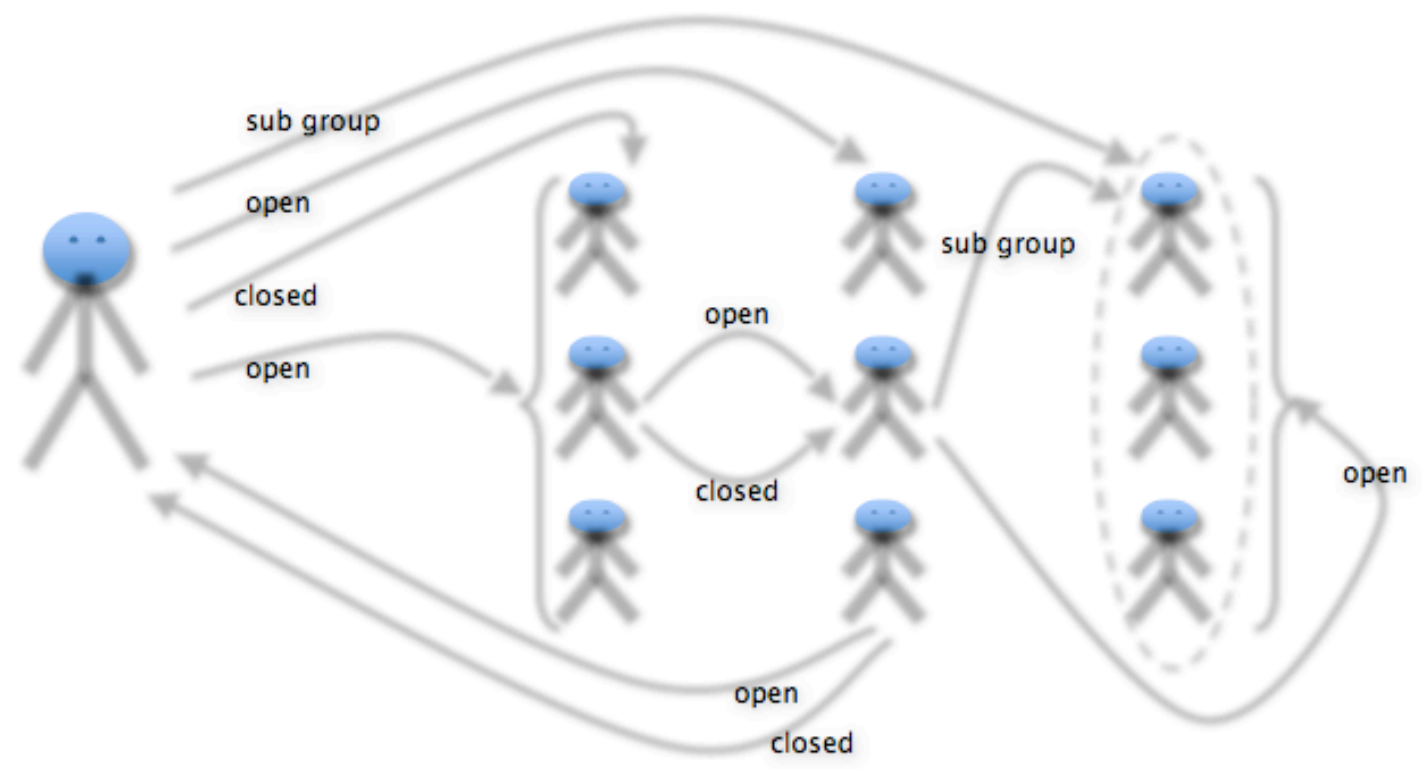

Figure 34 Routes of communication

An 'open' communication is one that can be seen/heard by everyone, for example, the teacher calling across the class or posting a message in a chat room. A closed communication is one where only the communicator and the recipient are aware of the message, for example, the teacher quietly telling a pupil to do something or the teacher sending a personal email. The teacher, tutor or trainer (on the left) communicates with the whole class/group, with individuals or with subgroups of the whole class. That communication can be open or closed. Superimposed on this diagram of the routes of communication are the layers of different types of communication. Ron Oliver and Catherine McLaughlin propose that there are five types of teacher-learner interaction: social, procedural, expository, explanatory and cognitive (Oliver and McLaughlin, 1996; Offir and Lev, 1999). The teacher will choose whether to employ open or closed or subgroup communication depending on the type of communication. This systematic approach will be used later to explain and describe technologies such as chat rooms, WIKIs and blogs. 


\section{engagement}

An important debate regarding the efficacy and efficiency of the learning systems is focussed upon 'quality' of provision. Tamer Abd El-Gawad's framework (Abd El-Gawad and Woollard, 2010) represents both the facilities and features of virtual learning environments but also connects them with the stakeholders and their requirements of a VLE. The important educational psychology dimension of this quality model includes the flexibility of access and interactivity to support associative (Mayes and de Freitas, 2007) teaching and learning; the range of social interaction opportunities (Web 2.0) to support social constructivism; and the personalised learning to motivate and promote engagement. The challenge for educational technologists is to identify the affordances of VLEs and ensure the learning activities and experienced at the appropriate level of engagement. The following example demonstrates the principles of the engagement hierarchy. Consider the situation where an online experience is to introduce someone to simple computer programming. The lowest level of engagement is giving a written description of computer programming for the learner to read. The next levels are presenting still or moving images of computer programs. There is more engagement if the learner can see the program and it is particularly engaging if the program is in-situ. However, understanding how the program works may need the opportunity to express their developing knowledge and engage in socially constructed understanding. If the learner has to make a spoken presentation of the programming process they will be more engaged and more likely to understand or remember. If that demonstration were of the coding process in front of an audience then the learner would be very engaged in the process.

There is a tension. In the practical situation there is often insufficient time for the learner to engage in the highest level of engagement for every topic. Also, it may generate a cognitive or emotional overload. The teacher needs to assess the appropriate level of engagement for a task based on the individuals needs, their previous experience, their capability and the potential to learn without very high levels of engagement. The skill of the teacher is to combine their subject knowledge with the appropriate pedagogic approaches is known as pedagogic content knowledge (PCK) - a blend of content knowledge and pedagogic knowledge. Whereas content knowledge is a prerequisite for all communication about a subject, pedagogic knowledge serves as framework to scaffold the teachers' activities. In a similar way, pedagogic knowledge serves as the framework to scaffold the technology-enabled learning activities. Educational technologists should be aware of the maxim, "Those who can, do. Those who understand, teach" (Shulman, 1986:14).

There is a further tension developing in schools. The 'work-life' balance is a well-known construct of adults. An important impact of the pervasive use of computers is that work, or aspects of the work, can so easily be taken home or, more correctly, accessed from home. The increased use of internet-accessible VLEs is that the learners' schoolwork is accessible from home. Homework is ceasing to be an add-on, preparation for the next lesson or follow-up from the previous. It can be exactly the same activity as being pursued in the classroom. As teachers adopt more online activity whilst the learner is in class the blurring of homework/classwork increases. The first signs of the learner's 'school-life' balance being impacted upon is the development of multiple GCSE programmes such as Diplomas in Digital Applications (Edexcel, 2010), National Certificates (OCR, 2009) where 4 GCSE equivalent awards can be taught in the equivalent school time of 2 GCSE awards ( $10 \%$ of the timetable). The time shortfall is addressed by learners doing more work, particularly on projects and skills development, outside of the school timetable and teachers doing more monitoring and assessments outside of the lessons. The role of the teacher may have to include providing information, advice and guidance raising 'work-life' balance issues.

\section{assessment}

Assessment is an essential element of teaching. The VLE and technology-enabled teaching in general reflects the value of assessment; here are many aspects of the systems that contribute to the assessment process. The following tables identify the different aspects of assessment and describe the e-learning perspective connecting it with the significant learning theory.

\begin{tabular}{|l|l|l|l|}
\hline & Description & Theory of learning & E-learning perspective \\
\hline baseline & $\begin{array}{l}\text { before or at the start of learning to } \\
\text { determine understanding, knowledge } \\
\text { and skills - medium stakes, results }\end{array}$ & $\begin{array}{l}\text { behaviourist } \\
\text { how do they respond? } \\
\text { cognitivist }\end{array}$ & $\begin{array}{l}\text { Closed responses, no feedback, } \\
\text { scores for different aspects of the } \\
\text { curriculum/skills area (see ILS) }\end{array}$ \\
\hline
\end{tabular}

$$
--<54>--
$$




\begin{tabular}{|c|c|c|c|}
\hline & determine teaching & what is their preferred learning style? & \\
\hline $\begin{array}{l}\text { formative } \\
\text { (diagnostic) }\end{array}$ & $\begin{array}{l}\text { during the learning process; identifies } \\
\text { errors and misconceptions } \\
\text { low stakes - learners may be unaware of } \\
\text { the process; the process is seen to be } \\
\text { supportive of learning; associated with } \\
\text { feedback and assessment for learning }\end{array}$ & $\begin{array}{l}\text { cognitivist } \\
\text { how do they think? } \\
\text { what are their preferred ways of } \\
\text { learning? } \\
\text { how do they represent their } \\
\text { thinking? } \\
\text { identifying errors and } \\
\text { misconceptions }\end{array}$ & $\begin{array}{l}\text { Feedback to the tutor } \\
\text { Similar to the baseline systems } \\
\text { Integrated Learning Systems (ILS) } \\
\text { Some online and VLE based quizzes } \\
\text { send the tutor/teacher information } \\
\text { as well as the learner }\end{array}$ \\
\hline ipsative & $\begin{array}{l}\text { measuring learners' attainment against } \\
\text { their prior performance } \\
\text { low stakes when used in a formative } \\
\text { mode } \\
\text { medium stakes when used to determine } \\
\text { rewards, outcomes, future opportunities }\end{array}$ & $\begin{array}{l}\text { behaviourist } \\
\text { when used to reward and encourage } \\
\text { constructivist } \\
\text { when discussion of responses is } \\
\text { undertaken } \\
\text { cognitivist } \\
\text { when errors and misconceptions are } \\
\text { identified }\end{array}$ & $\begin{array}{l}\text { Only the adaptive systems and ILS } \\
\text { can 'know' the ;learner and make } \\
\text { judgements about current } \\
\text { attainment compared with prior } \\
\text { attainment }\end{array}$ \\
\hline summative & $\begin{array}{l}\text { end of learning, measure of attainment } \\
\text { in terms of } \\
\text { mark/grade/level/performance } \\
\text { statement, planned, structured, } \\
\text { marked/graded/levelled and results } \\
\text { reported - very high stakes, results have } \\
\text { implications for future opportunities }\end{array}$ & $\begin{array}{l}\text { behaviourist: } \\
\text { do they respond correctly? } \\
\text { knowledge right/wrong } \\
\text { do they respond quickly? skills } \\
\text { are response rates sustained? }\end{array}$ & $\begin{array}{l}\text { Online tests, test centres, } \\
\text { authentication of the respondent }\end{array}$ \\
\hline
\end{tabular}

Figure 35 Types of assessment: baseline, formative (diagnostic), ipsative and summative

There are two aspects of assessment that are in vogue, arising from the 'assessment for learning' initiatives (DfES, 2005, 2006; DCSF, 2008): peer-assessment and self-assessment. They tend to be episodic activities with structure and formalities.

\begin{tabular}{|l|l|l|l|}
\hline $\begin{array}{l}\text { peer- } \\
\text { assessment }\end{array}$ & $\begin{array}{l}\text { learners assessing each other's work } \\
\text { low stakes in terms of consequence but } \\
\text { can be emotionally charged } \\
\text { usually not associated with summative } \\
\text { assessment or baseline assessment }\end{array}$ & $\begin{array}{l}\text { constructivist } \\
\text { helping each other understand } \\
\text { coming to a shared understanding } \\
\text { cognitivist } \\
\text { representation of understanding } \\
\text { identifying learning styles }\end{array}$ & $\begin{array}{l}\text { peer assessment is a feature of } \\
\text { current ICT teaching practice; } \\
\text { ICT gives the opportunity for } \\
\text { collaborative work; } \\
\text { ICT gives the facility for whole class } \\
\text { presentation of individual's work }\end{array}$ \\
\hline $\begin{array}{l}\text { self- } \\
\text { assessment }\end{array}$ & $\begin{array}{l}\text { learners assessing own work } \\
\text { low stakes in terms of consequences } \\
\text { when well structured supports } \\
\text { assessment for learning } \\
\text { usually not associated with summative } \\
\text { assessment or baseline assessment }\end{array}$ & $\begin{array}{l}\text { constructivist } \\
\text { representing understanding through } \\
\text { oral and physical means } \\
\text { cognitivist } \\
\text { representation of understanding } \\
\text { identifying learning styles }\end{array}$ & \\
\hline
\end{tabular}

\section{Figure 36 Peer-assessment and self-assessment}

The final classification of assessment types relates to the content of the quiz and how the results can be interpreted.

\begin{tabular}{|l|l|l|l|}
\hline $\begin{array}{l}\text { criterion } \\
\text { referenced }\end{array}$ & $\begin{array}{l}\text { well defined statements of success } \\
\text { tick box approach } \\
\text { the consequences determine whether this is high } \\
\text { stakes or not }\end{array}$ & $\begin{array}{l}\text { behaviourist } \\
\text { responses meet the criteria or not } \\
\text { do they respond correctly? }\end{array}$ & $\begin{array}{l}\text { norm } \\
\text { referenced }\end{array}$ \\
$\begin{array}{l}\text { results are usually numeric and can be compared } \\
\text { to the results of a particular or the whole } \\
\text { population - used for reading, spelling, non- } \\
\text { verbal, quantitative assessments - IQ scores are } \\
\text { norm referenced } \\
\text { typically used to determine grade, placements, } \\
\text { potential therefore high stakes }\end{array}$ & $\begin{array}{l}\text { behaviourist } \\
\text { responses are right or wrong } \\
\text { to what degree do they respond } \\
\text { correctly? }\end{array}$ & $\begin{array}{l}\text { used to deliver norm- } \\
\text { referenced tests - these are } \\
\text { only valid if taken under } \\
\text { controlled conditions - } \\
\text { authentication, test centres }\end{array}$ \\
\hline standardised & $\begin{array}{l}\text { standards-based assessments are applied across } \\
\text { populations but are not norm referenced; usually } \\
\text { summative and therefore high stakes }\end{array}$ & $\begin{array}{l}\text { behaviourist } \\
\text { responses meet the criteria or not } \\
\text { do they respond correctly? }\end{array}$ & $\begin{array}{l}\text { as with norm referenced } \\
\text { assessments above }\end{array}$ \\
\hline
\end{tabular}

\section{Figure 37 Forms of assessment}


The quiz is ubiquitous in computer-based assessments. Although the term suggests a degree of trivia, the sophistication and value of a particular quiz is determined by:

- the facilities of the system (question types);

- the degree of feedback to the learner and the tutor/teacher; and

- the skills of the author to construct a probe that gives useful information.

Quizzes appear to be effective in the classroom because they engage the learners. There is a competitive element; there can be challenge; there is the opportunity for celebration and there is the opportunity for reward and positive reinforcement. In the classroom there are two other connected technology-enabled teaching devices that support interactivity including tablet PCs (Gubacs-Collins and Juniu, 2009), the interactive whiteboard (Smith et al, 2005; Kennewell et al, 2008) and the classroom performance system (Wang et al, 2009). In their own way they offer the same opportunities for competition, challenge, celebration and reward. It is through these devices that the teacher can gain very useful assessment data and also provide positive classroom experiences for the learners. The challenge is to enable quizzes in the virtual learning environment to engender and take advantage of those positive aspects as well as provide the teacher with useful data to help plan and provide appropriate learning experiences.

\section{Cybergogy - learning in virtual worlds}

Cybergogy is comprised of building learning archetypes to elicit responses from the four learning domains that classify the focus of sessions, the modes of teaching and the types of learning activity. It is a pedagogy based on learning outcomes. The domains are: cognitive, dextrous, social and emotional. A teacher can plan to engage the learning domains to a greater or lesser degree depending on the desired learning outcomes. However, by catering to all four domains, a learning experience can become compelling, holistic and immersive.

\begin{tabular}{|c|c|c|}
\hline Domain & Description & Connections \\
\hline Cognitive & $\begin{array}{l}\text { Information processing (from remembering, recalling and archiving to analysing and } \\
\text { critically evaluating). } \\
\text { Application of knowledge in different contexts. } \\
\text { Creative intellectual activity; flexibility and plasticity of knowledge. } \\
\text { Hypothesis construction/destruction. } \\
\text { Retention of rules to abstract conjecture. }\end{array}$ & $\begin{array}{l}\text { Bloom's Taxonomy - cognitive } \\
\text { domain. } \\
\text { Adapted by Anderson and } \\
\text { Krathwhol (2001). } \\
\text { Additional adaptation for Web } \\
2.0 \text { by Churches (2008). }\end{array}$ \\
\hline Dextrous & $\begin{array}{l}\text { Dexterity at the interface with the virtual world. Acquisition of skills for navigating, } \\
\text { manipulating, inspecting and creating within the virtual world. Spatial awareness of } \\
\text { depth and distance in } 3 \text { dimensions. Also required is dexterity with mouse, keyboard } \\
\text { and other input devices and the ability to deal appropriately with personal items, in- } \\
\text { world objects and communications across several modalities. }\end{array}$ & $\begin{array}{l}\text { With reference to Bloom's } \\
\text { Taxonomy - psycho-motor } \\
\text { domain. }\end{array}$ \\
\hline Social & $\begin{array}{l}\text { Establishment of a sense of personal presence, awareness of the presence of others } \\
\text { and understanding the context of interactions. Ability to relay and perceive meaning } \\
\text { particularly in text based communications; to form affiliations and to network } \\
\text { amongst them. Collaboration, co-creation and to discerningly filter and channel } \\
\text { accurate information to identified groups or individuals. }\end{array}$ & $\begin{array}{l}\text { Adapted from Wang and Kang } \\
\text { (2006) 'Cybergogy for engaged } \\
\text { learning'. }\end{array}$ \\
\hline Emotional & $\begin{array}{l}\text { Perceiving emotional states of self and others and using emotional triggers to } \\
\text { enhance learning experiences. The environment can provide emotional stimuli } \\
\text { including fear of falling, the visual of falling, excitement, tension and aesthetic } \\
\text { appreciation. When learners are emotionally engaged, with each other in a spirit of } \\
\text { camaraderie, the subject at hand, or the environment, a condition of immersion is } \\
\text { attained which promotes deeper learning and retention. The nature of 3Di } \\
\text { experiences means that it is suited to learning activities relating to personal, social, } \\
\text { emotional and spiritual aspects of education. }\end{array}$ & $\begin{array}{l}\text { Salovey and Meyer (1994) 'Ability } \\
\text { based Model of Emotional } \\
\text { Intelligence'. Goleman (1998) } \\
\text { 'Working with Emotional } \\
\text { Intelligence'. Zins et al (2004) } \\
\text { 'The scientific base linking social } \\
\text { and emotional learning to school } \\
\text { success'. }\end{array}$ \\
\hline
\end{tabular}

Figure 38 The learning domains of cybergogy

Within and across the learning domains are learning archetypes. They are the activities that learners carry out and they are the expectations of the tutors and teachers. They are the instructional strategies that act as the building blocks that facilitate learning. Learning Archetypes (O'Driscoll, 2007), (Kapp and O'Driscoll, 2007) are pedagogic metaphors, a variety of activity types which can take a kinaesthetic approach comprised of concrete, physical actions such as doing, being, moving and making, or a theoretical, conceptual approach 
composed of the cognitive processes of thinking, writing, describing and imagining (Woollard, 2004). Some archetypes can display elements of combined metaphors for example a theoretical metaphor such as thinking or creative imagining promotes and strengthens a resulting literal, kinaesthetic activity such as a persona dramatised in role play conducted within a 3D teaching and learning environment. The teaching design strategy that employs the integration of Learning Archetypes should take full advantage of the affordances of Second Life ${ }^{\circledR}$ such as the opportunity to provide synchronous experiences for learners who may be separated by great distance allowing for interaction that feels very real, to provide a social networking opportunity promoting collaboration and the sharing of information and to create an alternative backdrop for learning that can break away from traditional settings providing the opportunity for unique immersive experiential learning experiences.

Karl Kapp identifies a number of categories of learning archetypes (Kapp, 2007) including: role-plays, treasure hunts, guided tours, conceptual orienteering, operational application, co-creation, critical incident, group forum, small group work and social networking. This model is extended to include assessment adopting the structure of the REAP Model (JISC, 2007; REAP, 2007). The resulting structure has both frames and sub-frames associated with each archetype that exemplify appropriate teaching methods.

\begin{tabular}{|c|c|c|c|c|c|}
\hline & Assessment & Meshed & Role play & Peregrination & Simulation \\
\hline
\end{tabular}

Figure 39 The learning archetypes with frames and sub-frames

The model is also extended to provide levels of implementation within each domain.

\begin{tabular}{|c|c|c|c|c|}
\hline $\begin{array}{c}\text { Level of } \\
\text { implementation }\end{array}$ & Cognitive Domain & Emotional Domain & Dextrous Domain & Social Domain \\
\hline Level 1 & Remembering & Perceiving emotion & Imitating & Personalising \\
\hline Level 2 & Understanding & Using emotion & Manipulating & Contextualising \\
\hline Level 3 & Applying & Understanding emotion & Developing precision & Communicating \\
\hline Level 4 & Analysing & Understanding emotions & Articulating & Affiliating \\
\hline Level 5 & Evaluating & Emotional self control & Naturalising & Networking \\
\hline Level 6 & Creating & Influencing emotions & Authoritative & Channelling \\
\hline
\end{tabular}

Figure 40 The levels of implementation for the domains of learning

The relation between domain, archetype, frame and sub-frame is illustrated in this example. The 'Meshed' archetype is not simply the creation of opportunities to communicate but to creatively combine and interconnect individuals and groups in various ways for desired educational purposes and outcomes. In this example, the 'small group work' frame is selected - the teaching activity will relate to a nominated group to work together on the activity and the major focus will be peer-to-peer communication and collaboration. At the lowest level of engagement the learner is making personal contributions. At a higher level they will be engaging with the group and becoming a member of the group through agreement, participation, consensus 
and mutual support (affiliation). At the highest level of working they will be acting as an intermediary for the group and representing the agreements of the group (channelling).

\begin{tabular}{|c|c|c|c|c|}
\hline Archetype & Frame & Sub-frame & & ocial Domain \\
\hline \multirow[t]{6}{*}{ Meshed } & \multirow{6}{*}{$\begin{array}{c}\text { Co-creation } \\
\text { Group forum } \\
\text { Small group work } \\
\text { Social networking }\end{array}$} & \multirow{6}{*}{$\begin{array}{c}\text { Classroom emulation } \\
\text { Lecture } \\
\text { Demonstration } \\
\text { Presentation } \\
\text { Synchronous } \\
\text { Asynchronous } \\
\text { Mixed reality } \\
\text { Peer-to-peer }\end{array}$} & 1 & Personalising \\
\hline & & & 2 & Contextualising \\
\hline & & & 3 & Communicating \\
\hline & & & 4 & Affiliating \\
\hline & & & 5 & Networking \\
\hline & & & 6 & Channelling \\
\hline
\end{tabular}

Figure 41 Exemplification of a learning activity within the social domain

The final chapter contains two vignettes. One describes the direct application of this theoretical approach in the development of a higher education curriculum. The second describes how activities to support teachers in training are developed in line with this pedagogy.

\section{Summary}

Pedagogy is the theoretical basis of teaching. It is influenced by teachers' knowledge, teachers' beliefs, policy, research and reflection on practice. The pedagogic use of technology to enable and enhance teaching and learning is established through research and practice (see Figure 27). The degree to which teachers adopt the technology is influenced by the same factors as those influencing pedagogy as a whole. The impact areas of the use of technology include: motivation; emotional aspect, action and cognitive engagement; and creative and critical thinking. The influential technologies are: the internet enabled virtual learning environment; internet and Web 2.0 technologies; subject specific applications; and the developing cybergogy of virtual worlds.

\section{Activities}

Consider, in the light of the content of this chapter, the important aspects of the technology-enabled pedagogy and how they could be translated into teaching strategies.

Consider the affordances of the virtual learning environment and establish a strategy for their full integration into a significant aspect of your teaching.

Consider the affordances of virtual worlds and how they can support your work as a teacher. 
By the end of this chapter will be able to:

- make informed choices about the appropriate application of technology within teaching and learning;

- identify the under-pinning theories of psychology and learning that determine the pedagogy and teaching strategies;

and you will have:

- reflected on the vignettes presented in the light of the preceding chapters and in the light of the commentaries.

This section will outline some of the approaches taken by teachers who have discovered that technology can enhance teaching and learning, enable new activities to take place and increasing the opportunities for teaching and learning.

The characteristics of teaching with technology are:

- providing ready access to the internet through networked computers, wireless and mobile devices;

- using technologies that support and enhance the traditional craft skills of teachers of exposition, explanation, presentation and managing the activities of the learners;

- enabling learners to access the curriculum, teaching activities and feedback when not in the classroom;

- engaging in classroom conversations using the technical terms in a confident competent way;

- possessing a 'creative and constructively critical approach towards innovation, being prepared to adapt their practice where benefits and improvements are identified' (TDA, 2008).

\section{Strategies of the technology-enabled teacher}

A teacher who values the role of technologies will utilise all of the above approaches with the intention of assisting in the process of learning. They are based on the premise that technology can assist learning, technology-enabled teaching can be more efficient and effective and today's learners are responsive to technology. Bearing in mind that any individual teacher is likely to use a range of different approaches to encourage learning, the following approaches to organising learning activities in and beyond the classroom, will be evident when a teacher has a bias towards directing learning through technology. Characteristics of some teaching with technology include:

- integrating technology, such as interactive whiteboards, VLEs, class response systems, subject specific software and internet-based resources, seamlessly into the classroom pedagogy;

- facilitating reward, reinforcement, stimulation and celebration (behaviourism);

- supporting communication with the learner including in the classroom and out of the classroom (social constructivism);

- supporting learner communication with each other - leading to cooperation, collaboration and camaraderie (social constructivism);

- creating opportunities for socially-constructed representations of understanding, through wikis, forum and shared documents (social constructivism);

- encouraging learner autonomy and initiative through choosing when, how and what to learn;

- providing ways of exploring ideas and concepts; providing mind tools to aid presentation of ideas (cognitivism); and

- enabling control over systems through programming and scripting; developing understanding through quiz writing and presentations (constructionism). 
Below is a series of vignettes set in classrooms or other learning contexts. Each of them illustrates at least one of the situations, often more than one, in which a teacher has chosen to utilise technology in order to help the learners in each case achieve the learning outcomes set for the teaching. These vignettes are designed to ground the models, theories and principles of learning in the practices of current technology-enabled teaching.

\section{Computer mediated collaboration}

In this example of technology-enabled learning in practice, the teachers are encouraging social interaction and dialogue between learners relating to e-safety issues using a conventional online chat room. The work is carried out making use of online websites related to e-safety and then using a computer-mediated dialogue via the medium of a closed chat room. The vignette illustrates a range of approaches to teaching that fall within the general area of supported social learning. It also illustrates that learners can operate in two media at the same time; they are creating presentations as well as simultaneously engaging in conversations within the chat environment.

The work took place with a group of mixed ability, mixed gender year 7 pupils in a large urban secondary school. For one teacher it was a development of work associated with her continuing professional development. The activity was part of the PSHE programme; learners were being given the 'opportunities to research, interpret and use a wide range of sources of information to inform their decision-making. This includes looking at the ways in which different media portray young people and health and social issues and present a balanced or partial view of issues', (QCDA, 2007:250). The National Curriculum continues, 'internet safety should be addressed explicitly'.

The traditional approach for the exercise is for pairs of pupils to independently create an e-safety presentation based upon the teacher's presentation and exploring pre-assigned websites. The development of this idea superimposes the element of dialogue between pairs of pupils during the exploration, design and production phases of the activity. The teacher's exposition on e-safety was carried out during the preceding lesson.

The aim of the activity is to increase the learners' awareness of e-safety issues. The outcomes of the lesson, by which the learners' engagement can be measured, included: attentive listening to the presentation; on-task examination of websites; contribution to the online chat and the detail of the presentation produced.

The learners were individually subscribed to a private (bounded) chat room where only they and the teacher could read or write comments. The teacher, prior to the lesson, sent the first messages in the chat room. These initial messages described the activity and the provided the URLs of the e-safety websites. The group entered the classroom, logged on and entered the chat room.

Where learners were uncertain about the process, they were able to check or ask within the chat environment. The teacher discouraged physical chat in the room so that the dialogues were all online. After experiencing several lessons with different groups, the teacher devised a set of rules relating to teacher online interventions:

- intervene through the chat room wherever possible;

- unless there is a health or safety or school discipline issue, never intervene physically;

- provide timed instructions through chat that are copy and pasted from a pre-written file;

- when appropriate, sending positive statements (rewards, compliments, acknowledgements);

- when appropriate, sending suggestions/ideas (modelling answers);

- encourage non-participants by asking them closed questions in the first instance; and

- guide off-task participants by asking them closed questions in the first instance.

Towards the end of the lesson the learners were encouraged to send copies of their e-safety rules, slogans or comments. In the final stages the teacher made plenary-like summary statements relating to e-safety.

\section{Commentary}


This vignette illustrates a range of approaches to teaching that fall within the realm of technology-enabled social learning. Dialogue mediated through technology, over large distances can be as effective (Bernard et al, 2004; Barak and Block, 2006; Danet et al, 1995; Freiermuth and Jarrell, 2006; Grigsby, 2001; Kordaki, 2005; Richards, 2003). The key pedagogic features of the activity are:

- teacher regulation of learning;

- computer mediated communication;

- differentiation by intervention (potential for strategic intervention);

- formative and informal assessment;

and some potential features are:

- peer assessment;

- celebration of learning;

- ICT skills development;

The teacher regulation in this vignette is strong. The learning outcomes are relatively fuzzy - being better aware of the issues of e-safety. The measure of whether learning has taken place is unlikely to be a postexperience test of facts. The measure is more likely to be an informal teacher assessment of learners' attitudes along with some judgement of understanding based upon the learners' responses during the activity. There is a need for strong teacher regulation of learning which takes the form of: determining the topic area, controlling the pace, intervening if learners are off-task or not fully engaged and finally, devising and delivering the plenary.

Computer mediated communication is supported by social networking sites, virtual learning environments and a wide range of Web 2.0 technologies. In a later vignette, a 3Di environment is used to support learning through social interaction. As described previously (see Figure 34), there are 10 potential routes of discourse. The chat room form of computer-mediated communication does no provide 'closed' communication and the number of routes is therefore limited. They include:

- teacher to the whole chat room;

- teacher to an individual learner (but open - readable by all);

- learner to the whole chat room;

- learner to the teacher (but open - readable by all); and

- learner to individual co-learner (but open - readable by all).

The traditional classroom has all these forms of communication between teacher and learners and learners with each other and each serves its particular purpose in classroom management (managing the resources of learning), behaviour management and curriculum management (regulation of learning). There is a high degree of complexity of human-human communication by verbal and non-verbal means and 'closed' communication between individuals can take place without others being aware of the content. The sophistication of communication in the traditional classroom is high but in this basic chat room scenario, there is no potential for 'closed' communication between individuals.

\section{Sustained online learning}

This vignette describes a technology-enabled learning experience that delivers a complete 3-year undergraduate BA (Honours) degree with no face-to-face element called 'Learning Through Technology' through Ultraversity at Anglia Ruskin University. It is a part-time and distance learning programme with a typical online learning commitment of 15-20 hours per week. The programme is work-based with students using their day-to-day experiences as the context for their academic pursuit and assignment submissions. All teaching is delivered online and, like most traditional programmes, students are assigned personal tutors who oversee course content, progress and achievement. The online community of fellow students is an important element of the learning experience. 
The features of this form of technology-enabled learning that are worthy of note are: the sustained nature of the learning, the high level of academic pursuit and the methods of evidencing attainment.

\section{sustained learning}

For sustained learning to be successful there needs to be a high level of commitment on behalf of the learner and the appropriate structures in place to support that commitment. The structures are both of a physical nature (the online environment) and those of policy (the procedures and expectations of the system).

The programme is supported by a number of technologies, each designed for a particular purpose in the learning experience and they include commercial and open-source resources. For example, there is a Facebook presence and they use Google Docs for collaboration and communication. For the anonymised submission of work and its processing through the assessment, second marking and moderation processes they use the open source virtual learning environment Plone ${ }^{\circledR}$ (http://plone.org) running on the University's servers. They use the commercial product First Class ${ }^{\circledR}$ (http://www.firstclass.com) for communication both through email and by sharing documents. It is a "single system" approach with the features and capabilities necessary to enable communication, collaboration, and learning for the post-16 and higher education student. The tutors and students use mobile telephones and conference calls to communicate.

Personalisation is a strong feature of the underpinning policy. The policy is reflected in the nature of assignments and the way in which assignments are assessed. They are reflected in the activities and the underlying core curriculum that focuses on:

- enabling students to take charge of their professional development and devise strategies to do that;

- developing skills of action inquiry situated in their working context;

- promoting capability to commit to lifelong learning;

- promoting a positive and flexible attitude to change;

- raising self-awareness and the student's recognition of his/her abilities; and

- providing the knowledge and understanding to help the students influence change.

The students' commitment to sustained learning is promoted through these curriculum aims.

\section{academic pursuit}

The high level of academic pursuit is a particular feature of this technology-enabled approach. To ensure that the learners can operate at undergraduate level there needs to be mechanisms in place that accommodate learning and assessment that is above the knowing and doing level of cognition, but can support the analysis, synthesis and evaluative levels (Bloom and Krathwohl, 1956). The students are required to: analyse and evaluate their learning experiences and requirements; research appropriate sources to gain knowledge and skills; develop, plan and implement projects; and communicate effectively at a range of levels within the workplace. The challenge of technology enabled teaching is to prevent the curriculum being dumbed down by the requirement to express every iota of the teaching in words on web pages. One is the assessment model, which is discussed below. The other is to make the learning environment and the activities 'situated' (Lave \& Wenger, 1991), i.e. embedded in the real world of the work-base context and the academic world of authoritative online resources. The students learn in learning communities based on the concept of a 'Community of Practice' (Wenger, 1998) where they have continual and required contact with peers and others operating at the high academic level.

\section{assessment method}

The materials the students make available for assessment are placed in an e-portfolio. The model of presentation is based upon Richard Winter's 'patchwork text' (Scoggins \& Winter, 1999, Winter, 2003) where writing and resources develop throughout the module as small 'patches', which are then stitched together, typically with a reflective commentary. The overall effect is summarised by a single document that describes the issues and conclusions but also makes direct reference to the evidence. Patchwork text is the assembly and stitching of text and is described as a 'coming to know' or 'making sense over time' (Winter 2003:120). 
The approach builds in the sharing of draft patches for peer formative feedback ('peer review'). A feature of patchwork writing is that it is continuingly developmental and never finished in a similar way that socially constructed understanding is an organic process and never ends as each person contributes their understanding to the collective.

\section{Commentary}

Technology-enabled learning is being influential in the lives of those in education. This vignette describes a project that has implications for social justice. The course 'was based upon the premise that conventional models of study at university fail to meet the needs of a significant number of potential students and their employers' (Powell et al, 2008:63). Stephen Powell, in his analysis of the course, observes that for a significant group of students face-to-face attendance can be perceived as too expensive and has employment issues. The vignette also illustrates how technology can empower learners at-a-distance to engage in cooperative and collaborative work leading to socially-constructed understanding. The use of technology enables a wider use of media in the production of work for assessment and they have developed the model into 'Patchwork Media' (Arnold, Williams \& Thompson, 2009). It should be noted that 'an increasing number of students report that they are making use of an iPhone Application version of FirstClass Client to access and communicate - in addition they are using internet enabled handhelds generally to access the course'. The third important aspect of technology-enabled teaching is that it builds the capacity for sustained and lifelong learning. The technology accommodates 'Assessment for Learning' (Black \& Wiliam, 1998a, 1998b) and indeed could be seen as 'Assessment as Learning' (Boud \& Falchikov, 2005; Carless, 2007). This approach builds the student's capability for effective self-assessment, a vital component of lifelong learning and 'sustainable assessment' (Boud, 2000; Boud \& Falchikov, 2005).

This approach to teaching, in which the learners have little or no face-to-face contact with the teacher, tutor or trainer, may come to our schools reflected in the support we give to some pupils for some of their courses.

\section{Teaching in the virtual world}

Drury University in Springfield, Missouri, USA is an independent university with a strong investment in online education. Traditionally, Drury's online courses are conducted using a learning management system (presently Blackboard) to deliver content. However, the Online Education directorship are interested in pioneering an opportunity to increase the immersive quality of distance courses for participants and to foster a sense of community spirit amongst geographically distributed learners by enhancing some courses with a 3D immersive Virtual World (3DiVW) component. Second Life ${ }^{\circledR}$ is the chosen delivery platform owing to it’s affordances in terms of: accessibility; multi modal communication facilities; and advanced user content creation opportunities. In preparation for the shift to 3DiVW, Drury University's Online Education e-Tutors require professional development and guidelines in order to transition course materials and teaching strategies away from the familiar 2D computer mediated model of the learning management system toward a framework that supports the potential of the learning environment presented by Second Life ${ }^{\mathrm{TM}}$.

Every Tuesday morning at 11.00 am (CT) the Drury's e-Tutors follow structured activities of professional development in training events conducted within the virtual world. This synchronous programme covers course design based on an understanding and application of the Cybergogy of Learning Archetypes. Introducing the e-tutors to cybergogy takes place in stages. Initially, the 'Efficacy Analysis Matrix' (EAM) is introduced as a pragmatic measure to assist e-tutors to discerningly evaluate the overall effectiveness of delivering content using Second Life ${ }^{\circledR}$. Use of the EAM provides a preliminary opportunity for e-tutors to critically analyse the environment for implementation of specific learning activities in terms of three key aspects:

Conjectured effectiveness for learners;

(is the use of Second Life gratuitous?)

Feasibility of implementation and management; and

(is the activity sustainable in the environment?)

Viability of content quantity and quality.

(can the learning activity produce the desired learning outcomes in a timely, economic manner?) 
The objective is to encourage e-tutors to re-examine their syllabus under the lens of Second Life $®$ and to exploit opportunities which can enhance their teaching by providing a learning experience with a greater level of immersion than by other means available and to identify incidents where straightforward delivery by conventional virtual learning environments (VLE) would be more effective therefore minimising counter arguments that Second Life is being used frivolously or without substantiation. Then the e-tutors identify the two interacting components, Learning Domains and Learning Archetypes. Learning Domains are strands drawn from real world understanding of pedagogy and cover the four areas of cognitive, emotional, dextrous and social learning designed to draw forth all of a person's sensibilities into the virtual environment. The Learning Archetypes are the activities with which the learners' avatars engage when in the virtual world; they act as a vehicle toward attaining a condition of immersion. The e-tutors establish learning outcomes by identifying the learning domain and selecting the learning archetypes to best achieve the outcomes. Further details of the theory of cybergogy (pedagogy in the virtual world) are described in chapter 4.

The Drury University e-Tutors are developing learning activities, for example:

Role-plays: Social Psychology Instructor, Fenix Muhindra, introduces students to experimental gender exchange in Second Life. Students are required to remodel their avatars from female to male and visa versa and to role-play a transposed sexuality role reporting on their thoughts, feelings and experiences as such and on any interactions they encounter whilst in character.

Peregrination: Arab Israeli Conflict studies Instructor, HG Vayander, takes students to sites in Second Life such as The Western Wall (or Wailing Wall) where a prayer can be written and delivered from the virtual world to be placed in the crevices of the real wall in Jerusalem. Orthodox traditions extend from the real world into Second Life, women (female avatars) are not allowed to pray at the wall but are to remain behind a barrier at the location.

Simulations: Astrology and Physics Instructor, Orion Haystack, uses virtual telescopes to simulate the use of powerful real world telescopes to view images of star formations, asteroids, comets and such. Importantly, these are not web-based images; the learning experience is available purely from within the Drury island within Second Life.

Meshed: The social constructivist aspect of the meshed archetype is employed during the orientation of Drury's Online Education students new to Second Life conducted by Samaj Susanowa. They are brought together by semester to network, collaborate and learn from each other. With the support of instructors they learn basic skills of dexterity by imitation to support their in-world learning activities. Students are encouraged to form affiliations, join groups and personalise their avatars. Communication skills (voice, instant messaging and local text-based chat) are honed during this time. Students experiment with adjusting their computer system settings to deliver an optimum virtual experience.

Assessment: All instructors carry out formative and summative assessments virtually, using tools for surveys, presentations, and assignment submissions.

Drury University's e-tutors final assessment requires them to participate in six hours teaching practice within the virtual world as virtual tutors (v-tutors). This consolidates their conceptual realignment to the ways of teaching and learning in the virtual world. They are immersed in the 3Di environment, the model of cybergogy and the v-teaching practices. This maximises the potential of the tutors' ability to 'splice teaching and learning away from classical methods of online delivery of education and training' (Scopes, 2009:19) to present learning opportunities that are unfettered by real life constraints.

\section{Commentary}

The social constructivist model of cybergogy of learning archetypes is identified as being the most pertinent deriving philosophically from the Vygotskian socio-cultural approach of knowledge internalisation supported by social processes leading to the development of higher cognitive functions. Virtual world learning is enabled through the new pedagogy called cybergogy. It enables the unique features of the virtual world to provide immersive experiences that would otherwise be too expensive, dangerous, remote or unimaginable using conventional pedagogy. 


\section{Using authoring to increase learner engagement}

This vignette describes how learners can be more engaged with the knowledge associated with their learning by creating quizzes for others to complete. In this particular scenario, the learners are key stage 2 pupils but this strategy works easily well for older learners producing quizzes for peers, younger people or another defined audience. The pupils use an online quiz programme provided through the school's VLE. The activity promotes a deeper knowledge and understanding of the topic of the quiz and creates a focus for collaboration between pupils and a better understanding of the subject matter.

The series of lessons relate to providing an overview of of how British society was shaped by the movement and settlement of different peoples in the period before the Norman Conquest and an in-depth study of how British society was affected by Roman or Anglo-Saxon or Viking settlement. The teacher's planning includes this statement:

Introduce the pupils to the quiz writer in the VLE, demonstrate the entry of a single question and save to the 'sandpit'; explain that in the 'sand pit' their quiz can be looked at and changed by other pupils - do not look at someone else's nor make changes without their permission. Talk about the different sorts of questions and the best type to be used giving examples. Break into pairs to plan quizzes on the assigned topic of 'Romans', ' Saxons' or 'Vikings'. Remember, the audience for your quiz are the other groups.

The National Curriculum for History at Key Stage 2 includes, 'Romans, Anglo-Saxons and Vikings in Britain. Effects of Roman settlement: the Roman Conquest and occupation of Britain; Boudicca, Caratacus and resistance to Roman rule; the building of Hadrian's Wall, roads, villas and towns by the Romans; Roman settlement in the local area. Effects of Anglo-Saxon settlement: the arrival and settlement of the Anglo-Saxons; the conversion to Christianity, the lives of monks and nuns, for example Bede and Hilda; religious beliefs and customs, including the Sutton Hoo and other ship burials, and myths and legends; Anglo-Saxon settlement in the local area. Effects of Viking settlement: Viking raids and settlement; King Alfred and Anglo-Saxon resistance to the Vikings; King Cnut and the Danes; Jorvik and other Viking settlements; heroic poems and sagas; Viking settlement in the local area' (QCA, 1999:19). These words are the starting points for the text and questions of the quizzes.

At the end of the activity the teacher has a number of quizzes - 5 on Romans, 5 on Saxons and 4 on Vikings. These are teaching resources for the future as well as the focus for the 'compare and contrast the historical developments' activities for the current group.

\section{Commentary}

The learning outcomes the teacher was aiming for were that pupils 'show factual knowledge and understanding of aspects of the history of Britain... describe characteristic features of past societies and periods... identify changes within and across different periods... describe some of the main events, people and changes... give some reasons for, and results of, the main events and changes', (QCA, 1999:39).

The classroom environment and limits on the access to computers did not permit extensive online research and compilation of information. If more computer time is available then the further attainments specified by the National Curriculum may be achieved - 'beginning to select and combine information from different sources... produce structured work, making appropriate use of dates and terms' (QCA, 1999:39).

The reaction of pupils to the writing of quizzes is mixed. They are motivated by the topics and would like to create a quiz but the quiz writing mechanism is rather complex and not particularly intuitive for the pupils. They do not necessarily have the same frustrations when authoring crosswords or quizzes by hand. There is time lost because some pupils find it difficult to grasp the value of the different question types. The outcomes for the successful are very good. They gain in three important ways:

- they better understand the structure and mechanisms of quiz making and so have a mind tool for future use;

- they can reflect their knowledge and understanding of the topic in a creative and rewarding way; and

- they create a product that has real value for the class and the teacher.

The teachers' observations include: 
- it is important to explain the different question types particularly the popular multi choice and short answer questions;

- to add value to the activity pupils need to be encouraged to add text to the question to set it in a context; (for example, the question, who led the Britons against the Roman invasion? is not as valuable as 'In 43 AD the Romans landed on the shores of Britain. They conquered many tribal groups but allowed the kings to rule their own areas. Some people were not treated well by the Romans and they revolted. Who led the Celts against the Romans during that time?)

- pupils needed to be taught how to create plausible wrong answers for the multiple choice questions; (for example, the choices: Minnie Mouse, Dracula, Boudicca, Madonna and Jedward, are not as good as: Bede, Hilda, Boudicca, Caratacus and King Cnut.) and

- the teacher must continually and rigorously check the authoring of the questions and answers to prevent pupils being exposed to other's errors and misconceptions.

It is that thinking which is critical to the value of authoring for understanding and the basis of the constructionist approach. An important feature of some quiz writing applications is the ability to allow the learner to 'mark their own work' enabling the quiz to become a teaching tool in the spirit of 'assessment for learning' (DfES, 2005; Black \& Wiliam, 1998a, 1998b).

Feedback is an important aspect of all learning theories. The behaviourist approach suggests that being rewarded for obtaining the correct answer will reinforce the appropriate actions, The constructivist sees it as an essential aspect of knowing that the developing model is correct. The social constructivist will want the language dialogue extending beyond the learner-computer but within itself, that exchange is reinforcing of the learner's understanding. The quiz authoring itself is a constructionist activity and the software system is a mind tool supporting cognitive approaches.

The feedback from the quizzes in general takes several forms. The simplest is the pupils seeing whether they have individual question right or wrong. Sometimes a scoring system can award marks to individual questions thus allowing harder questions to be weighted higher than easier questions. The final score can indicate overall performance. That score can be automatically e-mailed to the learner completing the quiz or to the teacher. The most sophisticated feedback records log files tracking the performance of the individual on each separate question, the time taken to complete the activity and the name (identifier) of the computer used.

\section{Professionals learning in the virtual world}

This vignette focuses on the use of a virtual world in postgraduate teacher training. Features of the experience include: the physical location of the activity is the trainee's choice; elements of the activities are new to every participant; trainees have to adopt an avatar to represent themselves; activities develop skills relating to dexterity and peregrination. There are challenges for teaching and learning in particular virtual world environments but these activities provide experiences that enhance trainee teachers' skills, knowledge and understanding of 3Di and technology-enhanced learning in general. This vignette is described by a small selection of the comments made by trainees following their first visit to Second Life.

This first experience of a multiuser environment inspires some trainees...

'I created and avatar called 'Teaching ******. It was a valuable experience as I had not been to Second Life before... I then made my way to the public sandbox along with other members of the PGCE. From there I tried to manipulate and build objects... I feel that there is more potential in Second Life than I had originally perceived. I think it would useful as a long distance learning tool/environment. Because it is more stimulating than chat rooms or groups (good for students that need both visual and audio tools to learn), and it's more personal than instant messaging.'

Others met technical difficulties or challenges with the interface...

'Second Life was interesting and whilst I was unable to navigate around the world, I did watch some of the interesting tutorials on the things that you could do whilst in the environment. This experience allowed me to gain an insight into why it is so hard to engage the pupils with ICT teaching, and maybe this sort of virtual world could be a way to engage them more.' 
'With instant message help, I succeeded in uploading my picture and adding it as a texture to a box primitive.'

Participants were able to reflect upon the affordances and challenges of virtual world teaching.

'The major issue was finding the PGCE IT Staffroom and as a result, the other problem with exploring environments - it is easy to waste time!'

'The positive aspects of the day were using new software such as Second Life, which has been extremely time consuming, but has shown me that working collaboratively, I was able to grasp the basics and get on with the product. I can see that introducing a new piece of software in a classroom would need to be done in stages, with guideline and help rather than making it a self taught class. So pupils, like me, would get frustrated with the seemingly unhelpful screen in front of them.'

There are a number of reported technical difficulties with the Second Life application. The frequency and nature of those difficulties is significant and should be considered when planning a virtual world teaching session for the first time. Finally, a comment on the immersive nature of working in virtual worlds...

'For some reason I could not teleport and after much help from Light Sequent and John I still could not follow the others. I recall a moment when Light Sequent said to me 'Don't worry I wouldn't leave you alone', which made me giggle. How silly I thought 'its only Second Life'. Eventually Light Sequent did have to leave me alone due to her commitments to the group, and I can honestly say for a spilt second I actually did feel abandoned. Then after 10 minutes of waiting for teleportation I felt a little lonely. Feeling these emotions made me realise the full potential of building and maintaining relationships in Second Life. I felt the same frustration and disappointment about not being able to join the rest of the trainees as I would have if I had been locked out of or stopped from entering a room during a training session at University'.

'This emotional response is an expression of 'immersion' with the environment. Personally, I view this as an extremely healthy experience, especially at such an early stage of adoption... this example serves to demonstrate how easy it is to both project and perceive a personal presence in the virtual world... this is a powerful tool for teachers indeed' (Woollard and Scopes, 2010:4).

\section{Commentary}

The popularity of online gaming, the demonstrable value of interactive programs for teaching and training and the growing potential for teachers to design and build their own 3Di environments, makes an imperative that teacher training includes experience of virtual worlds such as Second Life (http://secondlife.com). An online day where trainees work on their computers, in their work or home environment, offers many opportunities for them to be independent and personalise their own learning. As noted by Kristen Moore and Ehren Pflugfelder, there is a need for pedagogical and technological scaffolding in preparation for taking students into online environments if they are to function as 'fun and creative spaces' (Moore and Pflugfelder, 2010). The significant challenges are of a technical nature but the structure and resourcing for the online day must be considered so that individuals do not feel isolated or unsupported. Subsequent visits elicited an increase in positive impressions as the students began to feel less estranged in the virtual environment. The third and final Online Day is structured to give the students a choice of peregrination activities consisting of matched pairs of in world locations that present contrasting experiences. Trainees are asked to consider the locations in terms of the impact on each of the 4 Learning Domains discussed in the cybergogy sections, Cognitive, Emotional, Dextrous and Social.

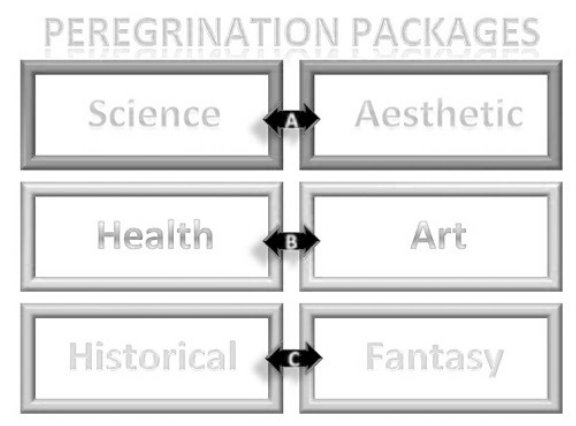

Figure 42 Three contrasting peregrination choices 
Comments made by the trainee teachers following this activity:

'The Particle Accelerator activity was graphically impressive and probably a very good illustration for a pupil, however the accompanying text was much too high level to be of any practical benefit. The graphics at this point however, were some of the best seen so far in a virtual environment'.

'Overall this learning experience encountered problems, yet there is merit to it, as technology and internet speeds develop, I see this as a viable learning platform'.

'The potential to stimulate learning is immense'

'It has a really WOW factor, with opportunities for gathering information that exceeds real life'.

'I found this room intriguing, I assumed that this sort of set up could be used for video conferencing, amazing! This would be so much cheaper to set up and run than standard video conferencing suites for schools and so widen the opportunities for pupils'.

'It feels a bit strange walking around an environment where you don't actually know the social rules, and the social rules are definitely an area that needs to be defined in an online virtual environment when considering the mental and physical wellbeing of pupils'.

'This is my third visit to Second Life and whilst still a little unsure of how to do things, I feel confident in my ability to move around and manipulate the environment. I think that initially pupils would need some help with the interface, they would soon be comfortable with using it'.

'The Lost Gardens of Apollo was the first site I visited and is clearly the aesthetics focussed site of the two packages. It was a very beautiful site and gave you a clear sense of visiting another, cohesive world'.

'In terms of how it lends itself to learning, if we start with how it may allow us to stretch our cognitive capabilities, well a possible use for this kind of environment would be one of simple exploration'.

'The social and aesthetic quality of such a task would lend it to being an emotional experience. All of these learning threads should allow for improved learning and recall due to the multi faceted ways of encoding the learnt information through the rich experience'.

'I really enjoyed that environment [art]. Some of the pieces were lovely. In the Art environment I was pleased to learn how to jump and move forward so that I could scale a wall. I was surprised when I found I could fly and walk through windows'.

'The most striking exhibit I found to be the 'hiding place', which oozed of claustrophobic dread. The authentic photo was poignant'.

'Despite the occasional technological glitches, I am very positive about the affordances of SL for teaching and learning as a forum for tolerance, information and knowledge exchange, and a locus of practical creative learning, all of which can happen in a collaborative engaging manner'.

'The holocaust museum was effective on a cognitive level. There was a lot of information on the notice boards that made you think. I found the fantasy environment very peaceful and calming'.

\section{E-safety in learning and teaching}

This vignette describes one school's initiative to raise the profile of e-safety with parents as well as give clear information, advice and guidance to pupils. In Glenwood School e-safety is coordinated by the ICT subject leader but involves the pastoral teams, the teacher responsible for child protection and sessions taking place in PSHCE as well as ICT lessons.

'E-safety is a whole school issue' was the opening remark; the head teacher goes on to explain the importance of the staff development day and the strategies that were being put in place to ensure the safety and wellbeing of pupils and staff with regard to the use of all forms of technology in teaching, administration and personal use.

The training session was designed around Tanya Byron's analysis based on the 3'C's of pupil content, contact and conduct (see below). Through small group discussions, individual tasks, and whole staff plenaries, the 
school has developed a shared understanding of the issues of e-safety, the resources available, the procedures and policies in place. Most importantly, the session ensured that the teachers had confidence that they, as well as the pupils, will be supported if e-safety issues arise.

\section{Commentary}

It is noted that children online are less risk-averse in their dealings with others. 'Over 75 percent of Internet users feel safer speaking their mind when they use an avatar' (Meadows, 2008: 36). They feel safer and speak more readily with those that they do not know in the physical sense but only know in the virtual world. 'The lack of contextual clues frees up social inhibition but also loosens commitment and trust' (Shortis, 2001:97). They more readily confide secrets and more readily expose themselves in both a physical way (Jenny's Story, 2005) and in a verbal way. Mark Meadows describes the avatar as a tool for regulating intimacy because intimacy and interaction with others is more easily controlled. In real life it can be difficult to remove oneself physically from uncomfortable positions but in the virtual world 'isolation' or 'home' is always just a mouse click or key press away. But, as Mark Meadows explains, 'in a world where information is more important than physical proximity, we are not as safe as we might assume... I have seen some extreme tragedies unfold because of the assumption of the mask... because we can immerse ourselves more and more into these environments we let our guards down' (Meadows, 2008: 36). Ringo Ma's study of student use of bulletin boards reveals that participants disclose personal information without acknowledging the consequences of that disclosure (Ma, 1996). The Byron Review in the UK identified an important element of education with regard to e-safety as developing children's hardiness in the face of inappropriate and potentially damaging materials and contacts that the internet presents. The report of the review states, 'we must also build children's resilience to the material to which they may be exposed so that they have the confidence and skills to navigate these new media waters more safely' (Byron, 2008:8). In terms of the model presented by Freud, we need to ensure the motivations of the Id whilst sometimes repressed and modified through the Ego by social mores ensure the learner behaves in a safe way. Freud's 'cap of hearing' is the key. We have to ensure that the learner has the opportunity to 'hear' clear and actionable information about their online lives. The 'hear' includes seeing appropriate behaviour by peers and models, experiencing appropriate scenarios, being rewarded for behaving appropriately as well as being given appropriate information, advice and guidance. The 3 ' $\mathrm{C}$ 's of content, contact and conduct, that Byron proposes helps guide the provision of information, advice and guidance to learners.

\begin{tabular}{|l|l|l|l|l|}
\hline & Commercial & Aggressive & Sexual & Values \\
\hline $\begin{array}{l}\text { Content } \\
\text { The learner is subject to } \\
\text { the inappropriate activity. }\end{array}$ & $\begin{array}{l}\text { The learner needs to be } \\
\text { understanding of and } \\
\text { resilient to advertising, } \\
\text { spam, sponsorships and } \\
\text { demands for personal } \\
\text { information. }\end{array}$ & $\begin{array}{l}\text { The learner needs to be } \\
\text { resilient to violent/hateful } \\
\text { content and know how to } \\
\text { deal with it. }\end{array}$ & $\begin{array}{l}\text { The learner needs to be } \\
\text { resilient to pornographic } \\
\text { and unwelcome sexual } \\
\text { content. }\end{array}$ & $\begin{array}{l}\text { The learner needs to be } \\
\text { able to identify bias, } \\
\text { racism, misleading } \\
\text { information and advice. }\end{array}$ \\
\hline $\begin{array}{l}\text { Contact } \\
\text { The learner is a participant } \\
\text { in the inappropriate } \\
\text { activity. }\end{array}$ & $\begin{array}{l}\text { The learner needs to be } \\
\text { aware of tracking, } \\
\text { harvesting and the } \\
\text { protection of personal } \\
\text { information. }\end{array}$ & $\begin{array}{l}\text { The learner needs to be } \\
\text { resilient to being bullied, } \\
\text { harassed or stalked and } \\
\text { know what action to take } \\
\text { in such situations. }\end{array}$ & $\begin{array}{l}\text { The learner needs to } \\
\text { understand the } \\
\text { implications of meeting } \\
\text { strangers and being } \\
\text { groomed. }\end{array}$ & $\begin{array}{l}\text { The learner needs to be } \\
\text { resilient to unwelcome } \\
\text { persuasions. }\end{array}$ \\
\hline $\begin{array}{l}\text { Conduct } \\
\text { The learner is initiating the } \\
\text { inappropriate action. }\end{array}$ & $\begin{array}{l}\text { Learners must be given } \\
\text { clear guidance with regard } \\
\text { to illegal downloading, } \\
\text { hacking, gambling, } \\
\text { financial scams and } \\
\text { terrorism and understand } \\
\text { the consequences of such } \\
\text { actions. }\end{array}$ & $\begin{array}{l}\text { Learners must be given } \\
\text { clear guidance with regard } \\
\text { to bullying or harassing } \\
\text { another and understand } \\
\text { the consequences of such } \\
\text { actions. }\end{array}$ & $\begin{array}{l}\text { Learners must be given } \\
\text { clear guidance with regard } \\
\text { to creating and uploading } \\
\text { inappropriate material and } \\
\text { understand the } \\
\text { consequences of such } \\
\text { actions. }\end{array}$ & $\begin{array}{l}\text { Learners must be given } \\
\text { clear guidance with regard } \\
\text { to providing misleading } \\
\text { information or advice and } \\
\text { plagiarising material. }\end{array}$ \\
\hline
\end{tabular}

Figure 43 Content, content and conduct aspects of e-safety, based on Byron (2008:16)

In Freud's world there is an important factor that modifies behaviour - it is the sex drive or libido. Freud's assertion is that repressed sexual drive leads to problems in later life. By articulating this explanation of human behaviour, Freud has been criticised for allowing some to excuse their behaviours and the behaviours 
of others rather than taking direct responsibility for their actions. The e-safety issue is brought into sharp focus because of the combined effect of:

- younger users of the internet feeling freer and more able to express themselves in a sexual way including their representation on social networking sites and their use of MMS (sexting); and

- the actions of paedophiles, bullies and stalkers who are freed by anonymity and false identity and an 'exhaustive potential to contact potential victims' (Powell, 2007:113) to groom, victimise and solicit on the internet.

The approach for to e-safety in this area is twofold; it is one of information and the other of guidance. There needs to be a clear and firm message about acceptable behaviour, reasonable behaviour and a explicit code of conduct. Schools adopting such procedures are more likely to impact upon children's behaviour. The 'acceptable use policy' (AUP) is the response that many schools use with both pupils and teachers. The acceptable use policy, along with classroom-based codes of conduct, are ways in which the social mores can impact upon the learners' decision making.

- philosophical motivation/corporate message about the underlying values;

- rationale for network and internet access;

- advice and instruction for appropriate patterns of use (netiquette);

- advice and instruction for expected patterns of use;

- declaration of the importance of self-regulation and personal responsibility;

- statements regarding legal requirements

(including computer misuse, protection of personal data, copyright and obscene materials); and

- description of consequences of violating the policy including punishments and appeal procedures.

Figure 44 Essential elements of acceptable use policies

Two years after the publication of the Byron Review Tanya Byron, at the invitation of the UK government, comments on progress; she confirms the UK as the world leader in child internet safety but advised that 'Government and Industry need to make faster progress in delivery if the UK is to stay ahead of advances in technology' (DCSF, 2010) and identifies the 'Zip it, Block it, Flag it' public awareness raising aimed at parents as a particular success (see below). However, there still remains the issue of many mainstream providers of resources and social networking not facilitating fast report mechanisms that would make children feel more secure and give information directly to the law enforcement agencies such as the UK Child Exploitation and Online Protection Centre - internet safety (CEOP, 2010) and parents condoning children's use of adult social networking sites such as Facebook (under the age of 13 years) and Second Life ${ }^{\mathrm{TM}}$ (under the age of 18 years).

\begin{tabular}{|l|l|l|}
\hline ZIP IT & BLOCK IT & FLAG IT \\
\hline $\begin{array}{l}\text { Keep your personal stuff } \\
\text { private and think about what } \\
\text { you say or do online }\end{array}$ & $\begin{array}{l}\text { Block people who send nasty } \\
\text { messages and don't open } \\
\text { unknown links and attachments. }\end{array}$ & $\begin{array}{l}\text { Flag up with someone you trust if } \\
\text { anything upsets you or if } \\
\text { someone asks to meet you offline }\end{array}$ \\
\hline
\end{tabular}

Figure 45 Click Clever Click Safe campaign, UK Council for Child Internet Safety

E-safety has to be a key consideration of any online educational activity. The impact of that consideration should not be to stop activities but to make those activities as safe as possible without unnecessarily impacting on the pedagogic value. The value of the VLE in providing that safe and secure environment is important. But, because of some of the limitations of the VLE, the value of access to the open internet is also necessary in the education of learners. It is therefore necessary to provide appropriate and repeated information, advice and guidance to learners. Only through the learner's own resilience can he or she becomes an independent and safe learner in the online and virtual worlds they will be exposed to in their education and personal lives.

\section{Activities}

Compare your teaching practice with one of the vignettes and consider how you could enhance teaching and learning by adopting the pedagogic or cybergogic principles. 
Consider how vignettes representing good teaching practice outside of the context of your teaching could be adapted and made usable by you, for example, as a primary school teacher, use a virtual world to explore ideas of travel.

Considering your own teaching, which aspect of your practice most fully integrates learning technologies? How could a vignette represent your teaching? 
4Mation (2010). Granny's Garden. Barnstaple, UK: 4Mation Educational Resources.

Abd El-Gawad, T. and Woollard, J. (2010). Embedding Quality in E-learning Systems; A Route to 'Classless Learning'. Paper presented at the INSPIRE XV e-Learning and Social Responsibility.

Abelson, H. (1982). Apple Logo. BYTE/McGraw Hill.

Acorn Computers (1993). The Horizon Project. Winchester, UK: Hampshire Microtechnology Centre.

Amey, C. A. (2007). Primary teachers' attitudes to Information and Communication Technology (ICT). in education Southampton, UK: University of Southampton Theses.

Anderson, L. W. and Krathwohl, D. R. (2001). A taxonomy for learning, teaching and assessing: A revision of Bloom's Taxonomy of educational objectives. New York, US: Longman.

Arnold, L., Williams, T. and Thompson, K. (2009). Advancing the Patchwork Text: The Development of Patchwork Media Approaches. The International Journal of Learning, (16)5, 151-166.

Askew, M., Brown, M., Rhodes, V., Wiliam, D. and Johnson, D. (1997). Effective Teachers of Numeracy: Report of a study carried out for the Teacher Training Agency. London, UK: King's College, University of London.

Atari (2010). Atari Museum: Historical Notes. Online. Available HTTP

<http://www.atarimuseum.com/computers/computers.html> (accessed August 1, 2010***).

Baby Toys (2010). Online. Available HTTP <http://babytoysandtoddlertoys.com/LeapFrogMyPalScout> (accessed August 1, 2010***).

Bailenson J. N. and Segovia, K. Y. (2010) Virtual Doppelgangers: Psychological Effects of Avatars Who Ignore Their Owners in Bainbridge W. S. (ed.), Online Worlds: Convergence of the Real and the Virtual, HumanComputer Interaction Series, London, UK: Springer-Verlag

Bailenson, J. N. and Yee, N. (2007). Virtual interpersonal touch: Haptic interaction and copresence in collaborative virtual environments. International Journal of Multimedia Tools and Applications, 37, 5-14

Bandura, A. (1977). Social Learning Theory. New York: General Learning Press.

Barak, A. and Block, N. (2006). Factors Related to Perceived Helpfulness in Supporting Highly Distressed Individuals through an Online Support Chat, Cyberpsychology and Behaviour, 9(1), 60-68.

Becta (2010). Impact of technology. Coventry, UK: Becta Online. Available HTTP <http://www.becta.org.uk/impact.php\#> (accessed August 1, 2010***).

Beetham, H. and Sharpe, R. (2007). Rethinking Pedagogy for a Digital Age. London, UK: Routledge.

Bernard, R., Abrami, P., Lou, Y., Borokhovski, E., Wade, A., Wozney, L., Wallet, P., Fiset, M. and Huang, B. (2004). How does distance education compare with classroom instruction? A meta-analysis of the empirical literature Review of Educational Research, 74(3), 379-439.

Black, P. and Wiliam, D. (1998a). Assessment and Classroom Learning. Assessment in Education, 5(1), 7-71 Black, P. and Wiliam, D. (1998b). Inside the Black Box: Raising Standards Through Classroom Assessment. Online. Available HTTP

<http://www.collegenet.co.uk/admin/download/inside\%20the\%20black\%20box_23_doc.pdf> (accessed August $1,2010^{* * *}$ )

Bloom, B. S. and Krathwohl, D. R. (1956). Taxonomy of Educational Objective Handbook 1 Cognitive Domain New York, US: Longman.

Bloome, D., Carter, S. P., Christian, B. M., Otto, S. and Shuart-Faris, N. (2005). Discourse Analysis and the Study of Classroom Language and Literacy Events: a microethnographic perspective Mahwah, US: Lawrence Erlbaum Associates. 
Bolliger, D. U., Supanakorn, S. and Boggs, C. (2010). Impact of podcasting on student motivation in the online learning environment. Computers and Education, 55 (2), 714-722.

Bono, de, E. (1967). The five-day course in thinking. New York, US: Basic Books.

Bono, de, E. (1985). Six Thinking Hats. Toronto, Canada: Key Porter.

Bono, de, E. (2007). How to have creative ideas. London, UK: Vermillion.

Book, B. (2006). 'Virtual Worlds: Today and in the future'. London, UK: British Computer Society. Online. Available HTTP <http://www.bcs.org/server.php?show=ConWebDoc.3336> (accessed August 1, 2010***).

Boud, D. (2000). Sustainable assessment: rethinking assessment for the learning society, Studies in Continuing Education, 22(2), 151-167.

Boud, D. and Falchikov, N. (2005). Redesigning assessment for learning beyond higher education. Research and Development in Higher Education, 28.

Brindley, S (2002). Teaching as professional inquiry: the importance of research and evidence In Ellis, $\mathrm{V}$ (ed). Teaching and Learning in Secondary Schools.

Brown, J. S., Collins, A. and Duguid, P. (1989). Situated cognition and the culture of learning. Educational Researcher, 18(1), 32-41.

Bruner, J. S. (1966). Toward a Theory of Instruction. Cambridge, US: Harvard University Press.

Bruner, J. S. (1990). Acts of Meaning. Cambridge, US: Harvard University Press.

Buckingham, D. (2001). After the Death of Childhood: Growing Up in the Age of Electronic Media. Oxford, UK: Polity Press.

Buckingham, D. and McFarlane, A. (2001). A digitally driven curriculum? London, UK: IPPR.

Bull, J. and McKenna, C. (2004). Blueprint for Computer-assisted Assessment. London, UK: RoutledgeFalmer.

Burton, D. and Bartlett, S. (2006). Shaping Pedagogy from Psychological Ideas in Kassem, D., Mufti, E. and Robinson, J. (2006). Education Studies: issues and critical perspectives. Milton Keynes, UK: Open University Press.

Byron, T (2008). Safer Children in a Digital World: the report of the Byron Review. London, UK: DCSF. Online. Available HTTP <http://www.dcsf.gov.uk/byronreview> (accessed August 1, 2010***).

Carless, D. (2007). Learning-oriented assessment: conceptual bases and practical implications. Innovations in Education and Teaching International, 44(1), 57-66.

Carrier, S. I. and Moulds, L. D. (2003). Pedagogy, andragogy, and cybergogy: exploring best-practice paradigm for online teaching and learning. Sloan-C 9th International Conference on Asynchronous Learning Networks (ALN) cited in Cronin et al, 2009.

CEOP (2010). The Child Exploitation and Online Protection Centre (CEOP). Online. Available HTTP <http://www.ceop.gov.uk> (accessed August 1, 2010***).

Chandler, D. (1984). Young learners and the microcomputer Milton Keynes, UK: Open University Press.

Chowdry, H., Crawford, C. and Goodman, A (2009). Drivers and Barriers to Educational Success Evidence from the Longitudinal Study of People in England London, UK: Institute for Fiscal Studies.

Churches, A. (2009). Bloom's digital taxonomy. Online. Available HTTP <http://edorigami.wikispaces.com/Bloom's+Digital+Taxonomy> (accessed August 1, 2010***).

Condie, R. and Livingston, K. (2007). Blending online learning with traditional approaches: changing practices. British Journal of Educational Technology, 38(2), 337-348.

Conole, G (2007). Describing learning activities in Beetham and Sharpe, Rethinking Pedagogy for a Digital Age. London, UK: Routledge. 
Conole, G. and Oliver, M. (2007). Contemporary perspectives in E-learning research: themes, methods and impact on practice. London, UK: RoutledgeFalmer.

Conole, G., Dyke, M., Oliver, M. and Seale, J. (2004). Mapping pedagogy and tools for effective learning design. Computers and Education, 43, 17-33.

Cook, J., White, S., Sharples, M., Sclater, N. and Davis, H. (2006) The Design of Learning Technologies. In, Conole, G. and Oliver, M. (Eds). Learning Technologies - Multiple Perspectives on an Emerging Field. Oxford: Routledge, 55-68.

Cranmer, S., Selwyn, N. and Potter, J. (2009). Exploring primary pupils' experiences and understandings of 'esafety'. Journal of Educational Information Technology, 14, 127-142.

Cronin, J. G. R., McMahon, J. P. and Waldron, M. (2009). Critical survey of information technology use in higher education -- blended classrooms. In Carla R. Payne Information technology and constructivism in higher education: progressive learning frameworks, (pp. 203-215). Hershey and New York: Information Science Reference ISBN 978-1-60566-654-9.

Cuban, L. (2001). Oversold and Underused: Computers in the Classroom. London, UK: Harvard University Press. Cunningham, M. and Harris, S. (2003). The Ever-Open Classroom: Using ICT to Enhance Communication and Learning. Slough, UK: National Foundation for Educational Research.

Curran, K., Kinney, S. M., Burns, F. and Meredith, G. (2006). Scheduled RSS Feeds for Streaming Multimedia to the Desktop Using RSS Enclosures. Consumer Communications and Networking Conference 2006. Las Vagas, US: IEEE. Online. Available HTTP <http://ieeexplore.ieee.org/xpl/freeabs_all.jsp?arnumber=1593029> (accessed August 1, 2010***).

Cuthell, J. P. (2002). Virtual Learning. Aldershot, UK: Ashgate.

Dale, E. (1969). Audio-Visual Methods in Teaching (3rd Edition). London, UK: Holt, Rinehart and Winston.

Danet, B, Wachenhauser , T, Bechar-Israeli, H, Cividalli, A and Rosenbaum-Tamari, Y (1995). Curtain Time 20:00 GMT: Experiments with Virtual Theater on Internet Relay Chat. Journal of Computer-Mediated Communication 1(2). Online. Available HTTP < http://jcmc.indiana.edu/issues.html> (accessed August 1, $2010 * * *)$.

DCSF (2008). The Assessment for Learning Strategy. London, UK: Department for Children, Schools and Families.

De Lucia, A., Francese, R., Passero, I. and Tortora, G. (2008). 'Supporting Jigsaw-Based Collaborative Learning in Second Life'. Online. Available HTTP

<http://delta4.dmi.unisa.it/francese/pubs/CR_ICALT08_232_delucia.pdf> (accessed August 1, 2010***).

DfES (2002a). ImpaCT2 The Impact of Information and Communication Technologies on Pupil Learning and Attainment. London, UK: Department for Education and Skills.

DfES (2002b). Key Stage 3 National Strategy Framework for teaching ICT capability: Years 7, 8 and 9. London, UK: Department for Education and Skills.

DfES (2003). Progress towards a Unified E-Learning Strategy. London, UK: Department for Education and Skills. DfES (2004a). Key Stage 3 National Strategy ICT across the curriculum. London, UK: Department for Education and Skills.

DfES (2004b). Progress towards a Unified E-Learning Strategy. London, UK: Department for Education and Skills.

DfES (2004c). Developing objective led lessons in mathematics. London, UK: Department for Children, Schools and Families. Online. Available HTTP

<http://nationalstrategies.standards.dcsf.gov.uk/downloader/10771718f524991286e7c52db63f4ec3.pdf> (accessed August 1, 2010***). 
DfES (2005). Working together: coaching and assessment for learning. London, UK: Department for Education and Skills. Online. Available HTTP

<http://nationalstrategies.standards.dcsf.gov.uk/downloader/bbf4ad0ddfebef6ab1ef24339f48e842.zip> (accessed August 1, 2010***).

DfES (2006). Assessment for learning Guidance for senior leaders. London, UK: Department for Education and Skills.

Donnelly, K. M. and Berge, Z. L. (2006). Podcasting: Co-opting MP3 players for education and training purpose. Online Journal of Distance Learning Administration, 9, 3. Online. Available HTTP

<http://www.westga.edu/ distance/ojdla/fall93/donnelly93.htm> (accessed August 1, 2010***).

Doyle, D. (2010). Immersed in Learning: supporting creative practice in virtual worlds. Learning, Media and Technology, 35(2), 99-110.

Dwyer, D. C., Ringstaff, C. and Sandholtz, J. H. (1990). Teacher Beliefs and Practices Part I: Patterns of Change The Evolution of Teachers' Instructional Beliefs and Practices in High-Access-to-Technology Classrooms: FirstFourth Year Findings. Cupertino, US: Apple Computer Inc.

ECDL (2010). European Computer Driving Licence. Online. Available HTTP <http://www.ecdl.com> (accessed August 1, 2010***).

Edexcel (2010) Diplomas in Digital Applications. Online. Available HTTP <http://www.edexcel.com/quals/dida> (accessed August 1, 2010***).

Edwards, A. D. and Westgate, D. P. G. (1994). Investigating Classroom Talk (Second Edition). London, UK: Falmer.

Ellis, V. (ed). (2002). Teaching and Learning in Secondary Schools Exeter, UK: Learning Matters.

Ellis, W. D. (1938). A Source Book of Gestalt Psychology. New York, US: Harcourt, Brace and World.

EPPI (2010). Why is it important to be systematic? London, UK: EPPI-Centre, Institute of Education. Online. Available HTTP <http://eppi.ioe.ac.uk/cms/Default.aspx?tabid=69> (accessed August 1, 2010***).

Erikson, E. H. (1968) Identity, Youth and Crisis. New York, US: Norton.

Felicia, P. (2011). International Journal of Game-Based Learning. Hershey, US: IGI Global.

Finlayson, H., Maxwell, B., Caillau, I. and Tomalin, J. (2006). Impact of e-learning in Further Education: the impact on student intermediate and end-point outcomes. London, UK: Department for Education and Skills. Online. Available HTTP <http://www.dfes.gov.uk/research/data/uploadfiles/RR739.pdf> (accessed August 1, $\left.2010^{* * *}\right)$.

Fose, L. and Mehl, M. (2007). Plugging into students' digitalDNA five myths prohibiting proper podcasting pedagogy in the new classroom domain MERLOT. Journal of Online Learning and Teaching, 3(3), 277-287.

Freedman, T. (2005). Every Child Matters: What it means for the ICT teacher. Online. Available HTTP <http://www.ictineducation.org> (accessed August 1, 2010***).

Freegrounds (2010). Virtual Learning Environment. Online. Available HTTP <http://www.freegroundsjun.hants.sch.uk/misc/misc/esafety.html> (accessed August 1, 2010***).

Freeman-longo, R. E. (2000). Children, teens, and sex on the internet. Sexual Addiction and Compulsivity, 7(1/2), 75-90.

Freiermuth, M. and Jarrell, D. (2006). Willingness to communicate: can online chat help? International Journal of Applied Linguistics, 16(2), 189-212.

Freud, S. (1960). The Ego and the Id. New York, US: Norton.

Futurelab (2010). Developing the home-school relationship using digital technologies Bristol, UK: Futurelab. Online. Available HTTP <http://www.futurelab.org.uk/resources/documents/handbooks/home-

school_relationships.pdf> (accessed August 1, 2010***). 
Gardner, H. (2008). Education, Social Media and Ethics. Online. Available HTTP <http://vimeo.com/2235438> (accessed August 1, 2010***).

Gardner, M. and Ward, H. (1999). 'Real-time interactive social environments: a review of BT's Generic Learning platform'. ALT-J, 7(3), 17-32.

Garris, R., Ahlers, R. and Driskell, J. (2002). Games, motivation and learning: a research and practice model. Simulation and Gaming, 33(4), 441-467.

Gee, J. P. (2003). What Video Games Have to Teach Us About Learning and Literacy. New York, US: Palgrave Macmillan.

Goldberg, L. R. (1993). The structure of phenotypic personality traits. American Psychologist, 48, 26-34.

GoodPlay Project (2009). Meeting of Minds: Cross-Generational Dialogue on the Ethics of Digital Life Cambridge MA, US: Project Zero, Harvard Graduate School of Education. Online. Available HTTP <http://www.goodworkproject.org/research/digital.htm> (accessed August 1, 2010***).

Goswami, U. (2008). Byron Review on the Impact of New Technologies on Children: A Research Literature Review: Child Development. London, UK: Department for Children, Schools and Families. Online. Available HTTP

<http://www.dcsf.gov.uk/byronreview/pdfs/Goswami\%20Child\%20Development\%20Literature\%20Review\%2 Ofor\%20the\%20Byron\%20Review.pdf> (accessed August 1, 2010***).

Govier, H. (1985). Posing and Solving Problems with a Micro. Coventry, UK: MEP.

Grant, D. (2009). Domesday Preservation Group. Online. Available HTTP <http://www.domesday1986.com> (accessed August 1, 2010***).

Greenfield, S. (2009). ID: The Quest for Identity in the 21st Century. London, UK: Sceptre.

Grigsby, A. (2001). Let's Chat: Chat Rooms in the Elementary School. Educational Technology and Society, 4(3).

Gubacs-Collins, K. and Juniu, S. (2009). The Mobile Gymnasium Using Tablet PCs in Physical Education. Journal of Physical Education, Recreation \& Dance, 80(2), 1-58

Gunawardena, C. N. and Mclsaac, M. S. (2004). Distance Education, 355-395 in Jonassen, D. H. Handbook of Research on Educational Communications and Technology.

Habbo (2010). Habbo. Online. Available HTTP <http://www.habbo.com> (accessed August 1, 2010***).

Hallworth, H. J. (1968). Educational uses of electronic computers in the United Kingdom. Journal International Review of Education, 14(2), 238-242.

Harden, R. (2006). E-Learning and All That Jazz. Medical Teacher, 28(2), 396-396.

Harris, P. L., Brown, E., Marriott, C., Whittall, S. and Harmer, (1991). Monsters, ghosts and witches: Testing the limits of the fantasy- reality distinction in young children. British Journal of Developmental Psychology, 9, 105123.

Heppell, S. (1993). 'Teacher Education, Learning and the Information Generation: the progression and evolution of educational computing against a background of change'. Journal of Information Technology for Teacher Education, 2(2), 229-237.

Herring, S. C. (1996). Computer-Mediated Communication: Linguistic, social and cross-cultural perspectives. Amsterdam, Netherlands: Benjamins.

Hope, M. (1986). The magic of the micro: a resource for children with learning difficulties. London, UK: Council for Educational Technology.

Hrastinski, S. (2008). A study of asynchronous and synchronous e-learning methods discovered that each supports different purposes. EDUCAUSE Quarterly 31 4. Online. Available HTTP

<http://www.educause.edu/163445> (accessed August 1, 2010***). 
Hung, D. and Khine, M. (2006). Engaged Learning with Emerging Technologies. Dordrecht, Netherlands: Springer.

Hunsinger, J. and Krotoski, A. (2010). Learning and researching in virtual worlds. Learning, Media and Technology, 35(2), 93-97.

Inhelder, B. and Piaget, J (1958). The Growth of Logical Thinking from Childhood to Adolescence. London, UK: Routledge.

ITCOLE (2003). Innovative Technology for Collaborative Learning and Knowledge Building (ITCOLE) project. Online. Available HTTP <http://www.euro-cscl.org/site/itcole> (accessed August 1, 2010***).

Jarvis, P. (2004). Adult Education and Lifelong Learning: Theory and Practice. London, UK: RoutledgeFalmer. Jenny's Story (2005). Jenny's Story an internet safety resource. London, UK: Childnet International. Online. Available HTTP <http://www.childnet-int.org/jenny> (accessed August 1, 2010***).

JISC (2004). Effective Practice with e-Learning. Online. Available HTTP

<http://www.jisc.ac.uk/media/documents/publications/effectivepracticedigitalage.pdf> (accessed August 1, $\left.2010^{* * *}\right)$.

JISC (2007). REAP: Re-engineering Assessment Practices in Scottish Higher Education. Online. Available HTTP <http://www.jisc.ac.uk/media/documents/programmes/elearningsfc/sfcbookletreap.pdf> (accessed August 1, $\left.2010^{* * *}\right)$.

John, O. P. and Srivastava, S. (1999). The Big Five trait taxonomy: History, measurement and theoretical perspectives. In Pervin, L. A. and John, O. P., Handbook of personality: Theory and research, 102-138. New York, US: Guilford.

Johnson, S. (2005). Everything Bad Is Good for You: How Today's Popular Culture Is Actually Making Us Smarter. London, UK: Riverhead.

Jonassen, D. H. and Driscoll, M. P. (2004). Handbook of Research on Educational Communications and Technology. London, UK: Routledge.

Jukes, I. (2010). Understanding the digital generation. Online. Available HTTP

<http://understandingthedigitalgeneration.com/dvd.cfm> (accessed August 1, 2010***).

Kapp, K. M. and O'Driscoll, T. (2007). Escape from Flatlands: The emergence of 3D synchronous learning Synchronous Learning Systems: Benchmarks, Best Practices and Real-time analysis about Real-time Learning. Santa Rosa, US: e-Learning Guild.

Kapp, K. M. and O'Driscoll, T. (2010). Learning in 3D: Adding a New Dimension to Enterprise Learning and Collaboration. San Francisco, US: Pfeiffer.

Kar2ouche (2010). Creative role-play, picture making, storyboarding and animation. Online. Available HTTP <http://www.immersiveeducation.eu/index.php/kar2ouchepg> (accessed August 1, 2010***).

Keller, J. M. (1979). Motivation and instructional design: A theoretical perspective. Journal of Instructional Development, 2, 26-34.

Keller, J. M. (1999). Motivation in Cyber Learning Environments. International Journal of Educational Technology, 1(1), 7-30.

Kelly, B. (2005). RSS - More Than Just News Feeds. New Review of Information Networking, 11(2), 219-227.

Kennewell, S. (2001). Using affordances and constraints to evaluate the use of information and communications technology in teaching and learning. Journal of Information Technology for Teacher Education, 10(1\&2), 101-116.

Kennewell, S., Connell, A, Edwards, A., Hammond, M. and Wickens, C. (2007). A Practical Guide to Teaching ICT in the Secondary School (Routledge Teaching Guides). Oxford, UK: Routledge. 
Kennewell, S., Parkinson, J. and Tanner, H. (2003). Learning to Teach ICT in the Secondary School. London, UK: RoutledgeFalmer.

Kennewell, S., Tanner, H., Jones, S. and Beauchamp, G. (2008). Analysing the use of interactive technology to implement interactive teaching. Journal of Computer Assisted Learning, 24(1), 61-73.

Knowles, M. (1970). The Modern Practice of Adult Education: Andragogy versus Pedagogy. New York, US: Association Press.

Knowles, M. (1980). The Modern Practice of Adult Education: From Pedagogy to Andragogy. Englewood Cliffs, US: Prentice Hall.

Kodu (2010). Programming as a Creative Medium. Online. Available HTTP <http://research.microsoft.com/enus/projects/kodu> (accessed August 1, 2010***).

Kohlberg, L. (1975). The cognitive-developmental approach to moral education. Phi Delta Kappan, 56, 670677.

Kollias, V. P. and Vosniadou, S. (2002). Systemic theory in classrooms: Results from the CL-Net and the ITCOLE projects. Cognitive Science and Educational Technology Laboratory. National and Kapodistrian University of Athens 2002. Online. Available HTTP <http://afscet.asso.fr/resSystemica/Crete02/Kollias.pdf> (accessed August 1, 2010***).

Kordaki, M. (2005). The role of synchronous communication via chat in the formation of e-learning communities, Proceedings Book of the 3rd International Conference on Multimedia and Information and Communication Technologies in Education m-ICTE2005. Online. Available HTTP <http://www.formatex.org/micte2006> (accessed August 1, 2010***).

Kudlian (2008). ReTreeval. Online. Available HTTP <http://www.kudlian.net/products/retreeval> (accessed August 1, 2010***).

Landsberger, H. (1958). Hawthorne revisited. New York, US: Cornell University Press.

Laurillard, D. (2002). Rethinking University Teaching: a framework for the effective use of educational technology (2nd edition). London, UK: RoutledgeFalmer.

Lave, J. and Wenger, E. (1991). Situated Learning: Legitimate Peripheral Participation. Cambridge, UK: Cambridge University Press.

Linden Lab (2010) Second Life ${ }^{\circledR}$ Online. Available HTTP <http://lindenlab.com> (accessed August 1, 2010***).

Livingstone, S. and Bober, M. (2005). UK children go online: Final report of key project findings. London, UK:

LSE Research. Online. Available HTTP <http://eprints.Ise.ac.uk/399> (accessed August 1, 2010***).

Livingstone, S. and Helsper, E. (2007). Taking risks when communicating on the internet: the role of offline social-psychological factors in young people's vulnerability to online risks. Information, communication and society, 10(5), 619-643.

Lockhorst, D., Admiraal, W. and Pilot, A. (2010). CSCL in teacher training: what learning tasks lead to collaboration? Technology, Pedagogy and Education, 19(1), 63-78.

Loveless, A. (1995). The Role of IT: Practical Issues for the Primary Teacher. London, UK: Cassell.

Loveless, A. and Ellis, V. (2001). ICT Pedagogy and the curriculum - subject to change. London, UK: Routledge.

Loveless, A., DeVoogd, G. L. and Bohlin, R. M. (2001). Something old, something new... Is pedagogy affected by ICT? in Loveless and Ellis ICT Pedagogy and the curriculum - subject to change. London, UK: Routledge.

Ma, R. (1996). Computer-mediated conversations as a new dimension of intercultural communication between East Asian and North American college students. In Herring S. C. 173-185.

Maier, P. and Warren, A. (2002). Integrating technology in learning and teaching: a practical guide for educators. London, UK: Kogan Page. 
Malaby, T. (2007). Contriving Constraints (The Gameness of Second Life and the Persistence of Scarcity). Innovations, 2(3), 62-67.

Malinowski, B. (1923). The Problem of Meaning in Primitive Languages, in Ogden, C. K. and Richards, I. A. The Meaning of Meaning, 146-152, London, UK: Routledge.

Mallan, K., Foth, M., Greenaway, R. and Young, G. T. (2010) Serious playground: using Second Life to engage high school students in urban planning. Learning, Media and Technology, 35(2), 203-225.

Markle, S. (1969). Good Frames and Bad New York, US: Wiley.

Martínez, A., Dimitriadisb, Y., Rubiac, B., Gómezb, E. and de la Fuentea, P (2003). Documenting Collaborative Interactions: Issues and Approaches. Computers and Education, 41(4), 353-368.

Maslow, A. H. (1943). A theory of human motivation. Psychological Review, 50, 370-396.

Mayes, T. and de Freitas, S. (2007). 'Learning and e-learning: The role of theory' in Beetham, H., Sharpe, R., (eds). Rethinking Pedagogy for a Digital Age: Designing and delivering e-learning, Abingdon, UK, Routledge 13-23.

Mayes, T. and Fowler, C. J. H. (1999) Learning technology and usability: a framework for understanding courseware. Interacting with Computers, 11, 485-497. Online. Available HTTP <http://apu.gcal.ac.uk/clti/papers/Mayes\&Fowler1999.pdf> (accessed August 1, 2010***).

Meadows, M. S. (2008). I, Avatar: The Culture and Consequences of Having a Second Life. Berkley, US: New Riders.

Medwell, J., Poulson, L., Avramidis, E., Fox, E. and Wray, D. (2001). 'The theoretical beliefs of effective teachers of literacy in primary schools: an exploratory study of orientations to reading and writing ', Research Papers In Education, 16(3), 271-292.

Mercer, N., Littleton, K. and Wegerif, R. (2004). Methods for studying the processes of interaction and collaborative activity in computer-based educational activities. Technology, Pedagogy and Education, 13(2), 193-209.

Meredith, M. D. and Briggs, B. I. (1982). Bigtrak plus. Case study 3 (Microelectronics Education Programme). London, UK: Council for Educational Technology.

Michael, M. (2000). Reconnecting culture, technology and nature: from society to heterogeneity. London, UK: Routledge.

Mitchell, P. D. (1997). The impact of educational technology: a radical reappraisal of research methods'. ALT-J, 5(1), 48-54.

Mohamad, M. and Woollard, J. (2008). Why does Malaysia need to consider mobile technologies? A review of current practices to support teaching and learning with school-age children. Mobile Learning and Edutainment Conference 2008. Kuala Lumpur, Malaysia, Malaysia 20-21 November. Online. Available HTTP <http://eprints.soton.ac.uk/52455> (accessed August 1, 2010***).

Mohamad, M. and Woollard, J. (2009). English language learning through mobile technology in Malaysian schools: An implementation strategy. International Conference on E-Learning, Kuala Lumpur, Malaysia, 1-2 December. Online. Available HTTP <http://eprints.soton.ac.uk/79366> (accessed August 1, 2010***).

Moore, K. and Pflugfelder, E. H. (2010) 'On being bored and lost (in virtuality)'. Learning, Media and Technology, 35(2), 249-253.

Mortimer, P. (1999). Understanding Pedagogy and its Impact on Learning. London, UK: Chapman.

Nonnecke, B. and Preece, J. (2000). Silent Participants: Getting to Know Lurkers Better? Chapter 6. 110-132. In. From Usenet to CoWebs. Online. Available HTTP

<http://www.cis.uoguelph.ca/ nonnecke/research/silentparticipants.pdf> (accessed August 1, 2010***).

North, M. and McKeown, S. (2005). Meeting SEN in the curriculum ICT. London, UK: David Fulton. 
OCR (2010) OCR Nationals (for 2010). Online. Available HTTP

<http://www.ocr.org.uk/qualifications/type/nationals_2010> (accessed August 1, 2010***).

Offir, B. and Lev, Y. (1999). 'Teacher-Learner Interaction in the Process of Operating DL (Distance Learning). Systems'. Educational Media International, 36(2), 132-136.

Offir, B., Leva, Y. and Bezalela, R. (2008). Surface and deep learning processes in distance education: Synchronous versus asynchronous systems. Computers and Education, 51(3), 1172-1183.

Oliver, R. and McLaughlin, C. (1996). An investigation of the nature and forms of interaction in live interactive television, ERIC Document ED396738. Online. Available HTTP < http://www.eric.ed.gov> (accessed August 1, $2010 * * *)$.

OPSI (1988). Education Reform Act 1988. London, UK: Office for Public Sector Information

Oswell, D. (1998). The place of 'childhood' in internet content regulation. International Journal of Cultural Studies, 1(2), 271-291.

Papert, S. A. (1980). Mindstorms: Children, Computers and Powerful Ideas. Boston, US: Basic Books.

Patterson, L. J. (2006). The Technology Underlying Podcasts. Computer, 39(10), 103-105.

Payne, C. R. (2009). Information technology and constructivism in higher education: progressive learning frameworks. New York, US: Information Science Reference.

Pearson (2009). SuccessMaker ${ }^{\circledast}$ Online. Available HTTP

<http://www.pearsonschool.com/index.cfm?locator=PSZdXp> (accessed August 1, 2010***).

Perrenoud, P. (1998). 'From Formative Evaluation to a Controlled Regulation of Learning Processes. Towards a wider conceptual field'. Assessment in Education: Principles, Policy and Practice, 5(1), 85-102.

Piaget, J. (1929/1964). The child's conception of the world. London, UK: Routledge.

Piper, G. (2000). The use of Roamer as a Constructivist Tool in Early Learning. Online. Available HTTP $<$ http://www.pgce.soton.ac.uk/ict/roamer> (accessed August 1, 2010***).

Potter, J. (2010). Podcast in Futurelab Harnessing Technology Series 2 Episode 5: Technology and Primary Education. Bristol, UK: Futurelab. Online. Available HTTP

<http://media.futurelab.org.uk/podcasts/becta_talks/primary_education/> (accessed August 1, 2010***).

Powell, A. (2007). Paedophiles, Child Abuse and the Internet. Oxford, UK: Radcliffe.

Powell, S., Tindal, I. and Millwood, R. (2008). Personalized learning and the Ultraversity experience. Interactive Learning Environments, 16(1), 63-81.

Prensky, M. (2001a). Digital Native, Digital Immigrants. On the Horizon, 9(5). Online. Available HTTP <http://marcprensky.com/writing> (accessed August 1, 2010***).

Prensky, M. (2001b). Digital Native, Digital Immigrants Part II: Do They Really Think Differently? On the Horizon 9 (6). Online. Available HTTP <http://marcprensky.com/writing> (accessed August 1, 2010***).

Prensky, M. (2001c). Why Games Engage Us Digital Game-Based Learning. New York, US: McGraw-Hill.

Pritchard, A. (2005). Ways of Learning. London, UK: David Fulton.

Pritchard, A. (2009). Ways of Learning (2nd edition). London, UK: Routledge.

Pritchard, A. and Woollard, J. (2010). Psychology for the Classroom: Constructivism and Social Learning. Oxford, UK: Routledge David Fulton.

QCA (1999). History. The National Curriculum for England. Key stages 1-3. London, UK: Qualifications and Curriculum Authority.

QCDA (2007). PSHE: Personal wellbeing. The National Curriculum Online. London, UK: Qualifications and Curriculum Development Agency. 
REAP (2007). Re-engineering Assessment Practices. Online. Available HTTP

<http://www.reap.ac.uk/public/Misc/REAPFlyer.pdf> (accessed August 1, 2010***).

Richards, C. (2003). Chatrooms in the classroom. InteracTive, 47, 23-25. Birmingham, UK: Questions Publishing.

Richards, C. (2009). How useful are bounded online chat rooms as a source of pastoral support in a sixth-form college? University of Southampton, School of Education, Doctoral Thesis, 281pp. Online. Available HTTP <http://eprints.soton.ac.uk/66451/> (accessed August 1, 2010***).

Robertson, J. (1998). Paradise Lost: Children, multimedia and the myth of interactivity. Journal of Computer Assisted Learning, 14(1), 31-39.

Rogan, A., Harth, A. and Breslin, J. G. (2005). Podcast Pinpointer: A Multimedia Semantic Web Application Integration of Knowledge, Semantics and Digital Media Technology. The 2nd European Workshop on the (Ref. No. 2005/11099), IEEE.

Rogers, E. M. (1983). Diffusion of Innovation (3 ${ }^{\text {rd }}$ edition). New York, US: The Free Press.

Rymaszewski, M., Au, W. J., Ondrejka, C., Platel, R., Van Gorden, S., Cézanne, J., Cézanne, P., BatstoneCunningham, B., Krotoski, A., Trollop, C. and Rossignol, J. (2008) Second Life: The Official Guide, 2nd Edition. Indianapolis, US: Wiley.

Salmon, G. (2000). E-Moderating: The Key to Teaching and Learning Online. London, UK: Kogan Page.

Schroeder, R. and Axelsson, A-S. (2006). Avatars at Work and Play: Collaboration and Interaction in Shared Virtual Environments (Computer Supported Cooperative Work). Dordrecht, Netherlands: Springer.

Scoggins, J. and Winter, R. (1999). The patchwork text: A coursework format for education as critical understanding. Teaching in Higher Education, 4(4), 485-500.

Scopes, L. J. M. (2009). Learning archetypes as tools of Cybergogy for a 3D educational landscape: a structure for eTeaching in Second Life. Southampton, UK: University of Southampton. Online. Available HTTP <http://eprints.soton.ac.uk/66169> (accessed August 1, 2010***).

Scrimshaw, P (1993). Language, Classrooms and Computers. London, UK: Routledge.

Segovia, K.Y. and Bailenson, J.N. (2009). Virtually true: Children's acquisition of false memories in virtual reality. Media Psychology, 12, 371-393.

Selwyn, N., Potter, J. and Cranmer, S. (2009). Primary pupils' use of information and communication technologies at school and home. British Journal of Educational Technology, 40(5), 919-932.

Shen, R. M., Wang, M. J., Gao, W. P., Novak, D. and Tang, L. (2009). Mobile Learning in a large blended computer science classroom: System function, pedagogies, and their impact on learning. IEEE Transactions on Education, 52(4), 538-546.

Sherston (2010). The Model Shop. Sherston, UK: Sherston. Online. Available HTTP <http://shop.sherston.com/products/details.aspx?prodld=103> (accessed August 1, 2010***).

Shortis, T. (2001). The Language of ICT. London, UK: Routledge.

Shulman, L. S. (1986). Those who understand: Knowledge growth in teaching. Educational Researcher, 15, 414.

Skinner, B. F. (1948). Walden Two. New York, US: Macmillan.

Skinner, B. F. (1954). The science of learning and the art of teaching. Harvard Educational Review, 24(1), 8697.

Skinner, B. F. (1968). The Technology of Teaching. New York, US: Appleton-Century-Crofts.

Smith, H. J., Higgins, S., Wall, K. and Miller, J. (2005). Interactive whiteboards: boon or bandwagon? A critical review of the literature. Journal of Computer Assisted Learning, 21(2), 91-101. 
Somekh, B. (2007). Pedagogy and Learning with ICT: researching the art of innovation. London and New York: Routledge.

Somekh, B. and Pearson, M. (2002). The PELRS Project. Manchester, UK: Manchester Metropolitan University. Online. Available HTTP <http://www.esri.mmu.ac.uk/resprojects/pelrs> (accessed August 1, 2010***).

Somekh, B. and Pearson, M. (2006). The PELRS Project Summary of Research Findings. Manchester, UK: Manchester Metropolitan University. Online. Available HTTP <http://www.esri.mmu.ac.uk/resprojects/pelrs> (accessed August 1, 2010***).

Somekh, B., Underwood, J., Convery, A., Dillon, G., Jarvis, J., Lewin, C., Mavers, D., Saxon, D., Sing, S., Steadman, S., Twining, P. and Woodrow, D (2007). Final Report of the Evaluation of the ICT Test Bed Project. Coventry, UK: Becta.

Spector, J. M. and Merrill, M. D. (eds). (2008). Effective, Efficient, And Engaging (E3). Learning In The Digital Era. Distance Education, 29, 2.

Squires, D., Conole, G. and Jacobs, G. (2000). The Changing Face of Learning Technology. Cardiff, Wales: University of Wales Press.

Stephenson, N. (1992). Snow Crash. London, UK: Penguin.

Straker, A. (1989). Children Using Computers. Oxford, UK: Basil Blackwell.

Tansley, A. G. (1920). The New Psychology and its relation to life. London, UK: Allen and Unwin.

TDA (2008). Professional Standards for Qualified Teacher Status and Requirements for Initial Teacher Training. London, UK: The Training and Development Agency for Schools. Online. Available HTTP

<http://www.tda.gov.uk/qts> (accessed August 1, 2010***).

Times Online (2009). Online. Available HTTP

<http://www.timesOnline.co.uk/tol/news/world/us_and_americas/article6460962.ece> (accessed August 1, $\left.2010^{* * *}\right)$.

Turkle, S (1984). The Second Self: Computers and the Human Spirit. New York, US: Simon and Shuster.

Turner-Bisset, R (2001). Expert Teaching. London, UK: Fulton.

Twining, P. (2002). ICT in Schools: Estimating the level of investment Report No: 02. MeD8 Online. Available HTTP <http://www. med8. info/docs/meD8_02-01. pdf> (accessed August 1, 2010***).

US DoE (2009) Evaluation of Evidence-Based Practices in Online Learning A Meta-Analysis and Review of Online Learning Studies. Washington DC, US: US Department of Education, Office of Planning, Evaluation, and Policy Development

Valient (2010). Roamer Discovery at every turn. Online. Available HTTP <http://www.valianttechnology.com/uk/pages/roamer_home.php?cat=1\&1> (accessed August 1, 2010***).

Vygotsky, L. S. (1962). Thought and Language Cambridge, US: MIT Press.

Vygotsky, L. S. (1978). Mind in Society Cambridge, US: Harvard University Press.

Wang, M. and Kang, M. (2006). Cybergogy for engaged learning: a framework for creating learner engagement through information and communication technology. In Hung, D. and Kline, M. S. Engaged Learning with Emerging Technologies. Dordrecht, Netherlands: Springer.

Wang, M. J. (2007). Designing online courses that effectively engage learners from diverse cultural backgrounds. British Journal of Educational Technology, 38(2), 294-311.

Wang, M., Shen, R., Novak, D. and Pan, X. (2009) The impact of mobile learning on students' learning behaviours and performance: Report from a large blended classroom. British Journal of Educational Technology, 40(4), 673-695. 
Wenger, E. (1998). Communities of practice: learning, meaning, and identity. Cambridge, UK: Cambridge University Press.

Wenger, E. (2006). Communities of Practice. Online. Available HTTP <http://www.ewenger.com/theory> (accessed August 1, 2010***).

Wenger, E., McDermott, R. and Snyder, W (2002). Cultivating communities of practice A guide to managing knowledge Boston, US: Harvard Business School Press .

Wenger, E., White, N. and Smith, J. (2009). Digital habitats Stewarding technology for communities Cambridge, US: CPsquare Press .

Whitty, C. M. (2003). Cyber-Flirting: Playing at Love on the Internet. Theory and Psychology, 13, 339-357. Whitty, C. M. and Joinson, A. (2008). Truth, Lies and Trust on the Internet. London, UK: Routledge.

Wickens, C. (2007). Creativity in Kennewell et al, A Practical Guide to Teaching ICT on the Secondary School. Williams, A. (2003). Using Integrated Learning Systems to support students with learning difficulties in a comprehensive school. British Journal of Learning Support. 16(4), 174-178.

Williams, D., Wilson, K., Richardson, A., Tuson, J. and Coles, L. (1998). Teachers' ICT Skills and Knowledge Needs: final report to SOEID. Aberdeen, UK: The School of Information and Media, Faculty of Management, The Robert Gordon University.

Winter, R. (2003). Contextualizing the Patchwork Text: addressing problems of coursework assessment in higher education. Innovations in Education and Teaching International, 40(2), 112-122.

Wood, D. (1998). The UK ILS Evaluations Final Report. Coventry, UK: British Educational Communications and Technology Agency.

Woollard, J. (2004). The rôle of metaphor in the teaching of computing; towards a taxonomy of pedagogic content knowledge. Southampton, UK: University of Southampton. Online. Available HTTP <http://eprints.soton.ac.uk/162857> (accessed August 1, 2010***).

Woollard, J. (2007). Learning and teaching using ICT in secondary schools (achieving QTS). Exeter, UK: Learning Matters.

Woollard, J. (2007). Prediction in Kennewell et al, A Practical Guide to Teaching ICT on the Secondary School. Woollard, J. (2010). Psychology for the Classroom: Behaviourism. Oxford, UK: Routledge.

Woollard, J. and Scopes, L (2010). Review of the second encounter with Second Life online. Online. Available HTTP <http://www.pgce.soton.ac.uk/IT/Research/SecondLife/SLevalreport2.pdf> (accessed August 1, $\left.2010^{* * *}\right)$.

Woollard, J., Wickens, C. A., Powell, K. and Russell, T. (2007a). E-safety: Evaluation of Key Stage 3 materials for initial teacher education London, UK: Childnet International. Online. Available HTTP <http://www.childnetint.org/kia/traineeteachers/about.aspx> (accessed August 1, 2010***).

Woollard, J., Wickens, C. A., Powell, K. and Russell, T. (2007b). E-safety: Evaluation of Key Stage 3 materials for initial teacher education Executive Summary London, UK: Childnet International. Online. Available HTTP <http://www.childnet-int.org/downloads/exec_sum.pdf> (accessed August 1, 2010***).

Woollard, J., Wickens, C. A., Powell, K. and Russell, T. (2009). 'Evaluation of e-safety materials for initial teacher training: can 'Jenny's Story' make a difference?' Technology, Pedagogy and Education, 18(2), 187-200.

Yee, N. (2005). The Psychology of MMORPGs: Emotional Investment, Motivations, Relationship Formation, and Problematic Usage in Schroeder, R. and Axelsson, A-S. (eds)., Avatars at Work and Play: Collaboration and Interaction in Shared Virtual Environments.

Yero, J. L. (2002). Teaching in Mind: How Teacher Thinking Shapes Education Hamilton, US: Mindflight. 
Young, M., Schrader, P. G. and Zheng, D. (2006). MMOGs as learning environments: An Ecological Journey into Quest Atlantis and The Sims Online. Innovate Journal of Online Education, (2)4.

Zhang, D., Zhou, L., Briggs, R. O. and Nunamaker, J. F. (2006). Instructional video in e-learning: Assessing the impact of interactive video on learning effectiveness. Information and Management, 43(1), 15-27 cited in (US DoE, 2009:40).

Zimmerman, B. J. and Schunk, D. H. (2011). Handbook of Self-Regulation of Learning and Performance. London, UK: Routledge.

Zins, J., Bloodworth, M., Weissberg, R. and Walberg, H. (2004). 'The scientific base linking social and emotional learning to school success' in Building Academic Success on Social and Emotional Learning: What Does the Research Say? Teachers College, Columbia University. Online. Available HTTP <http://www.casel.org/downloads/T3053c01.pdf> (accessed August 1, 2010***).

Zurbriggen, E. L., Collings, R. L., Lamb, S., Roberts, T-A., Tolman, D. L., Ward, L. M. and Blake, J. (2007). Report of the APA Task Force on the Sexualisation of Girls. Washington, US: American Psychological Association. Cited in Byron, 2008:51. Online. Available HTTP <http://www.apa.org/pi/wpo/sexualizationrep.pdf> (accessed August $\left.1,2010^{* * *}\right)$.

***(accessed August 1, 2010***) I will recheck all the URLs closer to the publication date, say January 1, 2011??? 
Not for inclusion in the book.

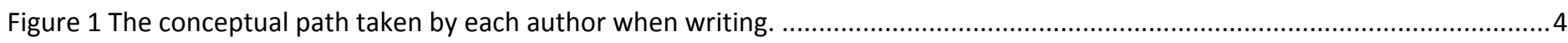

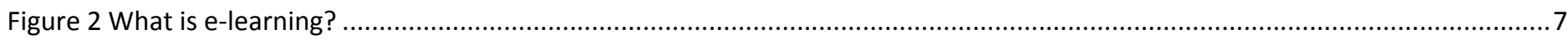

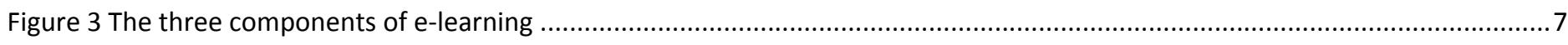

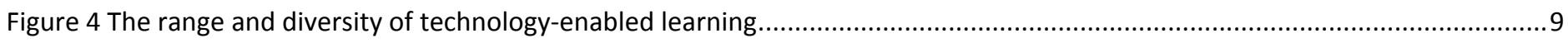

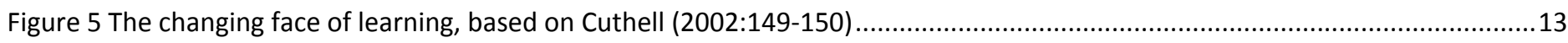

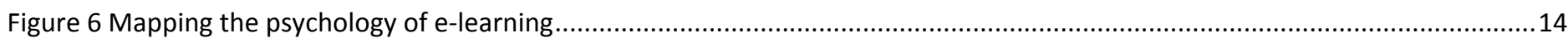

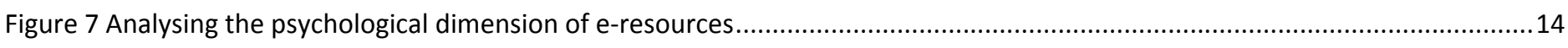

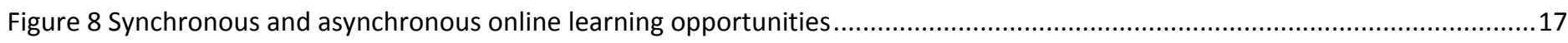

Figure 9 The cognitive/social asynchronous/synchronous dimensions of learning ..................................................................18

Figure 10 Examples of activities enhanced by computer supported collaboration .....................................................................19

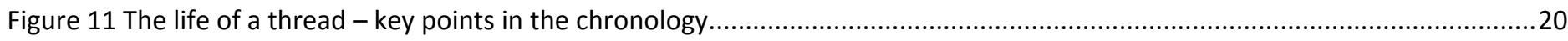

Figure 12 Measuring engagement in threaded discussions - the degree of social construction ......................................................21

Figure 13 Promoting participation and interaction, based on Lockhorst et al (2010) ..................................................................21

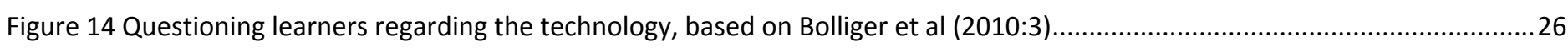

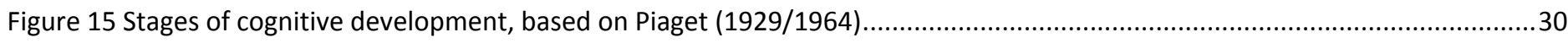

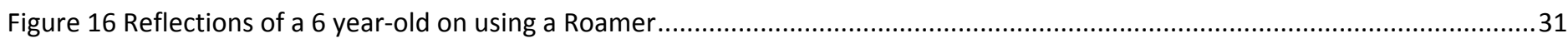

Figure 17 ReTreeval software from http://www.kudlian.net for creating tree data structures.......................................................32

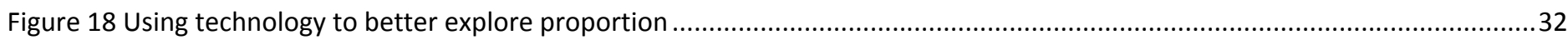

Figure 19 Scattergram showing the relationship between two values from each member of a set ..................................................33

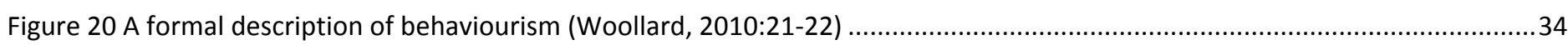

Figure 21 Five-stage model of learning and socialisation in a virtual world, based on Salmon (2000) and Scopes (2009) ..................36

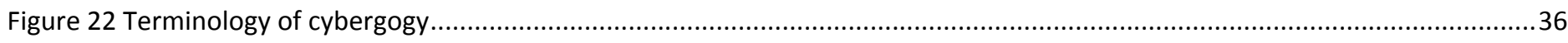

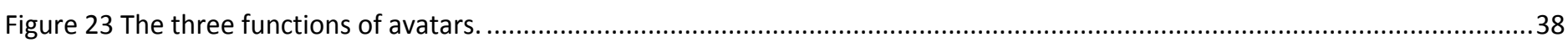

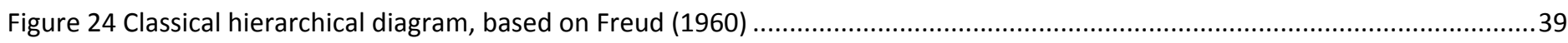

Figure 25 Moral development and response to ethics in learning environments, based on Kohlberg (1975) ..................................40

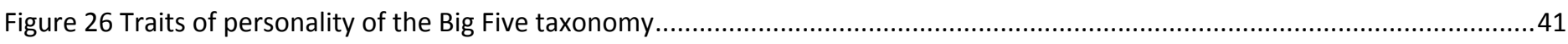

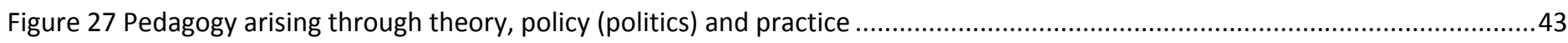

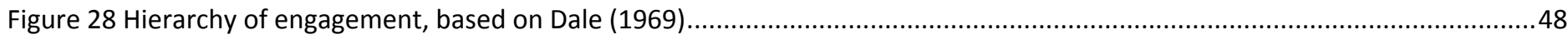

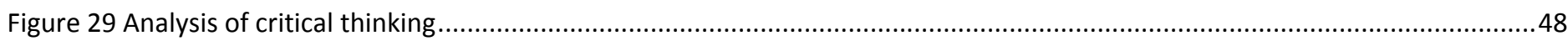

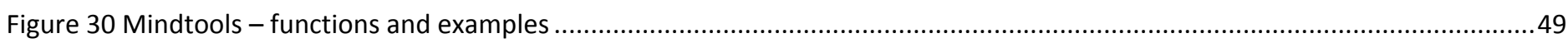

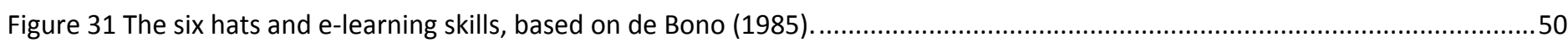

Figure 32 Learning platform architecture and learning processes, based on Gardner and Ward (1999) .........................................52

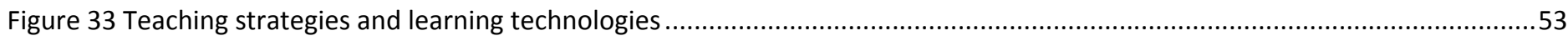

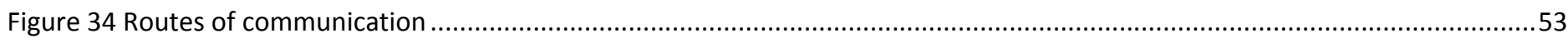

Figure 35 Types of assessment: baseline, formative (diagnostic), ipsative and summative .........................................................55

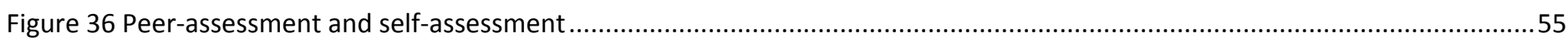

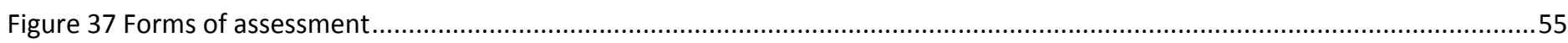

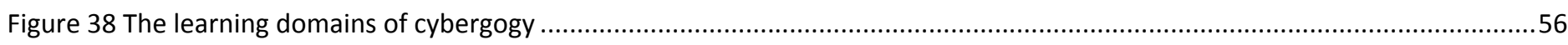

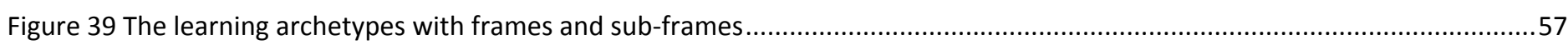

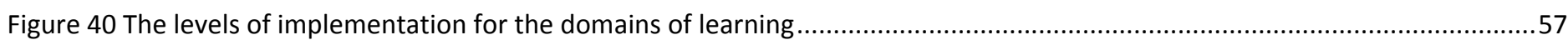

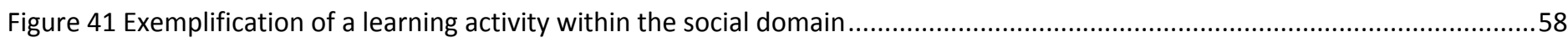

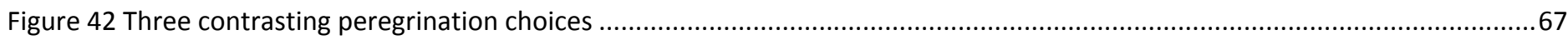

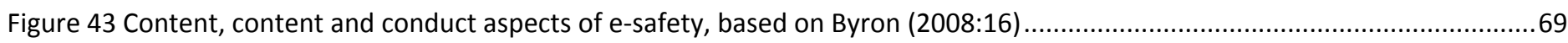

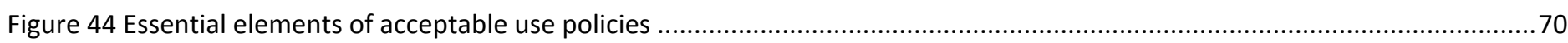

Figure 45 Click Clever Click Safe campaign, UK Council for Child Internet Safety...................................................................... 70 